\title{
Recent Advances in the Synthesis of Sulfones
}

\author{
Nai-Wei Liu \\ Shuai Liang \\ Georg Manolikakes*
}

Institut für Organische Chemie und Chemische Biologie, Goethe-Universität Frankfurt, Max-von-Laue-Str. 7, 60438 Frankfurt, Germany

g.manolikakes@chemie.uni-frankfurt.de

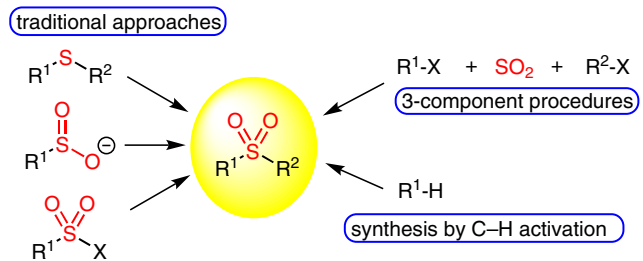

transformation. ${ }^{1,4}$ In addition, sulfone groups can stabilize adjacent carbanions. ${ }^{1,5}$ Classical reactions of sulfones in organic synthesis include the Ramberg-Bäcklund reaction of $\alpha$-halo sulfones ${ }^{6}$ or the Julia-Lythgoe as well as the modified Julia olefination (Scheme 1). ${ }^{7}$

Abstract Sulfones are versatile intermediates in organic synthesis and important building blocks in the construction of biological active molecules or functional materials. This review provides a summary of recent developments in the synthesis of sulfones.

1 Introduction

2 Classical Methods and Variants

2.1 Oxidation of Sulfides

2.2 Aromatic Sulfonylation

2.3 Alkylation/Arylation of Sulfinates

2.4 Addition to Alkenes and Alkynes

2.5 Miscellaneous Methods

3 Metal-Catalyzed Coupling Reactions

4 Sulfone Synthesis by C-H Functionalization

5 Sulfur Dioxide Based Three-Component Approaches

6 Biological Synthesis of Sulfones

7 Conclusion

Key words sulfone, addition, coupling, catalysis, medicinal chemistry, multicomponent reaction

\section{Introduction}

Sulfones $\left(\mathrm{R}-\mathrm{SO}_{2}-\mathrm{R}\right)$ are versatile synthetic intermediates in organic chemistry, and molecules bearing a sulfone unit have found various applications in diverse fields such as agrochemicals, pharmaceuticals and polymers. ${ }^{1}$ The sulfone group can be employed as a temporary modulator of chemical reactivity. Therefore a variety of different transformations are feasible with this functional group, leading to the description of sulfones as 'chemical chameleons'. ${ }^{2}$ Sulfone groups can function as activating, electron-withdrawing substituents in Michael acceptors ${ }^{1,3}$ or as good leaving groups producing a sulfinate anion, a reactivity that often facilitates removal of the sulfone moiety after the desired

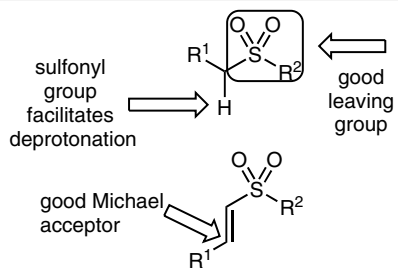

Ramberg-Bäcklund reaction
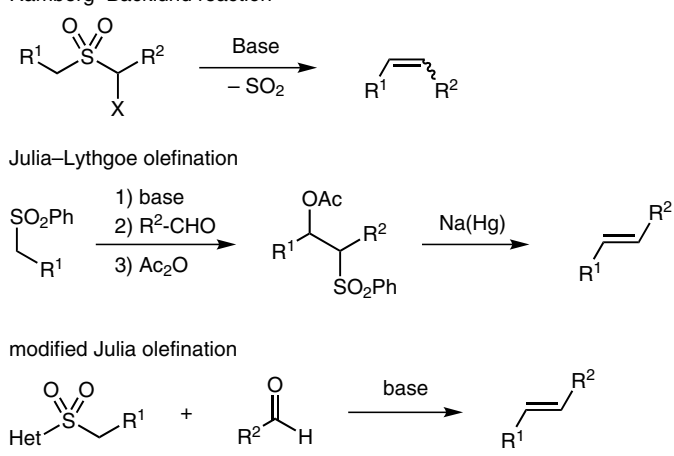

Het $=$ benzothiazole, 1 -phenyl- $1 H$-tetrazole,

1-tert-butyl-1 $H$-tetrazole

\section{Scheme 1}

Apart from these classical transformations, sulfones have been employed as versatile intermediates for the preparation of various product classes, for example the van Leusen synthesis of oxazoles and imidazoles ${ }^{8}$ or the synthesis of quinolines (Scheme 2). ${ }^{9}$ 
<smiles>[Y]O[NH+]=[NH+]CS(=O)(=O)c1ccc(OC)cc1</smiles>

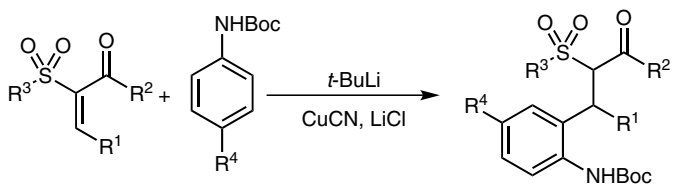<smiles>[R7]c1cc([2H])c2cc([12H])ccc2n1</smiles>

Scheme 2
Due to their distinct electronic and structural features, sulfones play a prominent role in various fields of applications. A large number of biologically active molecules contain this functional group. ${ }^{10}$ The sulfone scaffold is thus of particular relevance in medicinal chemistry. Molecules used against diverse medical indications such as eletrip$\tan ^{11}$ (treatment of migraine), bicalutamide ${ }^{12}$ (treatment of prostate cancer) or the antibacterial dapsone ${ }^{13}$ feature a sulfone unit (Figure 1). The sulfone group is also embedded in various important agrochemicals, for example mesotrione, ${ }^{14}$ pyroxasulfone ${ }^{15}$ or cafenstrole ${ }^{16}$ (Figure 1$)$. Sulfonecontaining polymers display interesting properties and bisphenol S (Figure 1) is used replacement for bisphenol A. ${ }^{17}$

Considering this plethora of possible applications, it is not surprising that a number of efficient methods for the synthesis of sulfones have been developed. Indeed, the first methods were reported in the $19^{\text {th }}$ century. The constant demand for efficient, robust and more sustainable approaches for the preparation of sulfones has led to a resurgence of research activities in this field in recent years. This review highlights advances in the synthesis of sulfones until the end of 2015.

\section{Biographical Sketches}
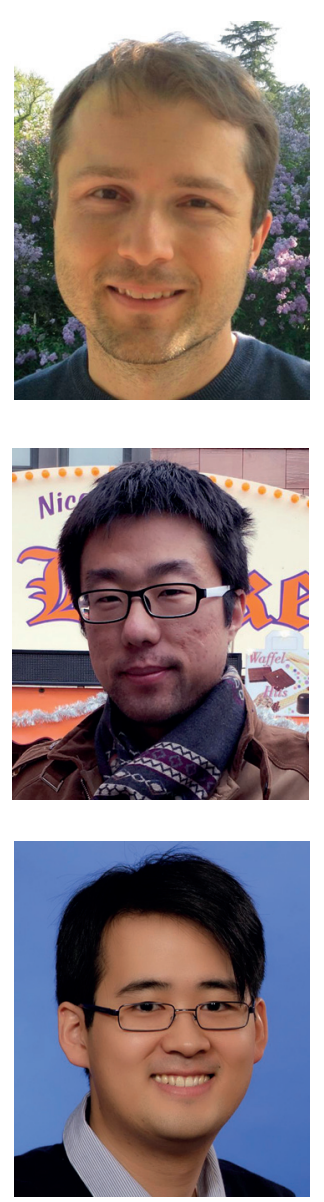

Georg Manolikakes was born in Ebersberg (Germany) in 1979. He studied chemistry at the LMU Munich (Germany) where he received his Diploma in 2005. In 2009 he obtained his $\mathrm{PhD}$ from the same university under the guidance of Prof. Paul Knochel working on functional-

Shuai Liang was born in Qingdao (P. R. of China) in 1988. He earned his BS degree in 2011 from Sichuan University. In 2014 he received his MS degree in chemistry from Sichuan Uni-

Nai-Wei Liu was born in Taipei (Taiwan R.O.C.) in 1987. He obtained his B.Sc. and M.Sc. degrees from the Goethe- ized organometallics and crosscoupling reactions. From 2009--2010 he worked as a postdoctoral fellow with Prof. Phil S. Baran at the Scripps Research Institute (La Jolla, USA) on synthesis of cortistatin A. At the end of 2010 he took up his current position as junior re-

versity under the supervision of Prof. Xiaoqi Yu. Since November 2014 he is a PhD student at the Goethe-Universität Frankfurt, under the supervision of Dr. Georg Manolikakes. His current search group leader at the Goethe-Universität Frankfurt. His research interests are multicomponent and one-pot reactions, synthesis of sulfonylgroup-containing molecules and asymmetric synthesis.

research interest focuses on novel methods for the synthesis of sulfones via selective $\mathrm{C}-\mathrm{H}$ functionalization.
Universität Frankfurt (Germany). He is currently working on his $\mathrm{PhD}$ thesis in the group of Dr. Georg Manolikakes and de- veloping new methods for the fixation of sulfur dioxide into small molecules. 
<smiles>COC(CS(=O)(=O)c1ccc(F)cc1)(C(=O)Nc1ccc(C#N)c(C(F)(F)F)c1)C(=O)N1CCCC1Cc1c[nH]c2ccc(CCS(=O)(=O)c3ccccc3)cc12</smiles><smiles>Nc1ccc(S(=O)(=O)c2ccc(N)cc2)cc1</smiles><smiles>CS(=O)(=O)c1ccc(C(=O)C2C(=O)CCCC2=O)c([N+](=O)[O-])c1</smiles><smiles>Cn1nc(CS(=O)(=O)C2=NOC(C)(C)C2)cc1OC(F)F</smiles><smiles>CCNC(=O)n1cnc(S(=O)(=O)c2c(C)cc([N+](=O)[O-])cc2C)n1</smiles><smiles>O=S(=O)(c1ccc(O)cc1)c1ccc(O)cc1</smiles>

Figure 1

\section{Classical Methods and Variants}

The four traditional and still most common approaches for the synthesis of sulfones are the oxidation of the corresponding sulfides or sulfoxides, alkylation of sulfinate salts, Friedel-Crafts-type sulfonylation of arenes, and addition reactions to alkenes and alkynes. ${ }^{1}$ Although all four reaction types were discovered several decades ago, new variants with improved substrate scope, functional group tolerance and efficiency, as well as new reagents, are constantly being developed. Other methods, such as rearrangements, reactions of sulfonic acid derivatives with nucleophiles, or cycloaddition reactions, although known for decades, are rarely used.

\subsection{Oxidation of Sulfides}

The oxidation of sulfides is perhaps still the most favored method for the synthesis of sulfones. While a variety of oxidants can be used for this transformations, ${ }^{1}$ peracids or hydrogen peroxide in combination with acetic acid are most frequently employed (Scheme 3 ). ${ }^{18}$ In general, excess oxidizing agent, high temperatures and/or long reaction times are necessary to achieve complete conversion of the intermediate sulfoxide to the sulfone. In most cases, existing procedures will furnish the desired sulfones in acceptable yields. Current research focuses mainly on safe oxidation reagents, such as urea-hydrogen peroxide, ${ }^{19}$ catalytic systems for milder and faster oxidations ${ }^{20}$ and solvent-free systems ${ }^{21}$ or highly sustainable methods. ${ }^{22}$

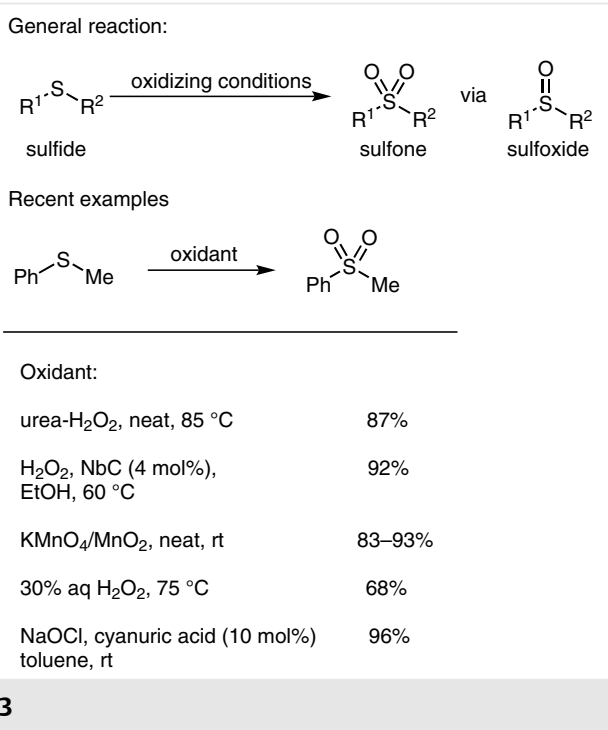

Scheme 3

\subsection{Aromatic Sulfonylation}

Another widely used strategy for the synthesis of sulfones involves the reaction between a (hetero)arene and a sulfonyl halide or sulfonic acid in the presence of a suitable Lewis or Brønsted acid catalyst (Scheme 4). ${ }^{1}$ Sulfonyl chlorides are most commonly employed in these Friedel-Craftstype reactions and substituents on the (hetero)arene exert activating/deactivating as well as directing effects as expected for electrophilic aromatic substitutions. ${ }^{23}$ Typically, these reactions are performed in the presence of stoichiometric amounts of conventional Lewis or Brønsted acid, such as aluminum trichloride, iron(III) chloride or phosphoric acid. ${ }^{24}$

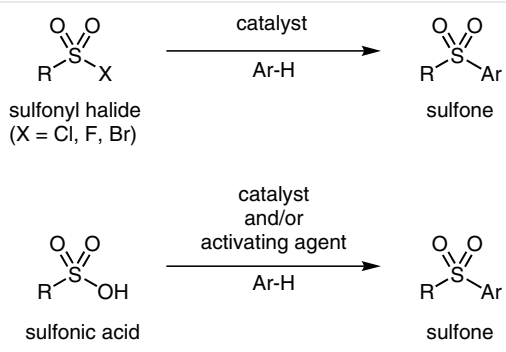

Scheme 4

In general, these reactions suffer from the typical drawbacks of Friedel-Crafts-type processes, such as harsh reaction conditions, low regioselectivity, the need for stoichiometric amounts of the catalyst, and the generation of substantial quantities of hazardous waste. Therefore, a variety of more efficient catalysts have been developed throughout the last decades. ${ }^{25}$ Special emphasis was placed on more sustainable methods such as reusable solid acids, ${ }^{25 e}$ solvent-free $^{25 \mathrm{i}}$ or ionic-liquid-based ${ }^{25 \mathrm{~d}, \mathrm{f}}$ systems and reactions 
with low catalyst loadings. ${ }^{25 i}$ The direct sulfonylation of arenes with sulfonic acids in the presence of acid catalysts has also been reported. ${ }^{25 e, 26}$ Activation of the sulfonic acid with suitable reagents, such as phosphorus pentoxide or triflic anhydride, leads to the in situ formation of reactive mixed anhydrides and an efficient sulfonylation of arenes at room temperature. ${ }^{27}$

Sulfones are frequently encountered side-products in the sulfonation of arenes with sulfuric acid. ${ }^{28}$ They are formed by the reaction of the intermediate sulfonic acid with an excess of the arene. Removal of water during the reaction furnishes the symmetrical diaryl sulfone as the major product (Scheme 5 ). ${ }^{29}$ In a similar manner, symmetrical diaryl sulfones can be prepared by the reaction of an arene with dimethyl pyrosulfate in the presence of sulfuric acid. ${ }^{30}$
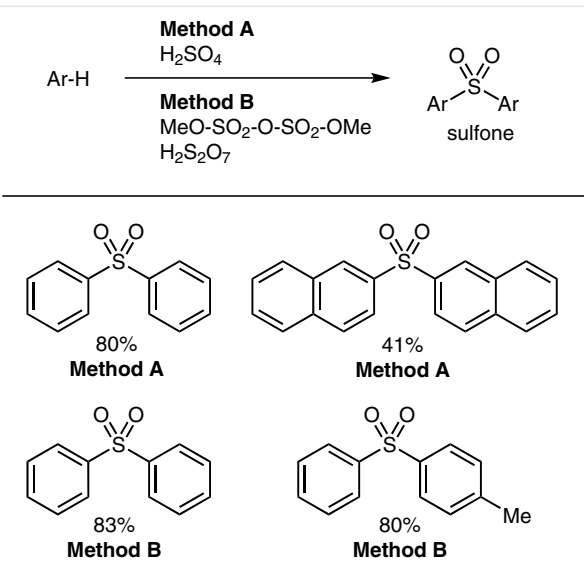

Scheme 5

Rao and co-workers reported a similar method. ${ }^{31}$ Their procedure enables the one-pot synthesis of symmetrical as well as unsymmetrical diaryl sulfones starting from arenes, a persulfate salt, trifluoromethanesulfonic acid (TfOH) and trifluoroacetic acid anhydride (TFAA) (Scheme 6). The reaction is presumed to proceed via a sulfonic acid which is activated to the corresponding anhydride with TFAA.

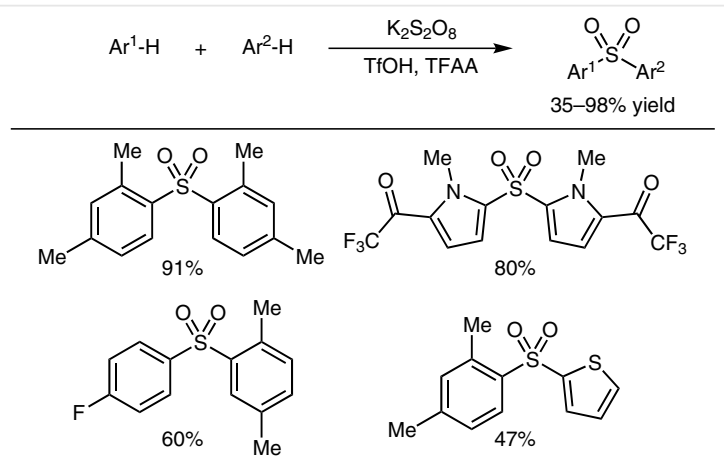

Scheme 6
An unusual process is the sulfonylation of arenes with sulfonamides in the presence of triflic anhydride as activating agent. ${ }^{32}$ This method provides an alternative access to aryl sulfones using a stable primary sulfonamide as sulfonylating agent (Scheme 7).

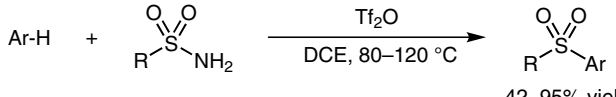

$$
\begin{aligned}
& \overbrace{\mathrm{Br}}^{(1)} \\
& \text { Me }
\end{aligned}
$$

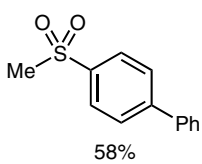

Scheme 7

\subsection{Alkylation/Arylation of Sulfinates}

The salts of sulfinic acids are useful precursors for the synthesis of sulfones. Sulfinates are powerful nucleophiles and react with a variety of different electrophiles at the sulfur atom to form sulfones. ${ }^{1,33}$ Only in the case of hard alkylating agents, such as dimethyl sulfate or diazomethane, does O-alkylation occur, and the corresponding sulfinate esters are produced predominantly (Scheme 8$).^{34}$

$$
\text { electrophile }
$$

\section{Scheme 8}

Typical electrophiles include alkyl halides, ${ }^{34,35}$ epoxides, ${ }^{36}$ Michael acceptors, ${ }^{37}$ and aryl halides activated towards nucleophilic aromatic substitution (Scheme 9). ${ }^{38} \mathrm{Al}-$ though the reactions are generally high-yielding, simple to perform and suitable for a broad scope of alkylating agents, this approach is limited owing to the modest availability of sulfinate salts. 


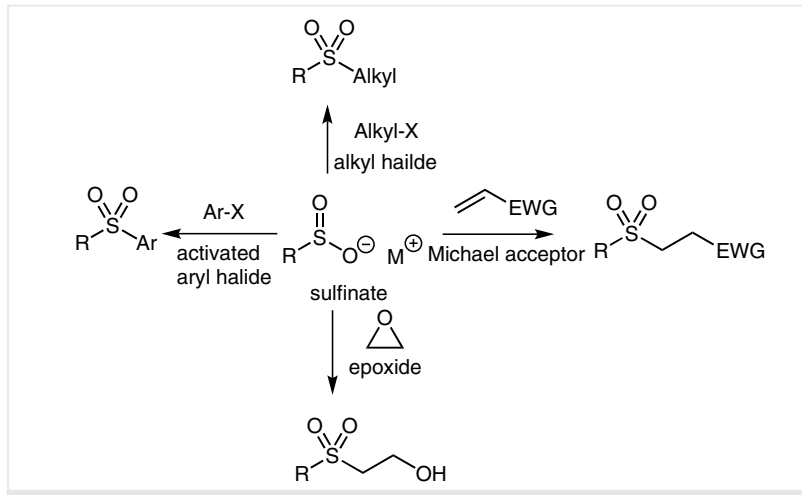

Scheme 9

Recent developments in this field include the sulfonylation of five- and six-membered heterocycles with sodium sulfinates by way of nucleophilic aromatic substitution (Scheme 10). ${ }^{39}$ Both methods enable the transition-metalfree synthesis of heterocyclic sulfones, of particular relevance for medicinal chemistry.
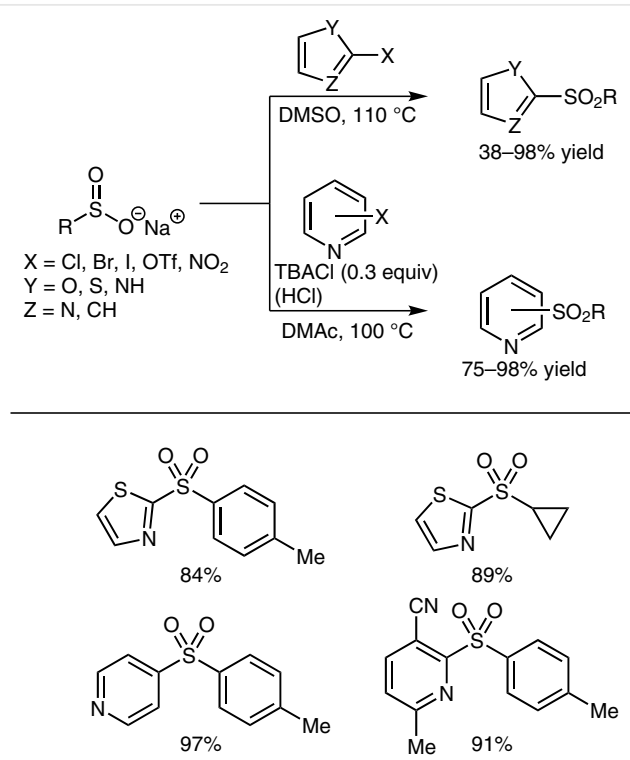

Scheme 10

In a similar manner, diaryliodonium salts, powerful arylating reagents, ${ }^{40}$ react with sodium sulfinates in the absence of any catalyst. ${ }^{41}$ In contrast to classical $S_{N} A r$ reac- tions, this method is not limited to activated arenes, and unsymmetrical diaryliodonium salts can transfer one aryl moiety with high degrees of chemoselectivity (Scheme 11).

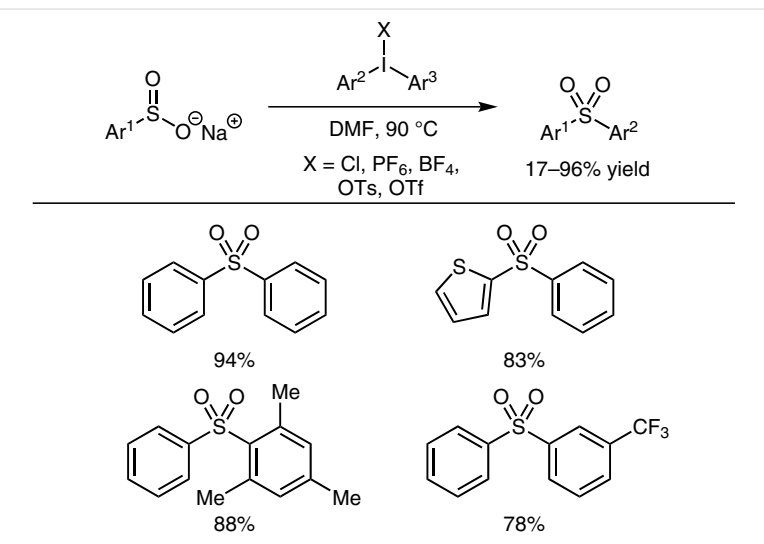

Scheme 11

Mhaske and Pandya developed a transition-metal-free process for the synthesis of aryl sulfones based on the addition of sodium sulfinates to in situ generated arynes (Scheme 12). ${ }^{42}$
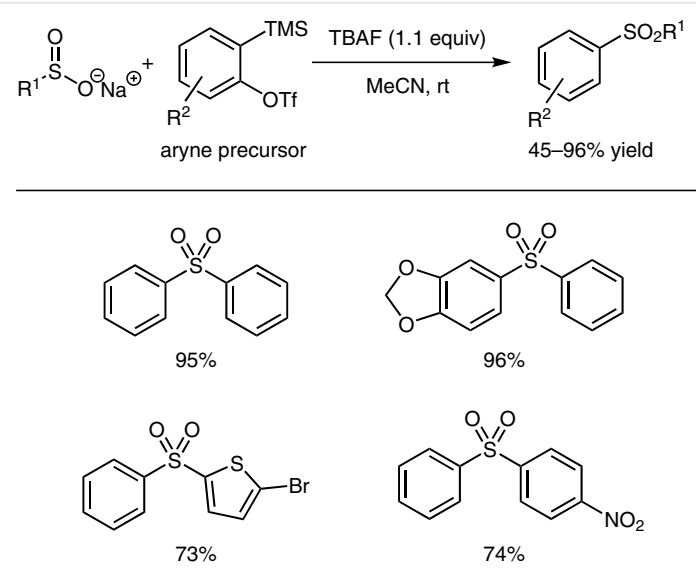

Scheme 12

Chen, Yu and co-workers extended the transitionmetal-free coupling of sodium sulfinates to employ vinyl halides (Scheme 13). ${ }^{43}$ The reaction proceeds in water with catalytic amounts of an acid and a phase-transfer catalyst. An addition-elimination mechanism is proposed for this transformation. 


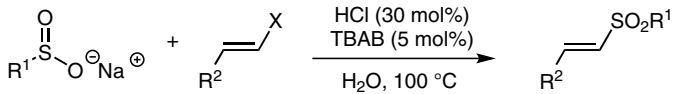

$$
\begin{aligned}
& \mathrm{X}=\mathrm{Br}, \mathrm{Cl} \quad 40-99 \% \text { yield }
\end{aligned}
$$<smiles>COc1ccccc1/C=C/Oc1ccc(C)cc1</smiles><smiles>Cc1ccc([Se]C2=Cc3ccccc3C2)cc1</smiles><smiles>O=C(O)C=CO[Sb]c1ccc([N+](=O)[O-])cc1</smiles>

$59 \%$<smiles>CO[Hg]OC=Cc1ccccc1</smiles>

$53 \%$

\section{Scheme 13}

The lithium bromide catalyzed reaction of sodium sulfinates with terminal epoxides in water provides a sustainable approach for the preparation of vinyl sulfones (Scheme 14). ${ }^{44} \mathrm{~A}$ mixture of the internal and the terminal regioisomer is obtained in most cases. The regioselectivity is governed by electronic and steric effects of the expoxide substituent. The reaction is presumed to proceed through initial expoxide opening with the sulfinate followed by dehydration of the formed $\beta$-hydroxy sulfone.

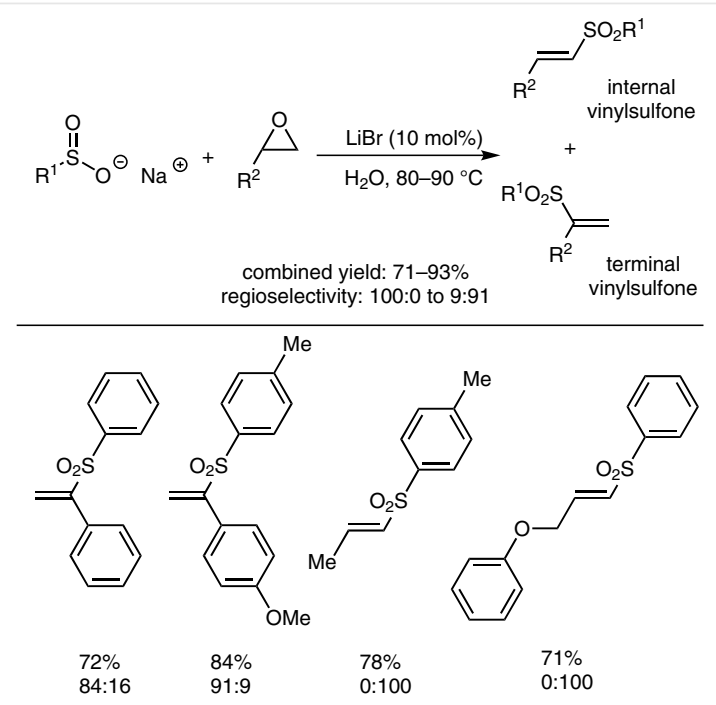

Scheme 14

Liang and co-workers developed a synthesis of vinyl sulfones starting from sodium sulfinates and 1,2-dibromides in the absence of any catalyst. ${ }^{45}$ The method provides the (E)-vinyl sulfone as the major stereoisomer or sole product (Scheme 15).

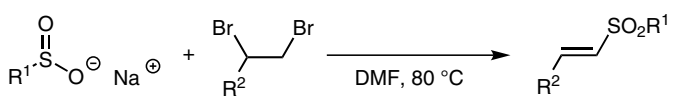

$$
\begin{aligned}
& 65-88 \% \text { yield }
\end{aligned}
$$
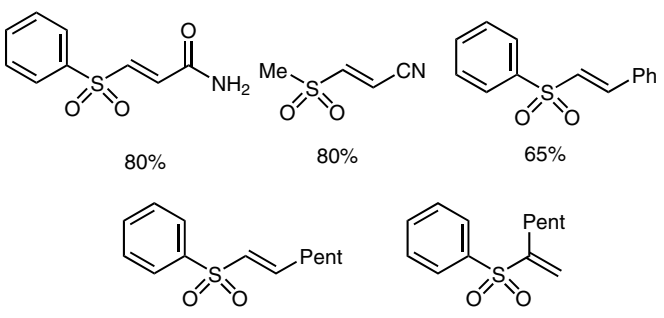

$66 \%(5: 1)$

Scheme 15

Sreedhar and co-workers reported an iron(III) chloride catalyzed direct sulfonylation of activated alcohols with sodium sulfinates (Scheme 16). ${ }^{46}$ The reaction proceeds through an activation of the alcohol and formation of a stabilized carbocation.

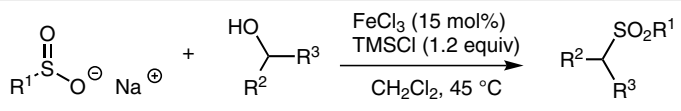$$
\mathrm{R}^{2}, \mathrm{R}^{3}=\text { alkyl, aryl, allyl }
$$
$35-96 \%$ yield

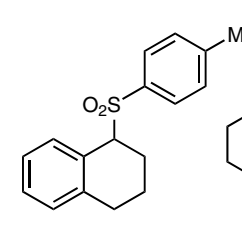

$75 \%$<smiles>Cc1ccc(S(=O)(=O)Cc2ccc(F)cc2)cc1</smiles><smiles>Cc1ccc(S(=O)/C=C/c2ccc(Br)cc2)cc1</smiles>

Scheme 16

The Ji group developed a one-pot synthesis of allylic sulfones, $\beta$-keto sulfones or triflic alcohols from allylic alcohols and sulfinic acids. ${ }^{47}$ Substitution of the allylic alcohol yields the allyl sulfone. Direct treatment of the reaction mixture with phenyliodine(III) diacetate (PIDA) and sulfuric acid leads to an oxidative rearrangement of the allyl sulfone and formation of $\beta$-keto sulfones. For triflated intermediates, no migration is observed and triflic alcohols are obtained instead (Scheme 17). 


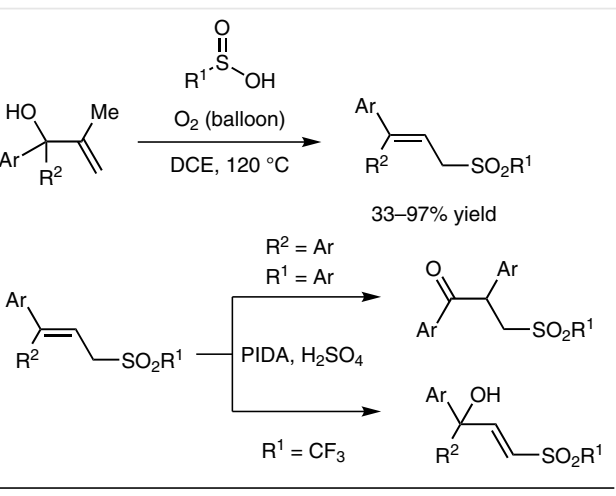

(1)<smiles>O=C(c1ccc(Br)cc1)C(CS(=O)(=O)c1ccccc1)c1ccccc1</smiles>
$69 \%$ $75 \%(1: 1)$<smiles>O=S(=O)(/C=C/C(O)(c1ccccc1)c1ccccc1F)C(F)(F)F</smiles>

$68 \%$

Scheme 17

Tian and co-workers reported a catalyst-free alkylation of sulfinic acids with allylic and benzylic sulfonamides. ${ }^{48}$ Cleavage of the $\mathrm{C}-\mathrm{N}$ bond takes place even at room temperature (Scheme 18).

$$
\begin{aligned}
& \mathrm{R}^{1 .} \stackrel{\mathrm{II}}{\mathrm{O}} \mathrm{-OH}_{\mathrm{OH}}+\mathrm{R}^{2} \prec_{\mathrm{R}^{3}}^{\mathrm{NHTS}} \underset{\mathrm{CHCl}_{3}, \mathrm{rt}}{\longrightarrow} \mathrm{R}^{2} \prec_{\mathrm{R}^{3}}^{\mathrm{SO}_{2} \mathrm{R}^{1}} \\
& \text { 56-99\% yield }
\end{aligned}
$$<smiles>COc1ccc(C(c2ccccc2)S(=O)(=O)c2ccccc2)cc1</smiles><smiles>O=S(=O)(c1ccccc1)C(c1ccccc1)c1ccccc1</smiles><smiles>COc1ccc(C(C)S(=O)(=O)O)cc1</smiles><smiles>[M]C(c1ccc(OC)cc1)S(=O)(=O)c1ccc(OC)cc1</smiles>

99\%

Scheme 18

Sulfonyl hydrazides can be considered as masked sulfinates, as treatment of a hydrazide with base or with water and heating can liberate the free sulfinic acid or the corre- sponding salt. ${ }^{1,49}$ If unmasking of the sulfinate is performed in the presence of a suitable electrophile, formation of a sulfone occurs. Exploiting this reactivity, Petrini and coworkers reported the synthesis of sulfones from alkyl and activated aryl halides and $p$-toluenesulfonyl hydrazide with sodium acetate as base (Scheme 19). ${ }^{50}$
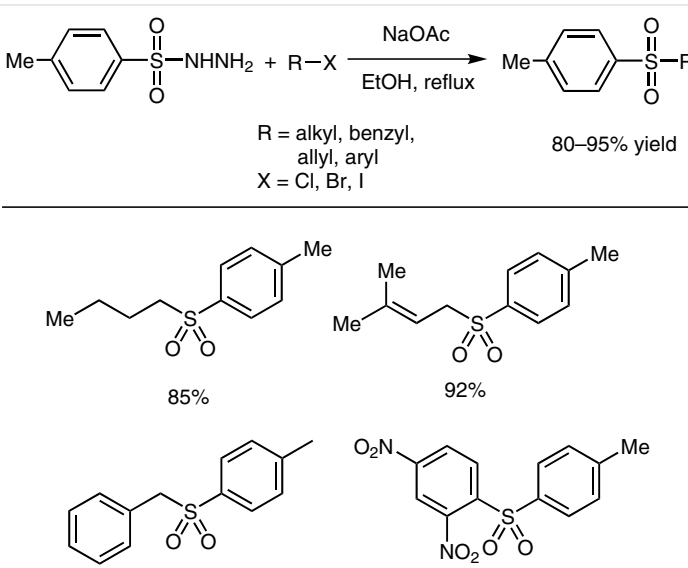

$84 \%$

95\%

Scheme 19

In a similar manner, sulfonyl hydrazides react with Michael acceptors to yield the corresponding ethyl sulfones. ${ }^{51}$ The reaction proceeds in water without any catalyst (Scheme 20).
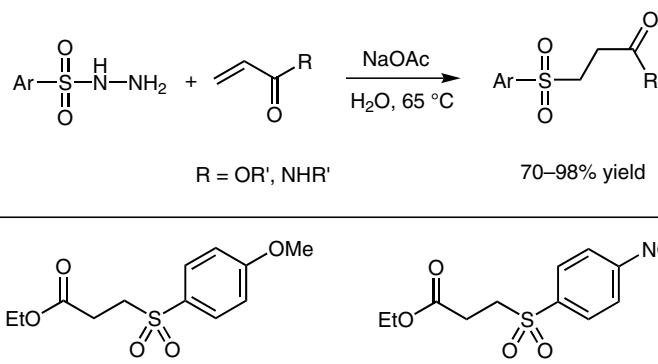

$93 \%$<smiles>CCOC(=O)CCS(=O)(=O)c1ccc([N+](=O)[O-])cc1</smiles><smiles>CC(C)OC(=O)CCS(=O)(=O)c1ccc([N+](=O)[O-])cc1</smiles>

$70 \%$<smiles>Cc1ccc(S(=O)(=O)CCC(=O)Nc2ccccc2)cc1</smiles>

99\%

\section{Scheme 20}

Tang and co-workers reported a sulfonylation of allylic acetates with sulfonyl hydrazides in water. ${ }^{52}$ The reaction is catalyzed by tetrabutylammonium iodide (TBAI), and tertbutyl hydroperoxide (TBHP) is employed as cooxidant (Scheme 21). 


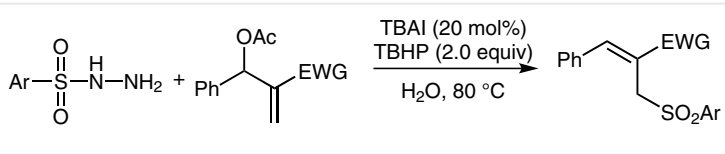<smiles>CC(=O)OC(C)=Cc1ccc(Cl)cc1</smiles>
$54 \%$
$Z I E=97: 3$<smiles>COC(=O)/C(=C\c1cccs1)CS(=O)(=O)c1ccc([N+](=O)[O-])cc1</smiles>
$Z \mid E=89: 11$<smiles>CCOC(=Cc1cccc([N+](=O)[O-])c1)CS(=O)(=O)c1ccc([N+](=O)[O-])cc1</smiles>
$Z \mid E=99: 1$<smiles>N#C/C(=C/c1ccccc1)CS(=O)(=O)c1ccccc1</smiles>

Scheme 21

Li and co-workers reported an interesting approach starting from 1,2-bis(phenylsulfonyl)ethane as sulfinate precursor. ${ }^{53}$ In the presence of a palladium catalyst, cleavage of one $\mathrm{C}-\mathrm{S}$ bond and formation of a palladium-sulfinate complex occurs. Transfer of the sulfinate to an activated alkyne affords the $(E)$-vinyl sulfone in good yields (Scheme 22).

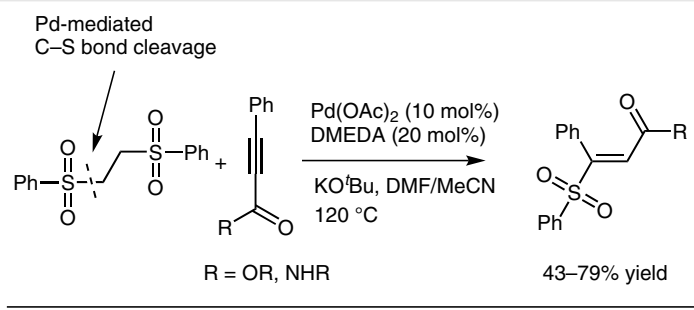

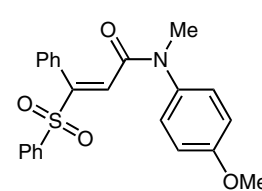<smiles>CCCCCCCCCCC(=O)N(C)c1ccccc1</smiles>

$54 \%$<smiles>COC(=O)/C=C(\c1ccccc1)S(=O)(=O)c1ccccc1</smiles>

$43 \%$

Scheme 22

Allylic alcohols react with arenesulfonyl cyanides to afford trisubstituted allyl sulfones (Scheme 23). ${ }^{54}$

Tian and co-workers developed a method to convert benzylic and allylic alcohols into the corresponding sulfones using sulfinyl chlorides (Scheme 24). ${ }^{55}$ The reaction proceeds through in situ formation of a sulfinic acid or a sulfinate ester and is catalyzed by the by-product $\mathrm{HCl}$.

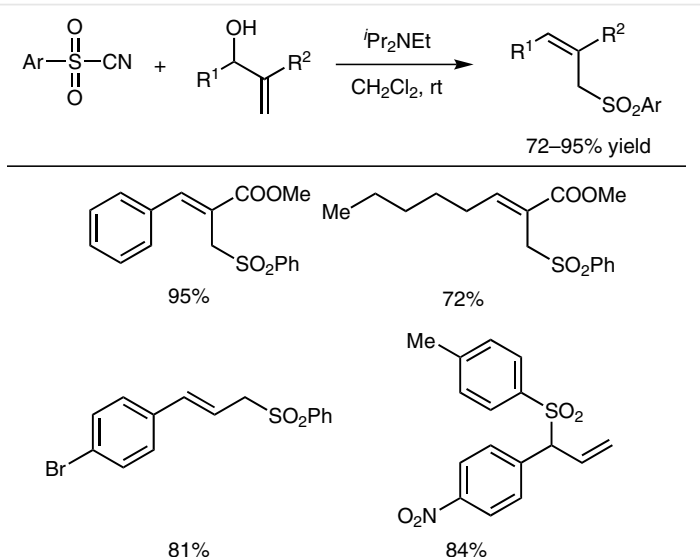

Scheme 23

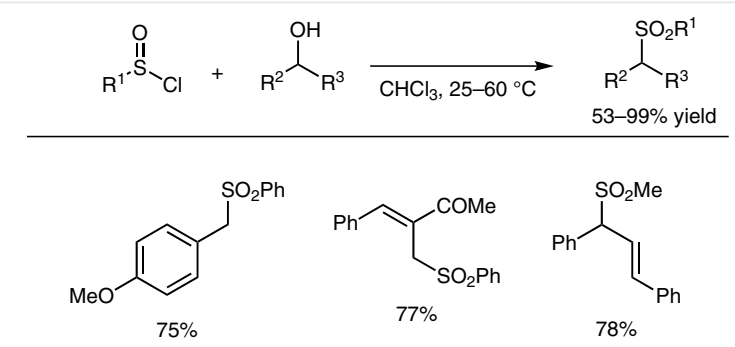

Scheme 24

\subsection{Addition to Alkenes and Alkynes}

The addition of sulfonyl radicals to alkenes and alkynes is an important method for the synthesis of sulfones (Scheme 25)., ${ }^{1,56}$ Since the first reports on addition of sulfonyl halides to alkenes in the presence of radical initiators, light or copper(I) chloride, ${ }^{57}$ various improvements and modifications of this atom-transfer radical addition (ATRA) process have been developed. Sulfonyl radicals can be generated from sulfonyl haldes, sulfonyl selenides, sulfonyl hydrazides, sulfonyl azides, or by the oxidation of sulfinates. ${ }^{58}$

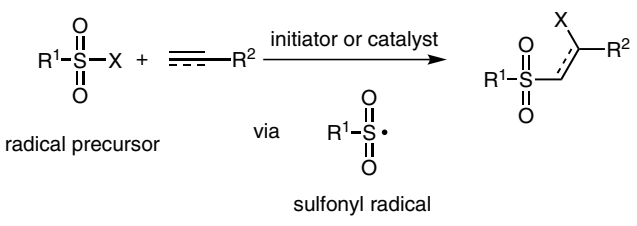

\section{Scheme 25}

Ruthenium complexes are amongst the most efficient catalysts for the ATRA of sulfonyl chlorides to olefins. Catalyst loadings as low as $0.1 \mathrm{~mol} \%$ and high turnover frequencies are observed for modified cyclopentadienyl-ruthenium complexes. ${ }^{59,60}$ 
Addition of sulfonyl halides to alkynes affords halogenated vinyl sulfones. In general, the $(E)-\beta$-halovinyl sulfones are obtained as either the major or the sole diastereomer (Scheme 26). ${ }^{1,57}$ Nakamura and co-workers reported an iron-catalyzed regio- and stereoselective addition of sulfonyl chlorides to terminal alkynes (Scheme 26). ${ }^{61}$ A bromosulfonylation of terminal alkynes was achieved with a triethylborane-initiated sulfonyl radical generation. ${ }^{62}$

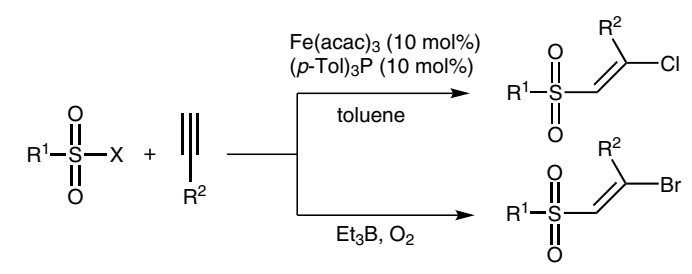<smiles>CC(=O)c1ccc(S(=O)(=O)C=C(Cl)c2ccccc2)cc1</smiles><smiles>O=[N+]([O-])c1ccc(S(=O)(=O)/C=C(/Br)c2ccccc2)cc1</smiles>

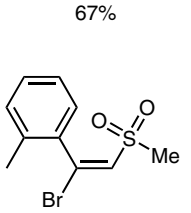

$99 \%$

$$
91 \%
$$

Scheme 26

The Kang group developed methods for the synthesis of heterocyclic compounds based on the radical additions of tosyl bromide or iodide to allenes. ${ }^{63}$ Treatment of the resulting allylic halides with base furnished the corresponding heterocycles (Scheme 27).

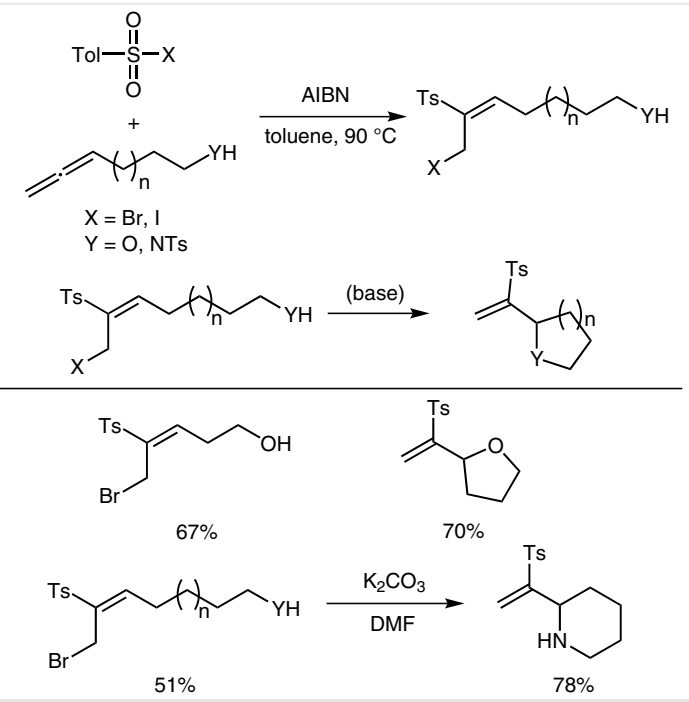

Scheme 27
The ATRA of tosyl bromide to bisallenes leads to the formation of five-membered rings bearing an exocyclic vinyl sulfone via a 5-exo-trig cyclization (Scheme 28). ${ }^{64}$

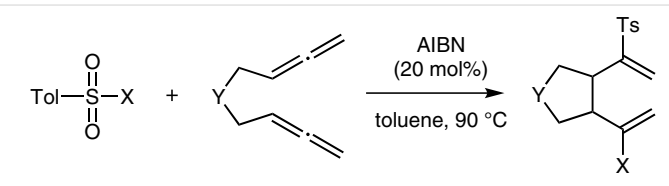

$\mathrm{X}=\mathrm{Br}, \mathrm{SePh} \quad \mathrm{Y}=\mathrm{O}, \mathrm{NR}, \mathrm{CR}_{2} \quad 48-73 \%$ yield

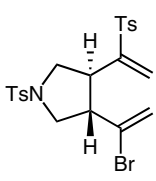

$73 \%$

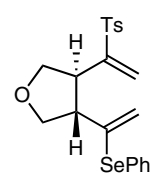

$55 \%$

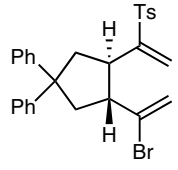

$63 \%$
Scheme 28

1,6-Diynes react with tosyl bromide in a similar manner, affording bromo-substituted sulfonylated methylcyclopentenes via a 5-endo-dig cyclization (Scheme 29). ${ }^{65}$

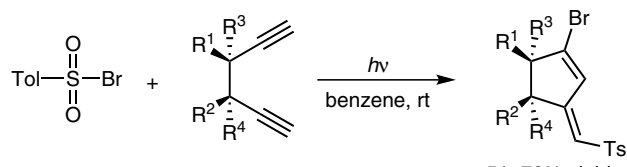

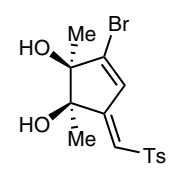

$68 \%$

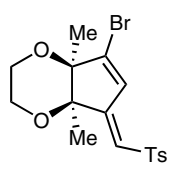

$72 \%$

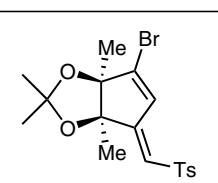

$51 \%$
Scheme 29

Generation of sulfonyl radicals from the corresponding azides is also possible. For example, Mantrand and Renaud developed a radical-mediated azidosulfonylation of alkenes, dienes and enynes with phenylsulfonyl azide (Scheme $30){ }^{66}$ The reaction is limited to 1,6-dienes, 1-en-6-ynes, or alkenes that are able to undergo a rapid radical rearrangement. In the case of simple alkenes, no reaction is observed owing to the reversibility of the sulfonyl radical addition and the low reaction rate of the final azidation of secondary alkyl radicals.

Sulfinic acids and their salts are competent radical precursors and yield the corresponding sulfonyl radicals upon single-electron oxidation. Various methods have been reported for the generation of sulfonyl radicals from sulfinates or the free acids. ${ }^{1,56,58}$ Addition to an alkene or alkyne can yield the formal hydrosulfonylation product as well as various other sulfonylated products arising from different trapping processes. Two-electron oxidation of sulfinic acids can yield a sulfonyl cation, which can undergo similar reactions with double or triple bonds. 


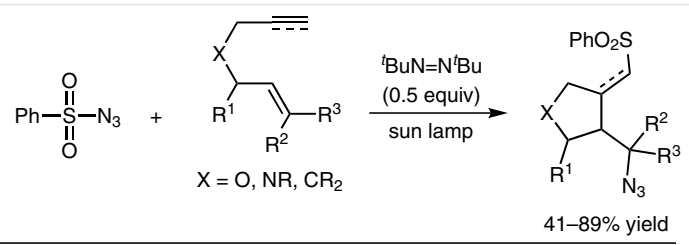

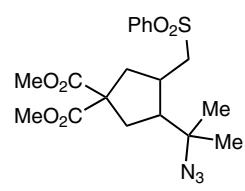

$76 \%$

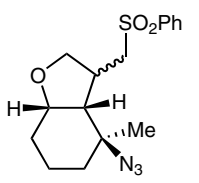

$82 \%$

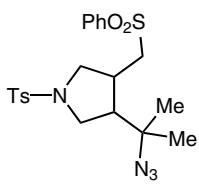

$89 \%$

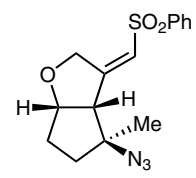

$80 \%$
Scheme 30

Taniguchi reported a copper-catalyzed addition of sodium sulfinates to alkenes and alkynes ${ }^{67}$ Addition to alkenes affords $(E)$-vinyl sulfones via an addition-elimination process. Reaction of alkynes in the presence of potassium halides furnishes (E)- $\beta$-haloalkenyl sulfones (Scheme 31 ). This method was later extended to a formal hydrosulfonylation of alkynes. ${ }^{68}$
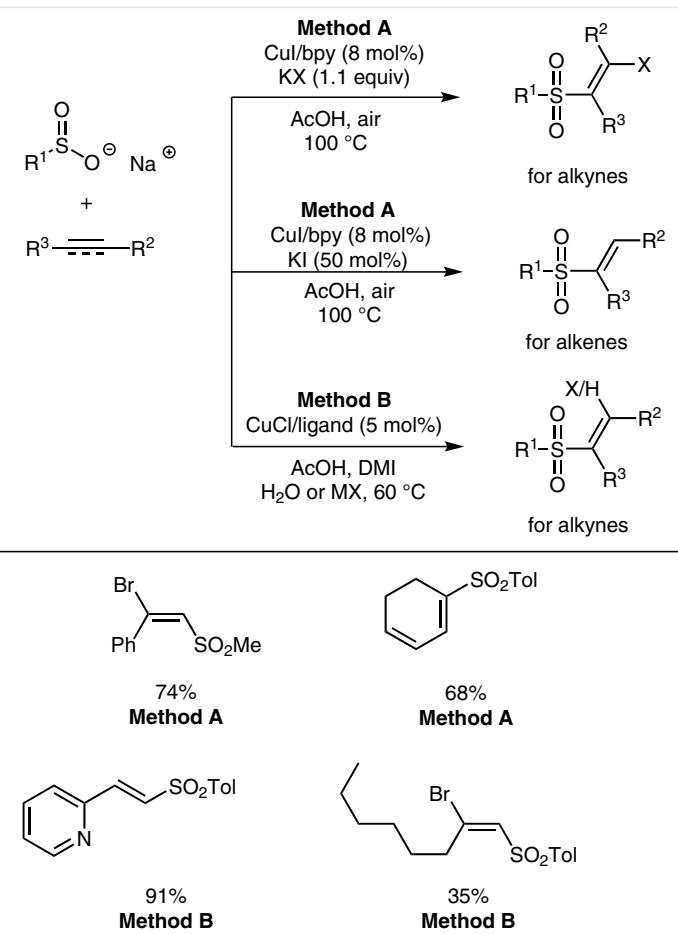

Scheme 31 DMI = 1,3-Dimethyl-2-imidazolidinone
Jiang and co-workers reported a palladium-catalyzed addition of sodium sulfinates to alkynes affording $(E)$-vinyl sulfones (Scheme 32). ${ }^{69}$

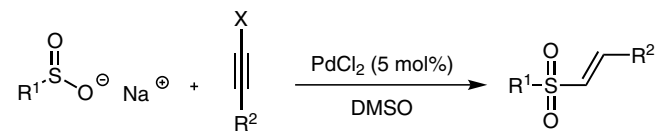

$$
\begin{aligned}
& \mathrm{X}=\mathrm{H}, \mathrm{COOH} \\
& 65-93 \% \text { yield } \\
& \mathrm{S}_{\mathrm{S}}^{\mathrm{O}_{2}}-\mathrm{NO}_{2} \\
& \begin{array}{l}
82 \% \\
X=H
\end{array} \\
& \mathrm{~F}_{3} \mathrm{C} \longrightarrow \mathrm{Sh} \\
& \begin{array}{r}
73 \% \\
x=c 00
\end{array} \\
& \mathrm{X}=\mathrm{COOH}
\end{aligned}
$$
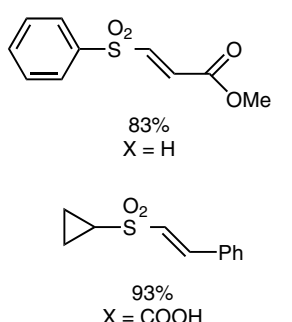

Scheme 32

Kuhakarn and co-workers developed a PIDA and potassium iodide mediated synthesis of vinyl sulfones and $\beta$-iodovinyl sulfones (Scheme 33). ${ }^{70}$ The reaction of sodium sulfinates with alkenes furnishes $\beta$-iodo sulfones, which eliminate to the corresponding vinyl sulfones under the reaction conditions or upon treatment with base. In the case of alkynes, (E)- $\beta$-iodovinyl sulfones are obtained as products. An in situ formation of sulfonyl iodides as reactive species is proposed.

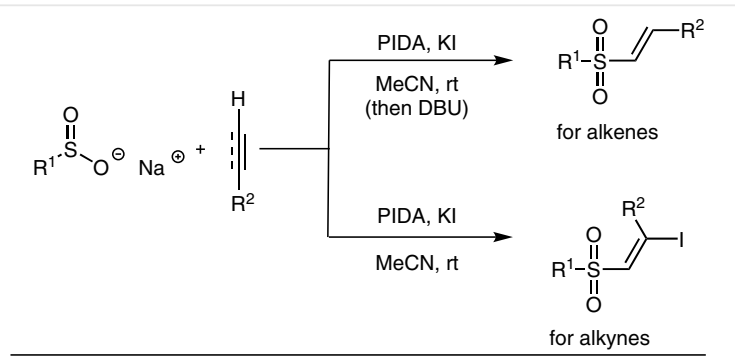<smiles>Cc1ccc(S(=O)(=O)/C=C(/I)c2ccc([N+](=O)[O-])cc2)cc1</smiles><smiles>C/C(I)=C\S(=O)(=O)c1ccc(C)cc1</smiles><smiles>Cc1ccc(S(=O)(=O)/C=C/COCc2ccccc2)cc1</smiles><smiles>COC(=O)/C=C/S(=O)(=O)c1ccc(C)cc1</smiles>

Scheme 33 
The potassium persulfate promoted direct sulfonylation of $N$-phenylmethacrylamides with sulfinic acids leads to the formation of sulfonylated oxindoles (Scheme 34). ${ }^{71}$

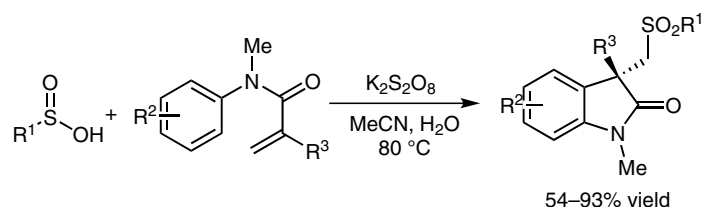<smiles>CC(=O)c1ccc2c(c1)[C@](C)(C[13C](=O)Oc1ccccc1)C(=O)N2C</smiles><smiles>[Y9][C@@]1(C[Se](=O)Oc2ccccc2)C(=O)N2CCCc3cccc1c32</smiles>

$70 \%$<smiles>CN1C(=O)C(CO)(COc2ccccc2)c2ccccc21</smiles>

$92 \%$

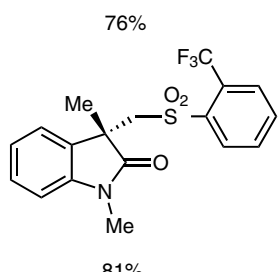

Scheme 34

In general, the addition of sulfinic acids or sulfinates to alkynes leads to the regioselective formation of the antiMarkovnikov-type products. Shi and co-workers reported a gold-catalyzed synthesis of $\alpha$-substituted vinyl sulfones. ${ }^{72}$ In the presence of a suitable gold catalyst and gallium(III) triflate, regioselective Markovnikov addition to terminal alkynes takes place (Scheme 35).

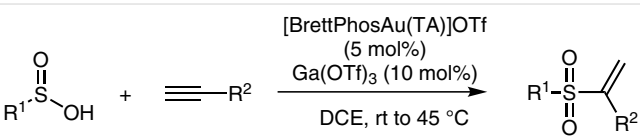

$$
\begin{aligned}
& \text { 50-91\% yield }
\end{aligned}
$$
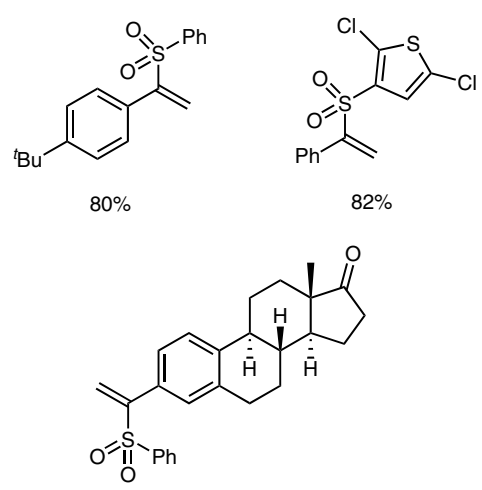

$86 \%$
Visible-light-photocatalyzed oxidation of sulfinates or sulfinic acids provides an attractive alternative for the generation of sulfonyl radicals. König and co-workers developed a visible-light-mediated addition of sodium sulfinates to alkenes. ${ }^{73}$ This method provides a general and simple procedure for the synthesis of vinyl sulfones (Scheme 36).
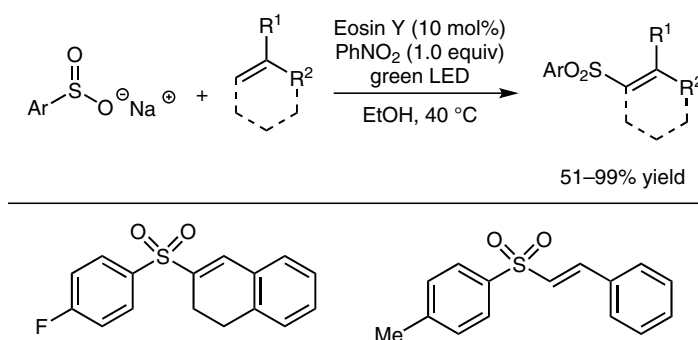

$79 \%$<smiles>Cc1ccc(S(=O)(=O)/C=C/c2ccccc2)cc1</smiles>

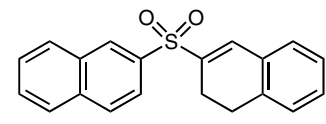

$88 \%$

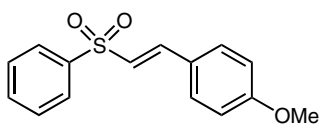

$90 \%$
Scheme 36

Visible-light-initiated addition of sulfinic acids to $\mathrm{N}$ arylacrylamides furnishes sulfonylated oxindoles via an addition/cyclization cascade (Scheme 37). ${ }^{74}$
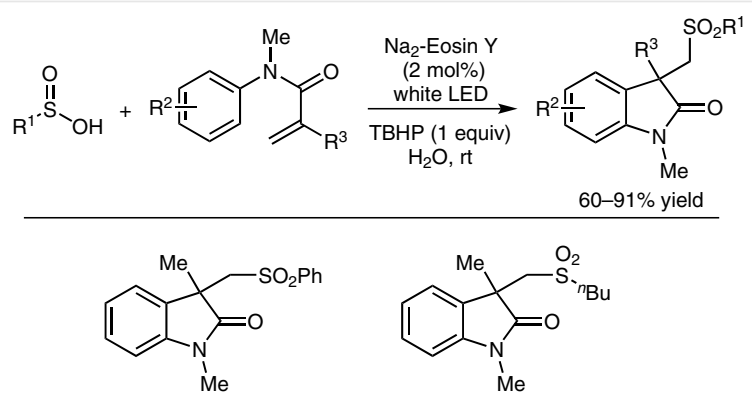

$60-91 \%$ yield

$85 \%$

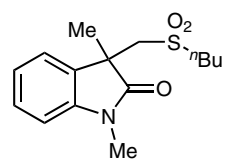

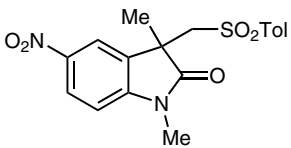

$70 \%$<smiles>CN1C(=O)C(C)(C[Se]O)c2cccc3cccc1c23</smiles>

$70 \%$
Scheme 37

Under similar reaction conditions, sulfinic acids react with phenyl propiolates to afford coumarins (Scheme 38). ${ }^{75}$ 

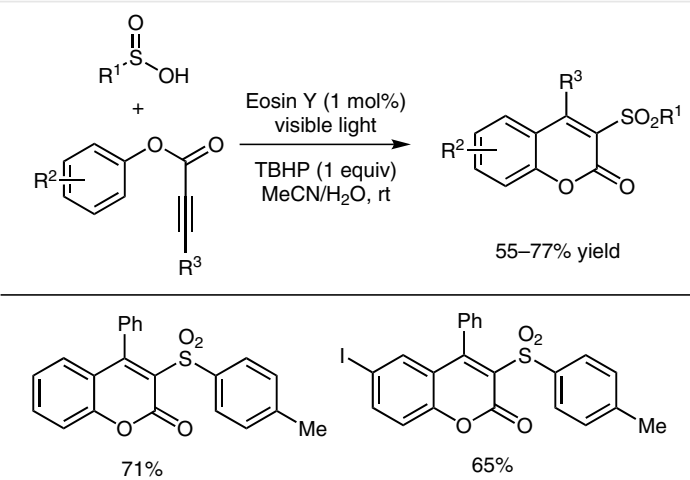<smiles>Cc1ccc(Sc2c(-c3ccccc3)c3cc(I)ccc3oc2=O)cc1</smiles><smiles>O=c1oc2ccccc2c(-c2ccccc2)c1[Se]c1ccc(Cl)c(C(F)(F)F)c1</smiles>

$58 \%$<smiles>Cc1ccc(-c2c(-c3cc(C)ccc3[N+](=O)[O-])c(=O)oc3ccccc23)cc1</smiles>

$77 \%$

Scheme 38

In the presence of oxygen or another oxidant as radical trapping reagent, the addition of sulfonyl radicals to alkenes and alkynes yields the corresponding hydroxy or keto sulfones. Taniguchi reported a nickel-catalyzed hydroxysulfonylation of alkenes with sodium sulfinates in the presence of air. ${ }^{76}$ Addition to disubstituted alkenes leads to the formation of trans-substituted $\beta$-hydroxy sulfones independent of the olefin configuration (Scheme 39).

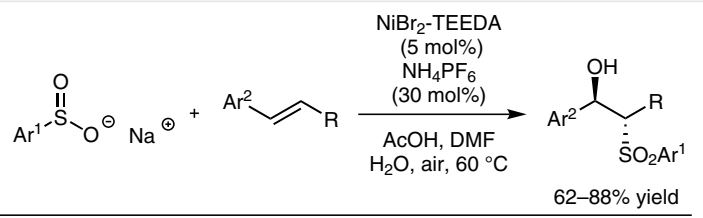<smiles>COc1ccc([Se]CC(O)c2ccccc2)cc1</smiles><smiles>Cc1ccc([Se]CC(O)c2ccccc2Br)cc1</smiles><smiles>Cc1ccc([Se]CC([O-])(O)c2ccccc2)cc1</smiles><smiles>Cc1ccc([C@@H](O)C2CCc3ccccc3C2O)cc1</smiles>

Scheme 39
The oxidative addition of sodium sulfinates to terminal alkenes can be catalyzed by molecular iodine in the presence of air. ${ }^{77}$ Oxygen acts as terminal oxidant, while iodine serves as radical initiator and reducing agent for the initially formed $\beta$-hydroperoxo sulfone (Scheme 40).

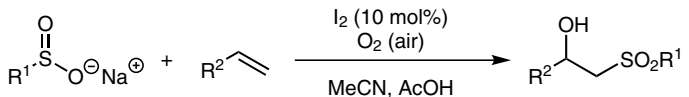

$$
\begin{aligned}
& \text { (1) } \\
& \begin{array}{lll}
93 \% & 72 \% & 79 \%
\end{array}
\end{aligned}
$$

Scheme 40

Interestingly, addition of sulfinic acids to alkenes can be mediated by oxygen alone. ${ }^{78} \mathrm{~A}$ basic additive, such as pyridine, enhances the reaction rate considerably (Scheme 41). The reaction proceeds through the initial formation of a $\beta$ hydroperoxo sulfone, which is reduced to the corresponding hydroxysulfone upon workup with triphenylphospine.
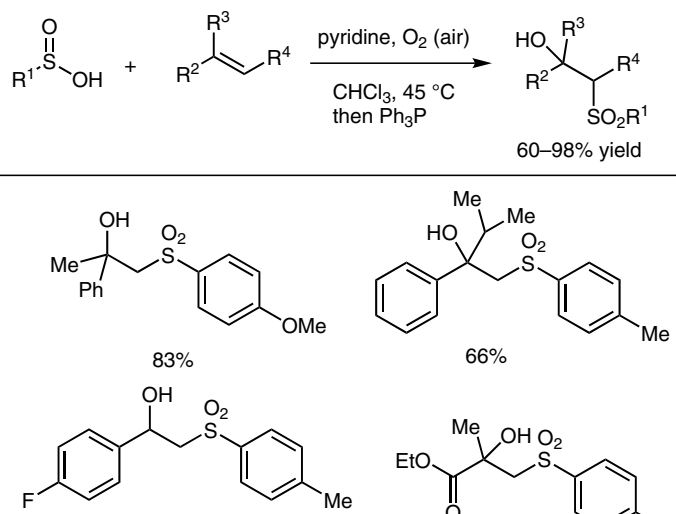

$66 \%$

$95 \%$<smiles>CCOC(=O)C(O)(O)CSc1ccc([N+](=O)[O-])cc1</smiles>

$82 \%$

\section{Scheme 41}

Yadav and co-workers reported a silver nitrate and potassium persulfate promoted synthesis of $\beta$-keto sulfones starting from alkenes and sodium sulfinates. ${ }^{79}$ The same keto sulfones can be also prepared by the oxygen-initiated addition of sulfinic acids to alkynes (Scheme 42). ${ }^{80}$ 


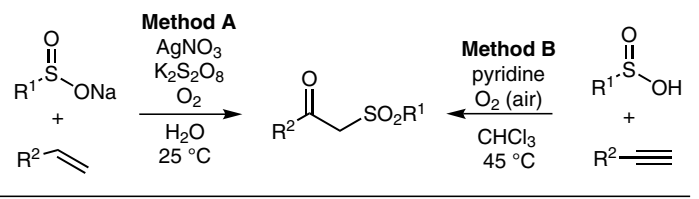<smiles>COc1ccccc1C(=O)CS(=O)(=O)c1ccccc1</smiles>

$71 \%$
Method A<smiles>CCC(C(=O)c1ccccc1)S(=O)(=O)c1ccccc1</smiles>

$76 \%$

Method B<smiles>O=C(CS(=O)(=O)c1ccc(F)cc1)c1ccccc1</smiles>

$75 \%$<smiles>O=C(CS(=O)(=O)c1ccccc1)c1cccs1</smiles>

$67 \%$

Method B

\section{Scheme 42}

Sulfonyl hydrazides can be employed as stable and easily accessible starting materials for the sulfonylation of double and triple bonds. Jiang and co-workers reported a copper-catalyzed synthesis of vinyl sulfones based on the oxidative cleavage of a hydrazide, followed by reaction of a reactive sulfonyl species with the alkene (Scheme 43). ${ }^{81}$ Lei and co-workers were able to achieve the generation of sulfonyl radicals from sulfonyl hydrazides with catalytic amounts of potassium iodide and TBHP (Scheme 43). ${ }^{82}$

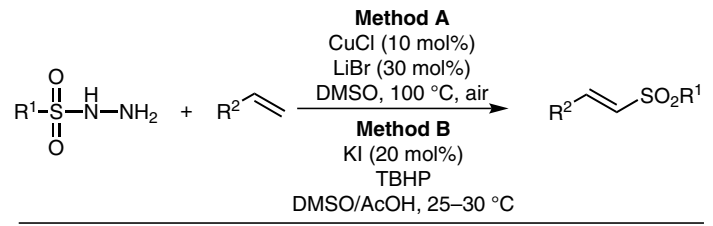<smiles>Cc1ccc([Se]C=Cc2ncc(C)s2)cc1</smiles>

$$
88 \%
$$

Method A<smiles>N#C/C=C/Sc1ccc([N+](=O)[O-])cc1</smiles><smiles>CCCCCCC[Sb]([O-])C=Cc1ccc(C)cc1</smiles><smiles>[111SnH2]</smiles><smiles>Cc1ccc(/C=C/OS(=O)c2cccc(Br)c2F)cc1</smiles>

$76 \%$

Method

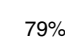

Method B
Interestingly, in the presence of stoichiometric amounts of iodine, the TBHP-mediated reaction of sulfonyl hydrazides with alkenes yields the corresponding $\beta$-iodo sulfones (Scheme 44). ${ }^{83}$ Performing the same reaction with alkynes furnishes (E)- $\beta$-vinyl sulfones (Scheme 45). ${ }^{84}$

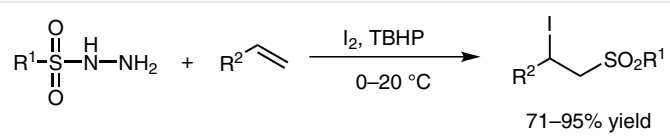<smiles>COc1ccc(CC(I)C[Se]c2ccc(C)cc2)cc1</smiles><smiles>Cc1ccc([C@@H](O)CC(I)CCBr)cc1</smiles><smiles>O=[N+]([O-])c1ccc([Sb](O)C2COCC2I)cc1</smiles>
$84 \%$

Scheme 44

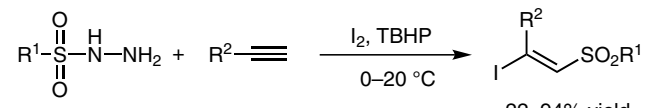<smiles>Cc1ccc(S/C=C(/I)c2ccccc2)cc1</smiles><smiles>Cc1ccc(S/C=C(/I)c2cccs2)cc1</smiles>

$94 \%$

$83 \%$<smiles>Cc1ccc(S/C=C(/I)c2cc(C(F)(F)F)cc(C(F)(F)F)c2)cc1</smiles>

$94 \%$

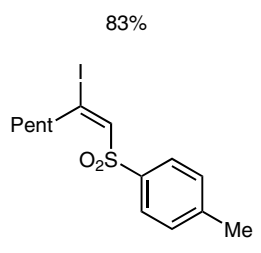

$22 \%$

Scheme 45

In the presence of catalytic amounts of copper acrylate and iron(II) chloride, the reaction of sulfonyl hydrazides with alkynes affords (E)-vinyl sulfones (Scheme 46). ${ }^{85}$ The iron-catalyzed reaction of sulfonyl hydrazides with alkenes in the presence of air yields $\beta$-hydroxy sulfones (Scheme 47). ${ }^{86}$ With $\mathrm{Cu}(\mathrm{OAc})_{2}$ as catalyst, the reaction of sulfonyl hydrazides with alkenes affords the corresponding $\beta$-keto sulfones (Scheme 48). ${ }^{87}$ 


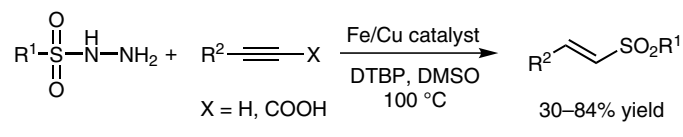<smiles>O=[N+]([O-])c1ccc(/C=C/c2ccccc2)cc1</smiles><smiles>COc1ccc([Se]/C=C/c2ccccc2)cc1</smiles>

$$
\mathrm{X}=\mathrm{81} \%
$$$$
\begin{gathered}
72 \% \\
\mathrm{X}=\mathrm{COOH}
\end{gathered}
$$<smiles>[O-]c1ccc(/C=C/c2ccc(Br)cc2)cc1</smiles><smiles>Cc1ccc([Se]/C=C/c2cccnc2)cc1</smiles>
$75 \%$
$X=H$

$$
\begin{array}{r}
80 \% \\
X=H
\end{array}
$$

Scheme 46

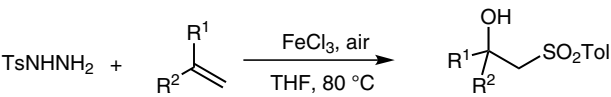

$21-95 \%$ yield

$$
\mathrm{SO}_{2} \mathrm{Tol}
$$

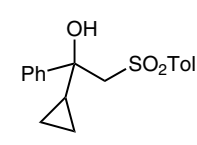

$54 \%$

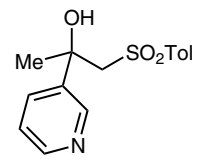

$48 \%$

\section{Scheme 47}

$\mathrm{R}^{1} \mathrm{SO}_{2} \mathrm{NHNH}_{2}$

$+$

$\mathrm{Ar}^{\mathrm{R}^{2}}$

$$
\underset{\mathrm{EtOH}, 70{ }^{\circ} \mathrm{C}}{\stackrel{\mathrm{Cu}(\mathrm{OAc})_{2}(5 \mathrm{~mol} \%)}{\mathrm{O}_{2}}}
$$

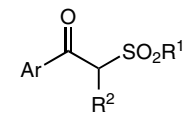

$50-72 \%$ yield<smiles>O=C(C[Se]Oc1ccccc1)c1ccccc1</smiles>

$70 \%$<smiles>COc1ccc(C(=O)CS(=O)(=O)c2ccccc2)cc1</smiles>

$52 \%$
Scheme 48

Breit and co-workers reported a rhodium-catalyzed synthesis of branched allylic sulfones starting from terminal alkynes and sulfonyl hydrazides (Scheme 49). ${ }^{88}$ The reaction proceeds via a benzoic acid mediated formation of a rhodium-allyl species, which undergoes nucleophilic displacement with a sulfinic acid generated in situ from the sulfonyl hydrazide.

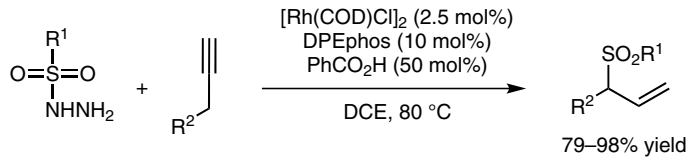

$$
\begin{aligned}
& \text { 等 } \\
& \mathrm{C}_{87 \%}^{\mathrm{SO}_{2}^{\mathrm{Tol}}} \\
& \overbrace{90 \%}^{\mathrm{SO}_{2} \mathrm{Bz}}
\end{aligned}
$$

Scheme 49

Another approach to allylic sulfones is the TBAI/TBHPmediated reaction of sulfonyl hydrazides with $\alpha$-substituted styrenes (Scheme 50). ${ }^{89}$ Generation of a sulfonyl radical, followed by addition to the double bond and elimination leads to the formation of nonconjugated sulfones.
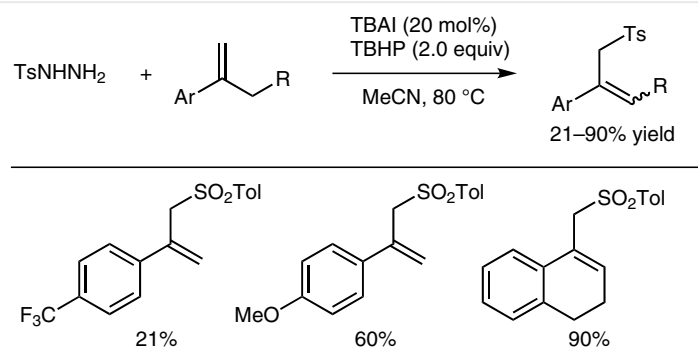

\section{Scheme 50}

$\mathrm{Qu}$, Chen and co-workers developed a copper-catalyzed sulfonylation of alkynes with tert-butylsulfinamide (Scheme 51). ${ }^{90}$ Phosphorous acid serves as terminal reducing agent and the oxidation of the sulfinyl (SO) to the sulfonyl $\left(\mathrm{SO}_{2}\right)$ moiety takes place under the reaction conditions.
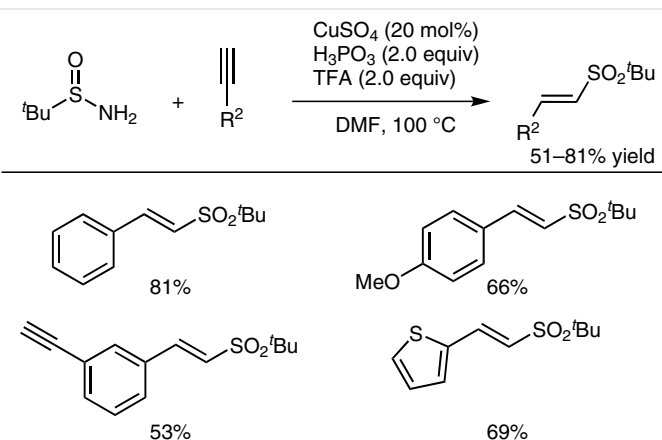

$69 \%$

\section{Scheme 51}

Widely available dimethyl sulfoxide (DMSO) is a suitable starting material for the methylsulfonylation of alkenes and alkynes. The ammonium iodide induced addition of DMSO to alkenes yields $(E)$-vinyl methyl sulfones (Scheme 
52). ${ }^{91}$ The authors propose that the reaction proceeds via the generation of thiomethyl radicals and water serves as the source of the second sulfonyl oxygen.

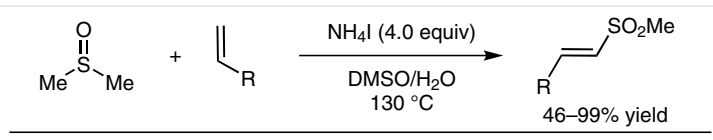<smiles>COc1ccc(/C=C/[Sb](=O)(=O)O)cc1</smiles>

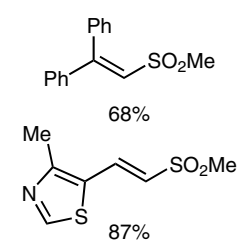

Scheme 52

The groups of Chen and $\mathrm{Qu}$ and the group of Loh reported two procedures for the copper-catalyzed synthesis of (E)-vinyl methyl sulfones from alkynes in DMSO.92 Diethyl $H$-phosphonate acts as terminal reducing agent (Scheme 53). Loh showed that under identical conditions, the reaction of alkenes affords $\beta$-keto sulfones (Scheme 54).92b
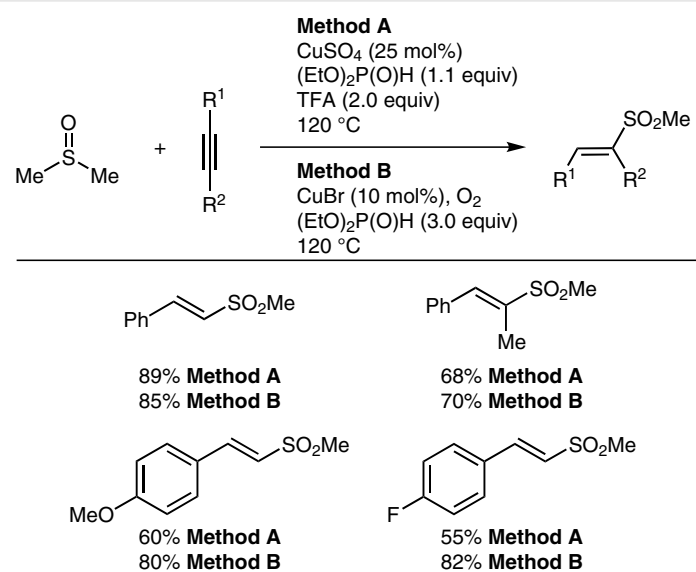

$$
\overbrace{\mathrm{Me}}^{\mathrm{SO}_{2} \mathrm{Me}}
$$

$68 \%$ Method A $70 \%$ Method B

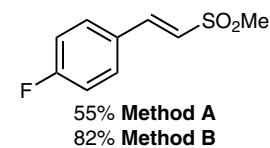

Scheme 53

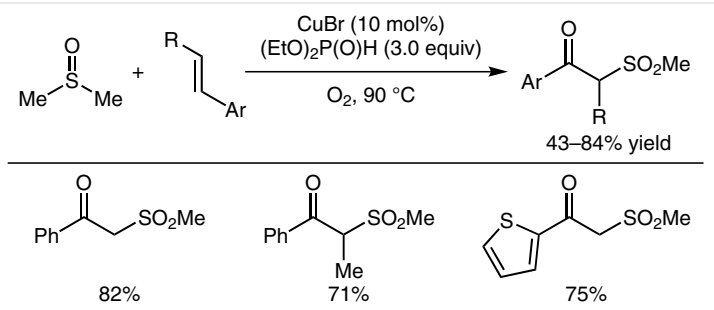

Scheme 54

Several groups have developed decarboxylative couplings of sodium sulfinates and cinnamic acids for the synthesis of vinyl sulfones. These reactions can be mediated by PIDA, ${ }^{93}$ catalytic ammounts of copper(I) chloride, ${ }^{94}$ iodine and TBHP, ${ }^{95}$ or iodine ${ }^{96}$ and even proceed in the absence of any catalyst at high temperatures in $\mathrm{DMSO}^{97}$ (Scheme 55). A mechanism consisting of sulfonyl radical formation followed by addition to the alkene and decarboxylation is proposed for all transformations.

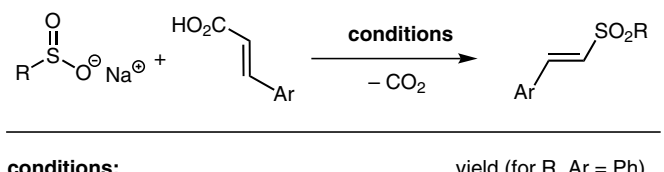

$\begin{array}{ll}\text { PIDA (2.0 equiv), DMF, } 100{ }^{\circ} \mathrm{C} & 73 \% \\ \mathrm{CuCl}\left(20 \text { mol\%), } \mathrm{KI} \text { (1.5 equiv), DMSO, air, } 100{ }^{\circ} \mathrm{C}\right. & 74 \% \\ \mathrm{I}_{2} \text { (2.0 equiv), TBHP (2.0 equiv), toluene, } 90{ }^{\circ} \mathrm{C} & 92 \% \\ \mathrm{I}_{2} \text { (1.0 equiv), } \mathrm{K}_{2} \mathrm{CO}_{3} \text { (1.0 equiv), } \mathrm{H}_{2} \mathrm{O}, 60^{\circ} \mathrm{C} & 78 \% \\ \mathrm{~K}_{2} \mathrm{CO}_{3} \text { ( } 0.50 \text { equiv), DMSO, } 100{ }^{\circ} \mathrm{C} & 82 \%\end{array}$

Scheme 55

Liu and Li reported a copper/silver-mediated domino reaction for the synthesis of 2-sulfonylbenzofurans based on a cyclization-decarboxylation sequence (Scheme 56). ${ }^{98}$
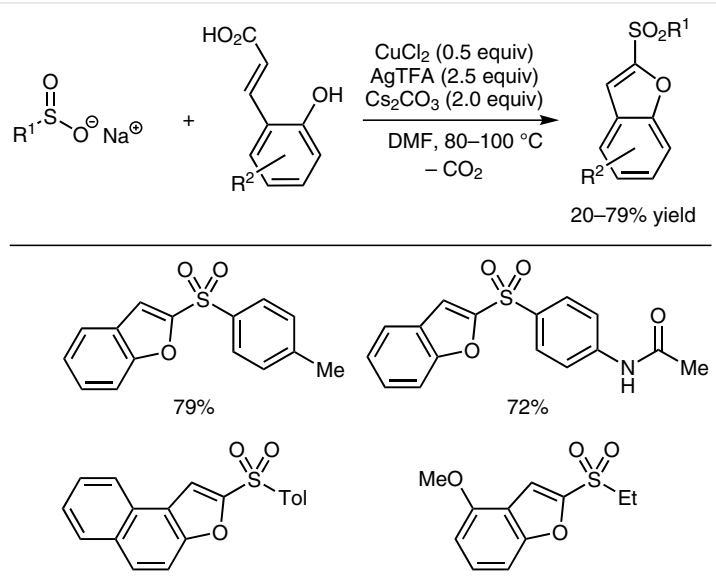

$81 \%$

$31 \%$

Scheme 56

Interestingly, palladium-catalyzed ${ }^{69}$ as well as phosphoric acid mediated ${ }^{99}$ decarboxylative coupling reactions of sodium sulfinates with aryl propiolic acids affords $(E)$-vinyl sulfones (Scheme 57).

As mentioned previously, sulfonyl hydrazides are attractive alternatives to sulfinates in various transformations. Accordingly, the iodine-mediated reaction of sulfonyl hydrazides with cinnamic acids yields $(E)$-vinyl sulfones via a radical addition and carbon dioxide extrusion (Scheme 58). ${ }^{100}$ The copper- ${ }^{101}$ or copper/iron-catalyzed ${ }^{86}$ decarboxylative hydrosulfonylation of phenyl propiolic acids with sulfonyl hydrazides furnishes the corresponding vinyl sulfones (Scheme 59). 

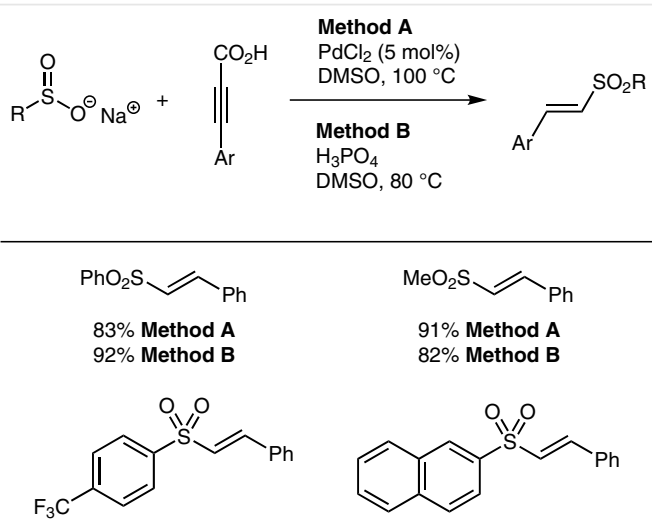

$73 \%$ Method A $73 \%$ $64 \%$ Method B 64\%

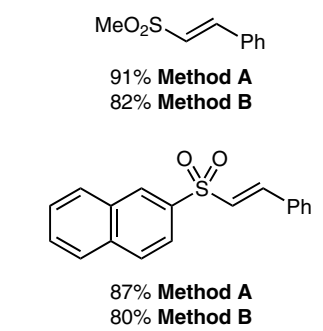

Scheme 57

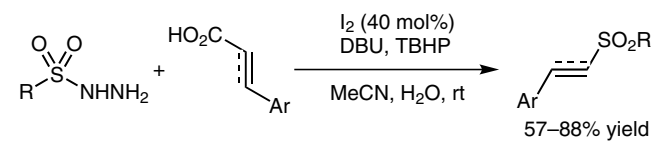

$$
\underset{87 \%}{\mathrm{SO}_{2} \mathrm{Tol}}
$$

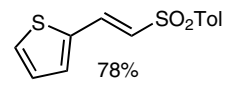

$\mathrm{PhO}_{2} \mathrm{Ph}$

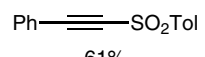

$68 \%$

$61 \%$

\section{Scheme 58}

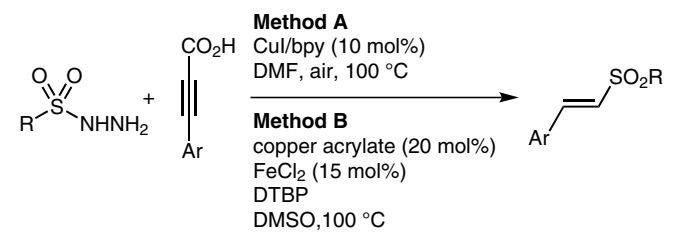

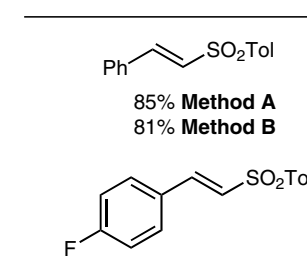

$43 \%$ Method A $72 \%$ Method B

$$
\begin{aligned}
& \text { 6o\% Method A } \\
& 73 \% \text { Method B }
\end{aligned}
$$

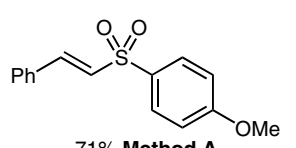

$71 \%$ Method A
Scheme 59

Lei and co-workers developed a copper-catalyzed decarboxylative oxosulfonylation of arylacrylic acids with sulfinic acids (Scheme 60). ${ }^{102}$ Evidence for a single-electrontransfer process between copper and the sulfinic acid was provided by extensive spectroscopic studies.
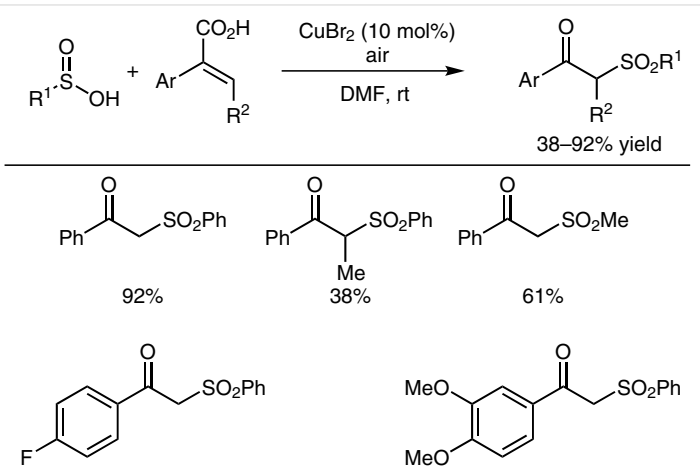

$81 \%$<smiles>COc1ccc(C(=O)CS(=O)(=O)c2ccccc2)cc1OC</smiles>

$63 \%$

Scheme 60

Vinyl acetates are suitable olefins for the synthesis of $\beta$ keto sulfones. Sulfonylation of vinyl acetates with sulfonyl hydrazides mediated by either iron(III) chloride in the presence of air ${ }^{103}$ or TBAI and TBHP104 affords the oxidative coupling products via a radical addition (Scheme 61).

$$
\begin{aligned}
& \text { Method A } \\
& \mathrm{FeCl}_{3}(10 \mathrm{~mol} \%) \text {, air } \\
& \mathrm{THF}^{\circ}, 70^{\circ} \mathrm{C}
\end{aligned}
$$

$$
\mathrm{SO}_{2} \mathrm{Tol}
$$

$91 \%$ Method A

$70 \%$ Method B<smiles>O=C(CS(=O)(=O)O)c1cccs1</smiles>

40\% Method A $45 \%$ Method B

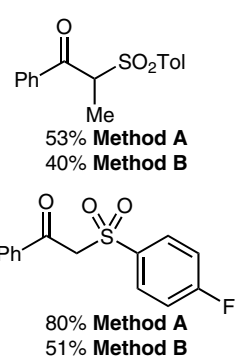

Scheme 61

A photoredox-catalyzed addition of sulfonyl chlorides to vinyl acetates for the synthesis of $\beta$-keto sulfones was developed by Zhang, Yu and co-workers (Scheme 62). ${ }^{105}$ 


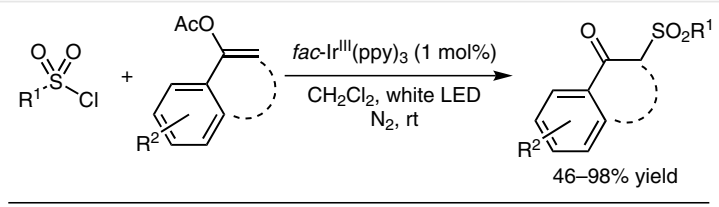<smiles>O=C(CS(=O)(=O)c1ccccc1C(F)(F)F)c1ccccc1</smiles>

$69 \%$<smiles>O=C(CS(=O)(=O)c1cccnc1)c1ccccc1</smiles>

$71 \%$

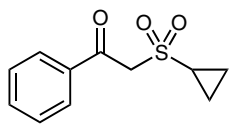

$98 \%$

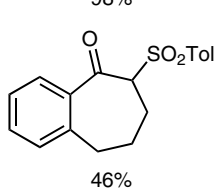

Scheme 62

The TBAI-mediated oxidative coupling of enamides with sulfonyl hydrazides yields $\beta$-keto sulfones in a similar fashion (Scheme 63). ${ }^{106}$

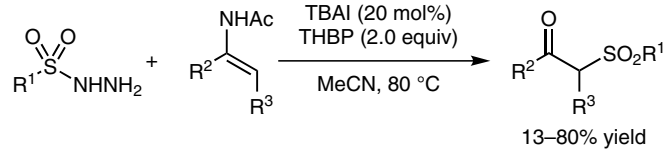<smiles>O=C(CS(=O)(=O)c1ccccc1)c1ccccc1</smiles>

$80 \%$<smiles>O=C1c2ccccc2CCC1S(=O)(=O)O</smiles>

$27 \%$

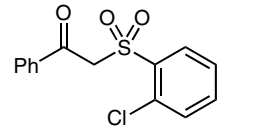

$63 \%$
Scheme 63

\subsection{Miscellaneous Methods}

Apart from these first four important approaches for the preparation of sulfones, several other synthetic routes exist. The reaction of sulfonic acid derivatives, such as sulfonate esters, or sulfonyl chlorides, with organometallic reagents produces sulfones (Scheme 64).1,107 Generally, these reactions are low-yielding and limited to certain substrate combinations. For example, reactions with sulfonyl chlorides frequently afford the corresponding sulfoxides as the major products. ${ }^{108}$ It has been shown that sulfonyl fluorides are superior electrophiles for reactions with organomagnesium or organolithium reagents. ${ }^{109}$

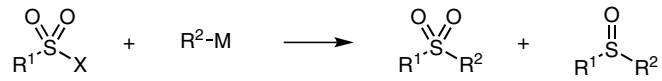

$$
\begin{aligned}
& X=\mathrm{OR}, \mathrm{Cl}, \mathrm{F} \quad \mathrm{M}=\mathrm{Li}, \mathrm{Mg}, \mathrm{Hg}
\end{aligned}
$$

Scheme 64
Katritzky reported on $\mathrm{N}$-sulfonylbenzotriazoles as advantageous reagents for the sulfonylation of lithiated heterocycles or lithium enolates (Scheme 65). ${ }^{110}$
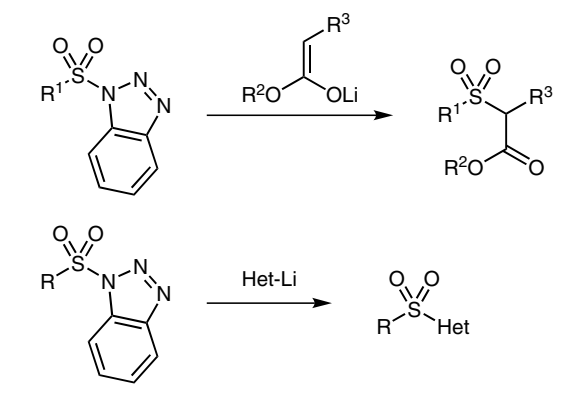<smiles>CCC(=O)C(c1ccccc1)S(=O)(=O)c1ccc(C)cc1</smiles>

$60 \%$<smiles>Cc1ccc(S(=O)(=O)c2cc3ccccc3o2)cc1</smiles>

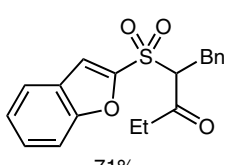

$71 \%$<smiles>CS(=O)(=O)c1cccs1</smiles>

Scheme 65

In the presence of Lewis or Brønsted acid, aryl sulfonates and aryl sulfonamides will rearrange to the corresponding hydroxyaryl and aminoaryl sulfones, respectively (Scheme 66). ${ }^{24 a, 111}$ This exetension of the classical Fries rearrangement affords a mixture of ortho and para isomers. Solvents and substituents on the aromatic ring can affect the ortho/para ratio.

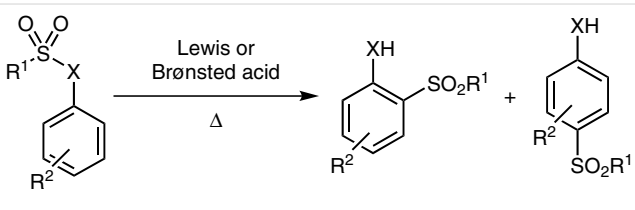

Scheme 66

Wang and co-workers reported a copper-catalyzed rearrangement of $\mathrm{N}$-tosylhydrazones to $(E)$-vinyl sulfones. ${ }^{112}$ Prabhu and Ojha developed a similar reaction mediated by cyanogen bromide and a phase-transfer catalyst (Scheme 67). ${ }^{113}$ 


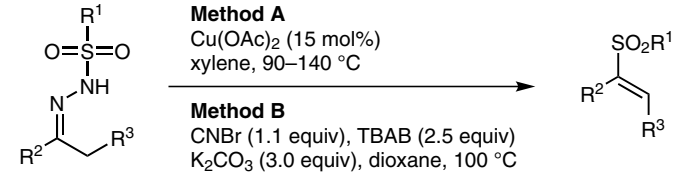<smiles>O=S(=O)(O[Na])OC(=Cc1ccccc1)c1ccccc1</smiles>

93\% Method A 93\% Method B

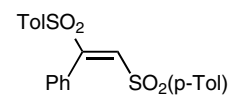

$87 \%$ Method A $69 \%$ Method B

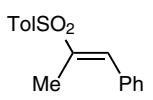

$81 \%$ Method A $84 \%$ Method B
Scheme 67

In the presence of a copper catalyst, sulfonyl hydrazones can undergo nitrogen extrusion to yield sulfones (Scheme 68). ${ }^{114}$

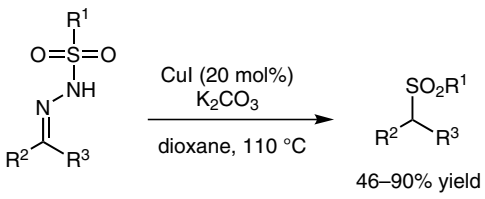

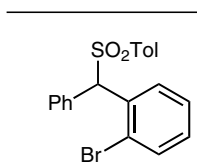

$88 \%$

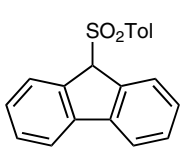

$46 \%$

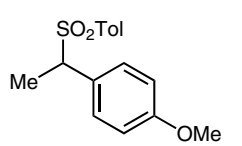

$76 \%$
Scheme 68

Jiang and Tu reported a THBP/TBAI-mediated synthesis of allenyl sulfones starting from propargylic alcohols and sulfonyl hydrazides (Scheme 69). ${ }^{115}$ The authors propose the formation of a sulfonyl hydrazone followed by a radical fragmentation/coupling process to afford the final product.

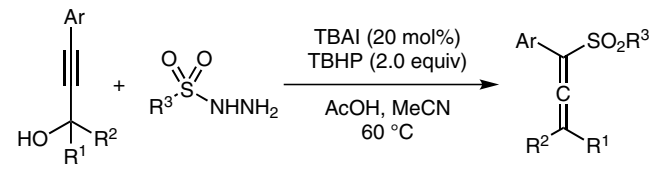<smiles>O=[Se](Cl)(=[Ge]OC(=C=C(c1ccccc1)c1ccccc1)c1ccccc1)c1ccccc1</smiles>

$84 \%$<smiles>O=S(=O)(C(=C=C(c1ccccc1)c1ccccc1)c1ccc(Cl)cc1)c1ccccc1</smiles>

$73 \%$

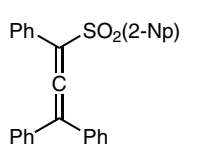<smiles>Cc1ccc(C(=C=C(c2ccc(F)cc2)c2ccc(F)cc2)[S+](=O)OCCCCCl)cc1</smiles>

Scheme 69
Dienediones react with sulfonamides in an acid-mediated cascade process furnishing sulfonated cyclopentanes with three contiguous stereocenters (Scheme 70). ${ }^{116}$
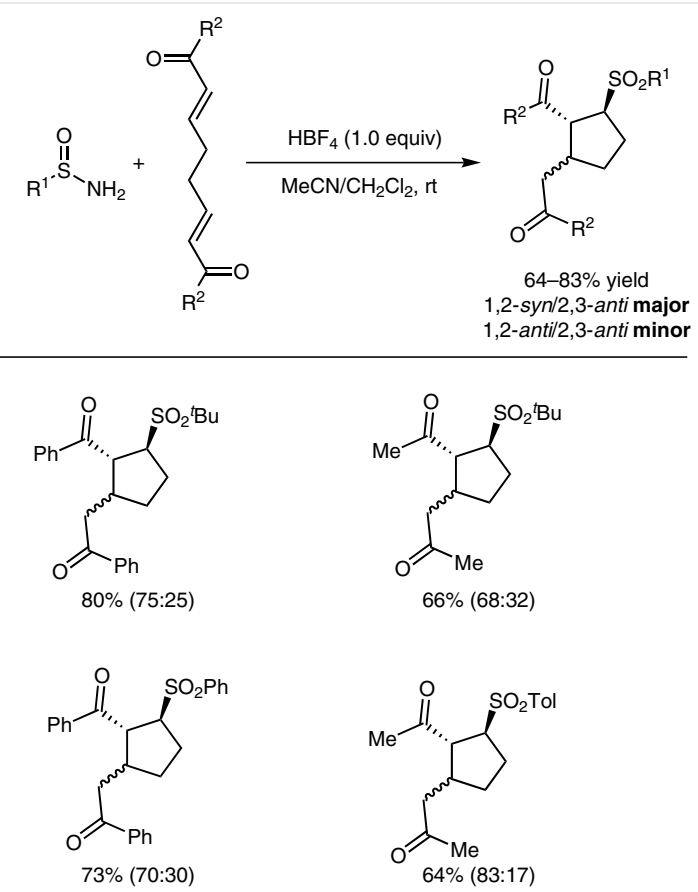

Scheme 70

The reaction of sulfur dioxide with dienes yields sulfolenes in a chelotropic reaction. Although this [4+1] cycloaddition is one of the classical textbook examples for a stereospecific, pericyclic reaction, it is rarely used in organic synthesis. ${ }^{1,117,118}$ Vogel and Sordo showed that the reaction of dienes with sulfur dioxide can indeed produce not only one but two products. ${ }^{119}$ Under kinetic control $\left(<-60{ }^{\circ} \mathrm{C}\right)$, a hetero-Diels-Alder reaction takes place and the corresponding sultine is formed. Under thermodynamic control $\left(>-40^{\circ} \mathrm{C}\right)$, the sulfolene is formed (Scheme 71).

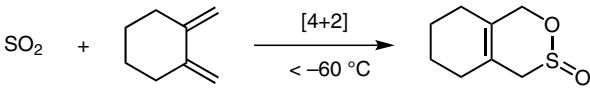

$$
\begin{aligned}
& \text { sultine } \\
& \mathrm{SO}_{2}+\underset{>-40^{\circ} \mathrm{C}}{\stackrel{[4+1]}{\longrightarrow}}
\end{aligned}
$$

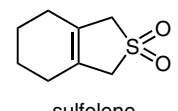

\section{Scheme 71}

\section{Metal-Catalyzed Coupling Reactions}

In the last 15 years, transition-metal-catalyzed coupling reactions of either sulfinates as nucleophilic or sulfonyl halides as electrophilic coupling partners have emerged as at- 
tractive alternatives to the traditional procedures. They allow the synthesis of sulfones in a regiospecific manner, often under milder reaction conditions compared to those used in sulfide oxidation or electrophilic sulfonylation reactions. Therefore metal-catalyzed coupling reactions can expand the functional group compatibility considerably.

Since the first report by Suzuki and Abe on the copperassisted coupling of sodium sulfinates with non-activated iodoarenes, ${ }^{120}$ various improvements have been developed. The introduction of ligands such as proline, ${ }^{121} \mathrm{~N}, \mathrm{~N}$-dimethyethylenediamine (DMEDA), ${ }^{122}$ D-glucosamine, ${ }^{123}$ functionalized ionic liquids ${ }^{124}$ or 1,10 -phenanthroline ${ }^{125}$ enables the copper-catalyzed coupling of sulfinic acid sodium salts with aryl iodides or bromides (Scheme 72). However, there is only one report for copper-catalyzed crosscouplings with aryl chlorides, ${ }^{126}$ and this procedure is limited to activated, electron-poor (hetereo)aromatic chlorides, which should undergo a direct, uncatalyzed nucleophilic aromatic substitution. ${ }^{1,38}$

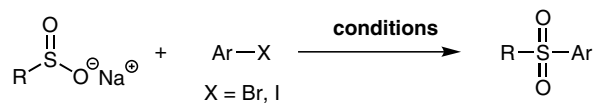

\begin{tabular}{|c|c|}
\hline conditions & $\begin{array}{c}\text { yield } \\
\text { (for } \mathrm{R}=\mathrm{Ph}, \mathrm{Ar}=\mathrm{Tol}, \mathrm{X}=\mathrm{I} \text { ) }\end{array}$ \\
\hline $\begin{array}{l}\text { Cul (10 mol\%), L-proline sodium salt (20 mol\%) } \\
\text { DMSO, } 90^{\circ} \mathrm{C}\end{array}$ & $77 \%$ \\
\hline $\begin{array}{l}\text { (CuOTf) })_{2} \cdot \mathrm{PhH}(5 \mathrm{~mol} \%) \text {, DMEDA (10 mol\%) } \\
\text { DMSO, } 110^{\circ} \mathrm{C}\end{array}$ & $70 \%$ \\
\hline $\begin{array}{l}\text { Cul (10 mol\%), D-glucosamine (20 mol\%) } \\
\text { KOAc, DMSO } / \mathrm{H}_{2} \mathrm{O}, 100^{\circ} \mathrm{C}\end{array}$ & $94 \%$ \\
\hline $\begin{array}{l}\text { Cul ( } 10 \mathrm{~mol} \%) \text {, [enim][Val] ( } 20 \mathrm{~mol} \%) \\
\text { DMSO, } 95^{\circ} \mathrm{C}\end{array}$ & $81 \%$ \\
\hline $\begin{array}{l}\mathrm{CuFe}_{2} \mathrm{O}_{4}(10 \mathrm{~mol} \%), 1,10 \text {-phenanthroline }(10 \mathrm{~mol} \%) \\
\mathrm{DMF}, 110^{\circ} \mathrm{C}\end{array}$ & $78 \%$ \\
\hline
\end{tabular}

Nagarkar and co-workers developed a copper-catalyzed cross-coupling of sodium $p$-toluenesulfinate with arenediazonium salts as an alternative to aryl halides. ${ }^{127}$ The authors propose a TBAI-mediated in situ formation of aryl iodides as coupling partners by way of a Sandmeyer-type reaction (Scheme 73 ).

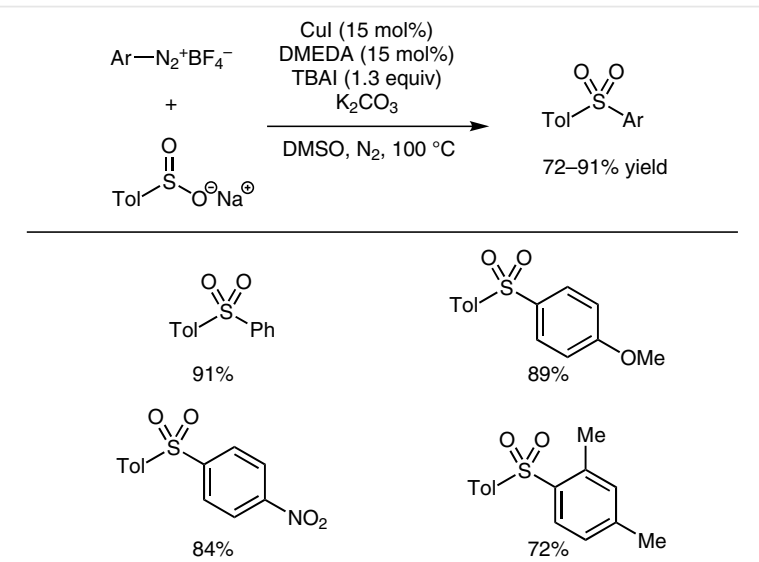

Scheme 73

$\mathrm{Xu}$ and Qing employed arenediazonium salts as starting materials in a copper-catalyzed coupling with sodium trifluoromethylsulfinate. ${ }^{128}$ This method allows the mild synthesis of trifluoromethanesulfonyl-substituted arenes, of particular interest for medicinal chemistry, in good yields (Scheme 74).

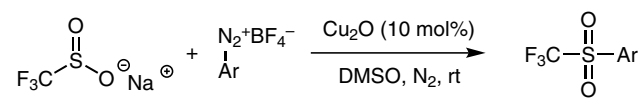

$$
\begin{aligned}
& 45-90 \% \text { yield } \\
& \text { (1) } \\
& \text { (c) } \\
& \underbrace{\mathrm{O}}_{\mathrm{N} /}
\end{aligned}
$$

Scheme 74

Cacchi and co-workers developed a palladium-catalyzed coupling of sodium sulfinates with aryl and vinyl halides for the synthesis of diaryl and aryl vinyl sulfones. ${ }^{129}$ The best yields were obtained with $\mathrm{Pd}_{2}(\mathrm{dba})_{3}$-Xantphos as the catalyst system. The reaction is strongly influenced by the addition of tetraalkylammonium salts, such as tetrabutylammonium chloride (Scheme 75 ). The palladium-catalyzed coupling of vinyl tosylates with aryl sulfonate salts gives aryl vinyl sulfones in a similar manner (Scheme 76). ${ }^{130}$ 


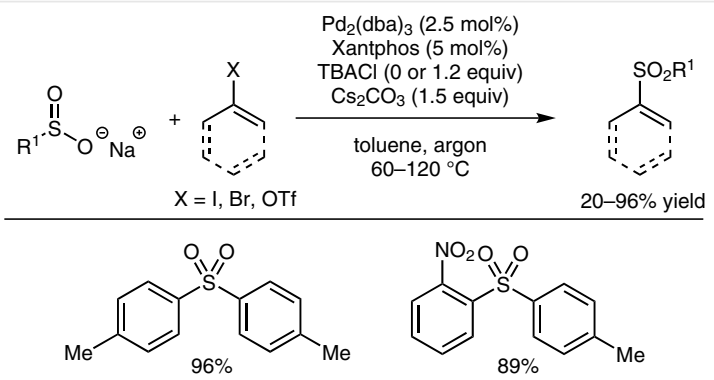<smiles>Cc1ccc(S(=O)(=O)C2=CC(C)(C)CC(C)(C)C2)cc1</smiles><smiles>Cc1ccc(S(=O)(=O)c2ccccn2)cc1</smiles>

Scheme 75

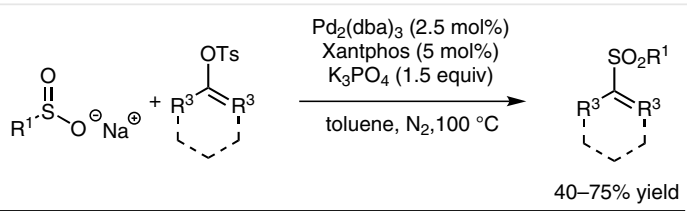<smiles>O=C1CCCCC1</smiles>

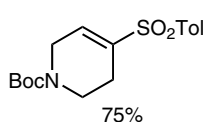<smiles>[Z16]C1CC(S(=O)(=O)C2CC2)=Cc2ccccc21</smiles><smiles>[Se][Se]C=C(c1ccccc1)c1ccccc1</smiles>

$40 \%$

Scheme 76

Yu and $\mathrm{Wu}$ reported an interesting palladium-catalyzed synthesis of sulfones by a denitrative coupling of nitroarenes with sulfinic acid salts (Scheme 77). ${ }^{131}$

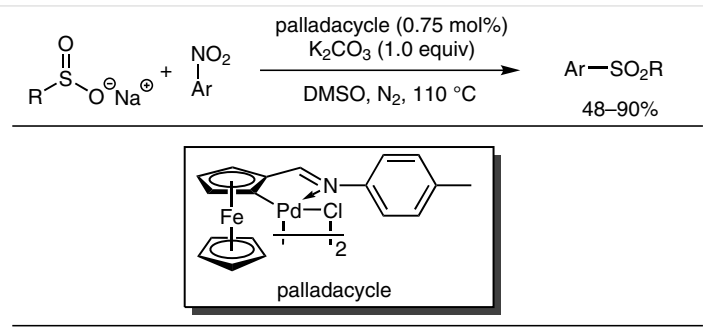<smiles>O=[N+]([O-])c1ccc(S(=O)(=O)c2ccc([N+](=O)[O-])cc2)cc1</smiles>

$85 \%$

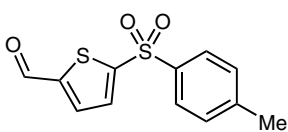

$68 \%$<smiles>Cc1ccc(S(=O)(=O)c2ccc([N+](=O)[O-])c(C)c2)cn1</smiles>

$90 \%$

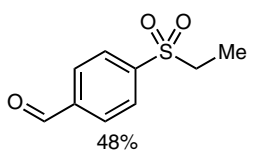

Scheme 77
The groups of Beaulieu and Evans developed a coppermediated cross-coupling of boronic acids and sodium sulfinates (Scheme 78). ${ }^{132}$ This oxidative coupling reaction provides a useful and mild alternative to the just-described coupling reactions.

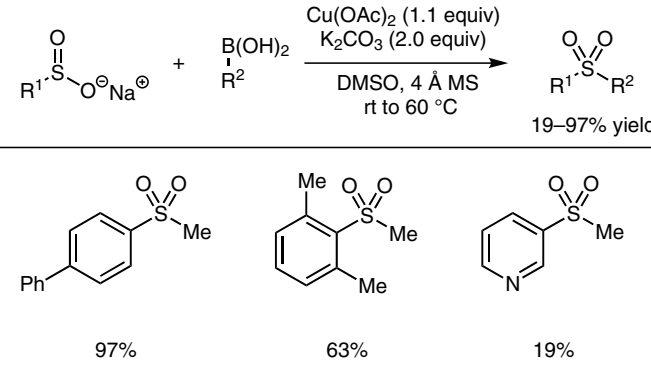

Scheme 78

Later, several catalytic versions of these Chan-EvansLam-type couplings were reported (Scheme 79), including methods with imidazole ${ }^{133}$ or phenanthroline ${ }^{134}$ ligands, in ionic liquids ${ }^{135}$ or water ${ }^{136}$ and utilizing magnetically separable copper ferrite nanoparticles. ${ }^{125}$

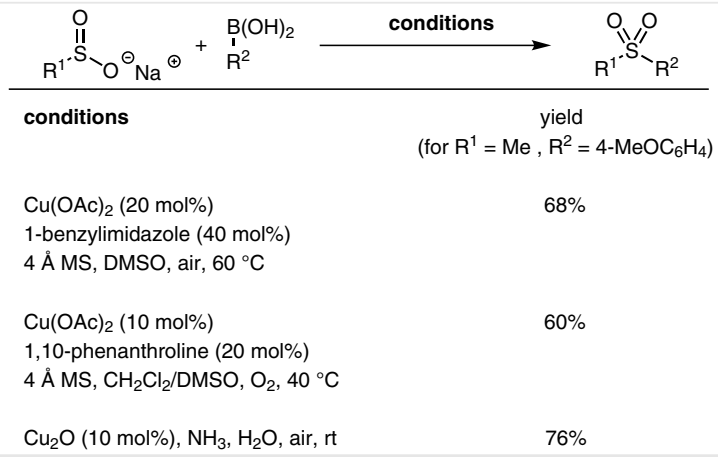

\section{Scheme 79}

$\mathrm{Xu}$, Liang and co-workers developed a palladium-catalyzed coupling of sulfonyl hydrazones with aryl iodides for the synthesis of allylic sulfones. ${ }^{137}$ Base-mediated decomposition of the hydrazine leads to the simultaneous formation of a diazo compound and a sulfinate as nucleophilic coupling partners (Scheme 80).

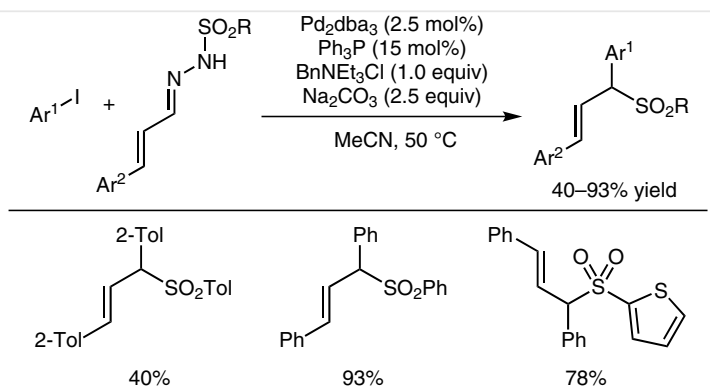

Scheme 80 
A common method for the regio- and stereoselective preparation of allylic sulfones is the transition-metal-catalyzed coupling of allylic electrophiles with sulfinate salts or sulfininic acids. ${ }^{138}$ Allylic carboxylates, ${ }^{139}$ carbonates, ${ }^{140}$ alcohols $^{141}$ or nitro compounds ${ }^{142}$ can undergo substitution reactions with sulfinic acids and their salts (Scheme 81). Reactivities and regioselectivities can differ significantly depending on the structure of the allyl electrophile and the catalyst system.

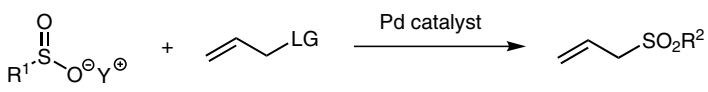

$$
\begin{aligned}
& \mathrm{Y}=\text { metal or } \mathrm{H} \quad \mathrm{LG}=\mathrm{OAc}, \mathrm{OCO}_{2} \mathrm{Et} \text {, } \\
& \mathrm{OH}, \mathrm{NO}_{2} \text {, etc. }
\end{aligned}
$$

Scheme 81

Tian, Gu and co-workers reported a stereospecific substitution of enantioenriched allylic alcohols with sodium sulfinates that proceeds with complete retention of configuration (Scheme 82). ${ }^{141 \mathrm{~b}}$ Palladium-catalyzed direct substitution of allylic amines with sulfinate salts is also possible, furnishing allyl sulfones with almost complete retention of configuration (Scheme 83). ${ }^{143}$

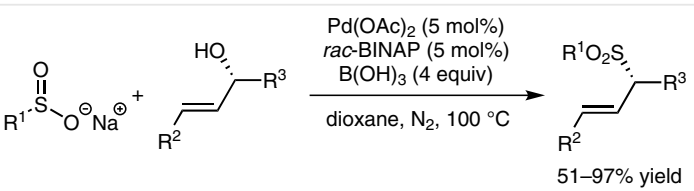

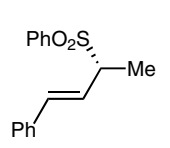

$90 \%, 97 \%$ ee

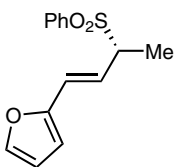

$72 \%, 97 \%$ ee

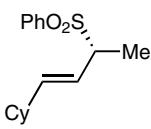

$51 \%, 97 \%$ ee
Scheme 82

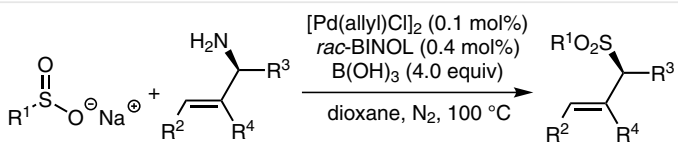

$86-93 \%$ yield<smiles>C[C@H](/C=C/c1ccccc1)[S@@](=O)O[Na]</smiles>

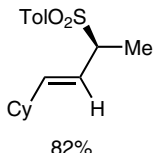<smiles>C[C@H](/C=C/c1ccccc1)[S@@](=O)O[Ga]</smiles>

Scheme 83

In addition, various efficient chiral catalyst systems for the asymmetric allylic sulfonylation were developed in the 1980s and 1990s (Scheme 84). ${ }^{144}$ In general, these methods enable the highly enantioselective synthesis of allylic sulfones, which are useful asymmetric building blocks. ${ }^{145} \mathrm{~A}$ more recent example is the iridium-catalyzed regio- and enantioselective allylic substitution with sodium sulfinates. ${ }^{146}$ Branched allylic sulfones are obtained in high regio- and enantioselectivities (Scheme 85).

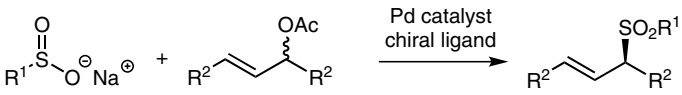

Scheme 84
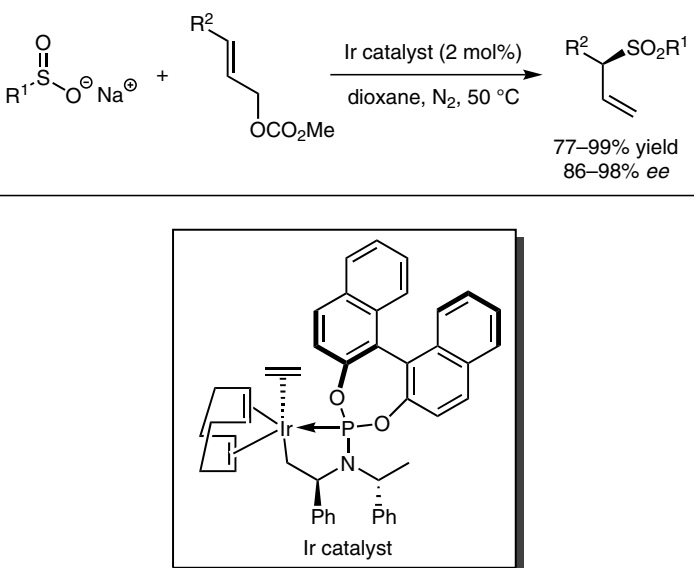

$$
\text { 92\%, } 94 \% \text { ee }
$$

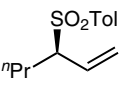

$92 \%, 94 \%$ ee

$92 \%, 94 \%$ ee<smiles>C=C[C@H](c1ccc(OC)cc1)S(C)(=O)=O</smiles><smiles>C=CC(C=C)c1ccc(OC)cc1</smiles>

\section{Scheme 85}

Plietker and Jegelka showed that low-valent iron(II) complexes can catalyze the allylation of sodium sulfinates. ${ }^{147}$ The sulfonylation of allylic carbonates proceeds with excellent retention of configuration (Scheme 86). They later extended their work to include $\alpha$-sulfonyl succinimides as sulfonyl donors. ${ }^{148}$
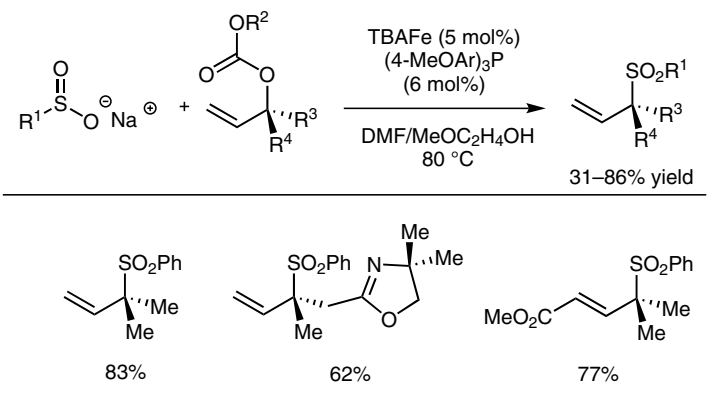

Scheme 86 
The transition-metal-catalyzed coupling of sulfonyl chlorides with various organometallic reagents is another approach for the synthesis of sulfones. Crucial for the success of these transformations is the reaction temperature. Vogel and co-workers showed that, at higher temperatures, desulfinylative carbon-carbon bond formation via sulfur dioxide extrusion takes place. ${ }^{149}$ Palladium-catalyzed reaction of organostannes ${ }^{150}$ or organoboronic acids ${ }^{151}$ with sulfonyl chlorides at low temperatures yields the desired sulfones (Scheme 87).

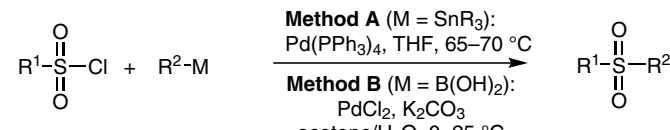

$$
\begin{aligned}
& \mathrm{M}=\mathrm{SnR}_{3}, \mathrm{~B}(\mathrm{OH})_{2}
\end{aligned}
$$

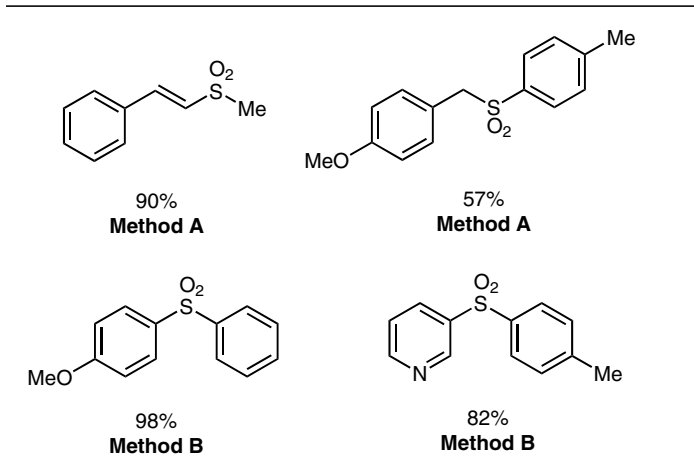

Scheme 87

$\mathrm{Hu}$ and Lei reported copper-catalyzed coupling reactions of sulfonyl chlorides with arylboronic acids ${ }^{152}$ or organozinc reagents, ${ }^{153}$ respectively (Scheme 88 ).

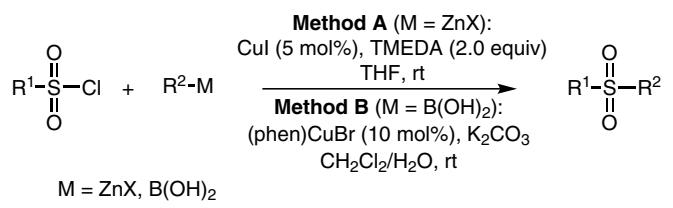<smiles>O=S(O)c1ccccc1</smiles><smiles></smiles><smiles>[M]Oc1ccsc1</smiles><smiles>COC(=O)c1ccc([Se]c2ccc([N+](=O)[O-])cc2)cc1</smiles>

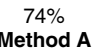

$76 \%$ Method A<smiles></smiles>

Method
The copper-catalyzed reaction of silyl dienol ethers with sulfonyl chlorides affords $\gamma$-sulfonylated $\alpha, \beta$-unsaturated carbonyl compounds (Scheme 89). ${ }^{154}$

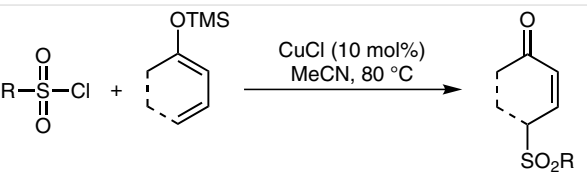

$38-87 \%$ yield
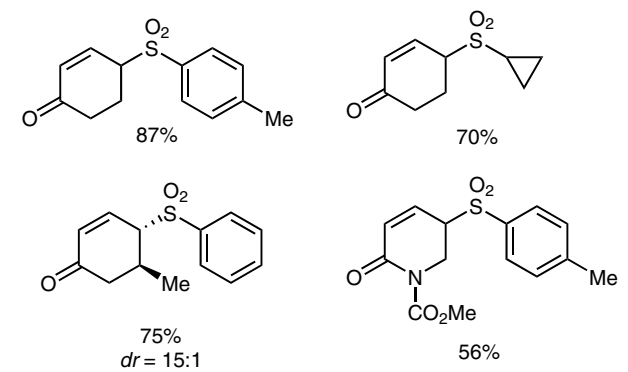

Scheme 89

\section{Sulfone Synthesis by C-H Functionaliza- tion}

The selective functionalization of $\mathrm{C}-\mathrm{H}$ bonds plays a key role in the development of efficient and sustainable methods for organic synthesis. ${ }^{155}$ Regioselective metal-catalyzed as well as metal-free activations of $\mathrm{C}-\mathrm{H}$ bonds have emerged as valuable tools for the preparation of carboncarbon and carbon-heteroatom bonds. In recent years, synthesis of sulfones by selective functionalization of $\mathrm{C}-\mathrm{H}$ bonds has become an important area of research. Although the established Friedel-Crafts-type sulfonylation can be considered as $\mathrm{C}-\mathrm{H}$ functionalization, recent research efforts focus on different reactivity profiles.

Dong and co-workers reported the first palladium-catalyzed $\mathrm{C}-\mathrm{H}$ bond sulfonylation of phenylpyridines with sulfonyl chlorides (Scheme 90). ${ }^{156}$ Mechanistic studies indicate a Pd(II)/Pd(IV) catalytic cycle. ${ }^{157}$
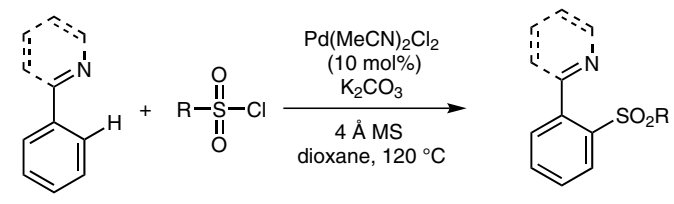

$41-88 \%$ yield

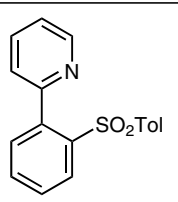

$82 \%$<smiles>CO/N=C(\c1ccccc1)c1ccccc1OC</smiles>

$78 \%$<smiles>O=[SH]c1ccccc1-n1cccn1</smiles>

$42 \%$
Scheme 90 
Palladium-catalyzed sulfonylation of 2-aryloxypyridines with sulfonyl chlorides proceeds in the ortho-position relative to the directing group. ${ }^{158}$ Removal of the pyridyl group thus gives access to ortho-sulfonylated phenols, which are difficult to synthesize otherwise (Scheme 91).
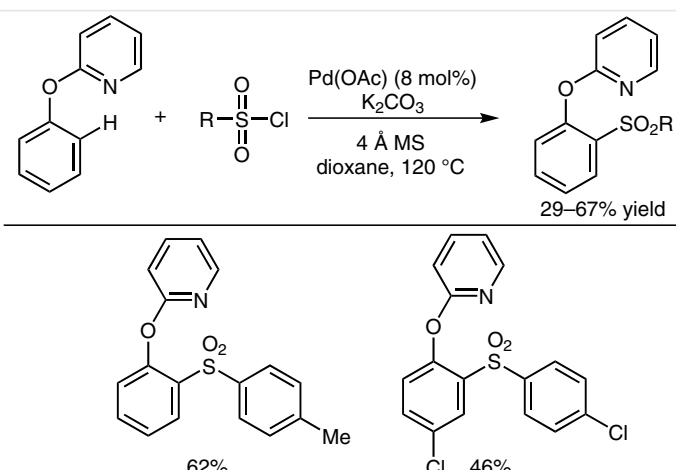<smiles>NC(=O)c1ccc(S(=O)(=O)c2ccccc2)c(Oc2ccccn2)c1</smiles><smiles>Cc1ccc(Oc2ccc3ccccc3c2Oc2ccccn2)cc1</smiles>

Scheme 91

Two independent reports describe the ortho-sulfonylation of azobenzenes with arylsulfonyl chlorides via palladium-catalyzed C-H activation (Scheme 92). ${ }^{159}$ Loh and coworkers developed a palladium-catalyzed alkenyl $\mathrm{C}-\mathrm{H}$ bond sulfonylation of vinyl pyridines and enamides with sulfonyl chlorides (Scheme 93). ${ }^{160}$

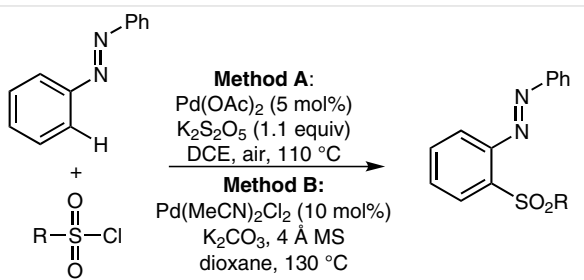<smiles>Cc1ccc(Oc2ccccc2/N=N/c2ccccc2)cc1</smiles><smiles>N#Cc1ccccc1Oc1ccccc1/N=N/c1ccccc1</smiles>

$71 \%$<smiles>Fc1ccc(Oc2ccccc2/N=N/c2ccccc2)cc1</smiles>

$86 \%$<smiles>Cc1noc(C)c1Oc1ccccc1/N=N\P(=O)(O)c1ccccc1</smiles>
Heck-type coupling (Scheme 94). ${ }^{161}$ fonyl chlorides gives rise to arylsulfonyl quinones via a

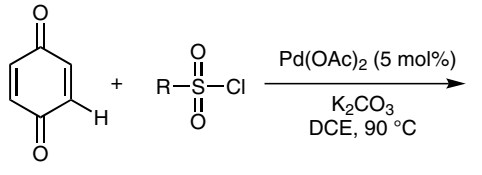<smiles>O=C1C=CC(=O)C(O[GaH])C1</smiles>

$52-91 \%$ yield<smiles>COc1ccc(OC)c(OC2=CC(=O)C=CC2=O)c1</smiles>

$89 \%$

$81 \%$

$63 \%$

Scheme 94

Regioselective ortho-sulfonylation of quinolone $\mathrm{N}$-oxides was achieved via copper-catalyzed $\mathrm{C}-\mathrm{H}$ bond activation (Scheme 95). ${ }^{162}$
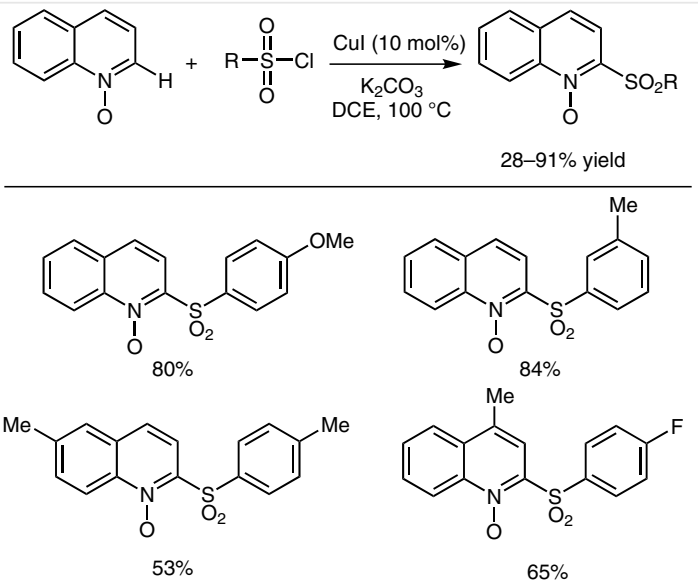

Scheme 95 
Kambe and co-workers reported a nickel-mediated C-H bond sulfonylation of benzamides enabled by the 8-aminoquinoline (AQ) directing group (Scheme 96). ${ }^{163}$

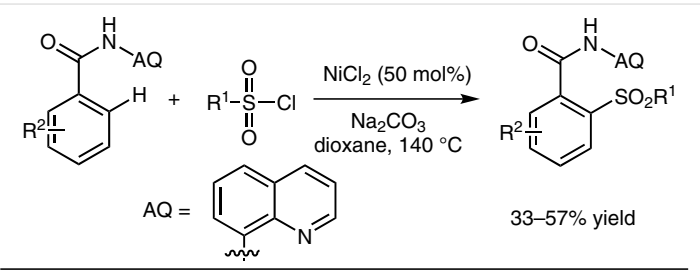<smiles>Cc1cccc([Se]c2ccc(Cl)cc2)c1C(=O)NO</smiles><smiles>COc1ccc(OSc2ccc3ccccc3c2C(=O)NC(=O)[O-])cc1</smiles>

Scheme 96

Interestingly, the copper-catalyzed reaction of benzamides bearing the 8-aminoquinoline moiety with sulfonyl chlorides leads to a remote functionalization of the quinoline (Scheme 97). ${ }^{164}$

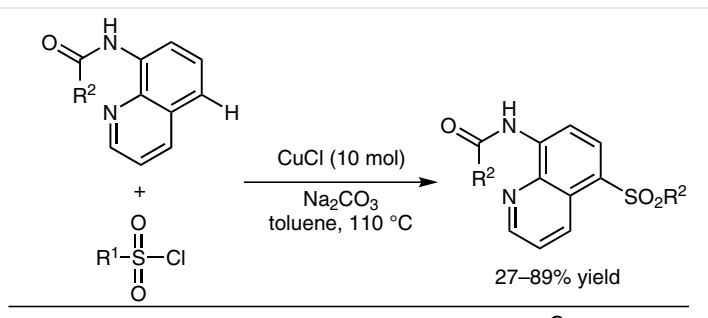<smiles>O=C(Nc1ccc(S(=O)(=O)c2ccccc2)c2cccnc12)c1ccccc1</smiles>

$86 \%$<smiles>O=C(Nc1ccc([123I])c2cccnc12)c1ccsc1</smiles>

$78 \%$<smiles>O=C(Nc1ccc(O)c2ncccc12)c1cccs1</smiles>

$86 \%$<smiles>O=C(Nc1ccc(F)c2cccnc12)C1CCCCC1</smiles>

$70 \%$
Scheme 97

A ruthenium-catalyzed regioselective meta-sulfonylation of 2-phenylpyridines with sulfonyl chlorides was developed by Frost and co-workers. ${ }^{165}$ The observed switch in regioselectivity is attributed to a change in the mechanistic pathway via a para-directing $\mathrm{Ru}-\mathrm{C}$ bond (Scheme 98 ).
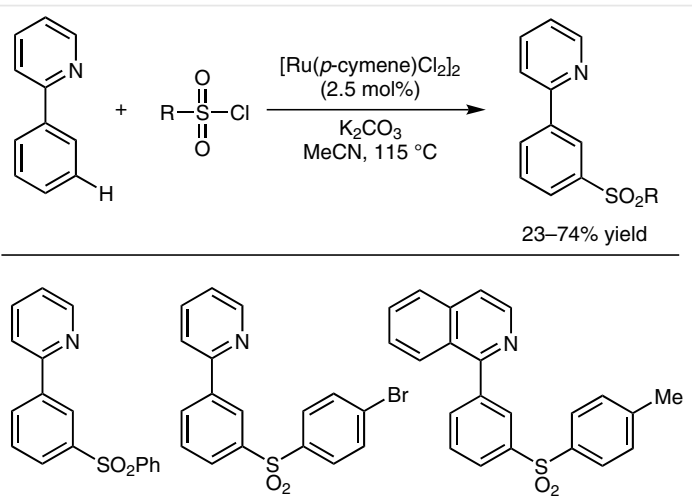

$70 \%$

$74 \%$

$40 \%$

\section{Scheme 98}

Several groups reported copper-mediated ortho-sulfonylations of benzoic acid derivatives with sodium sulfinates employing the 8 -aminoquinoline (AQ), ${ }^{166}$ the 2-pyridinyl isopropyl (PIP), ${ }^{167}$ or the amide-oxazoline (Oxa) ${ }^{168}$ directing groups (Scheme 99). These oxidative coupling reactions utilize sulfinates as the coupling partner.
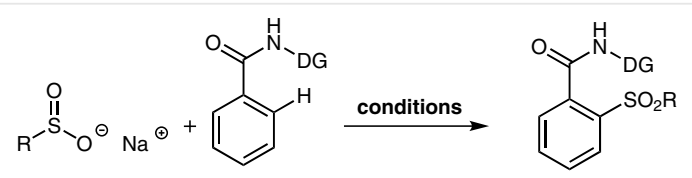<smiles>CC(C)(C)Nc1cccc2cccnc12</smiles>

$\mathrm{AQ}$

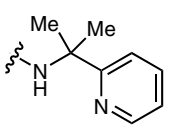

PIP

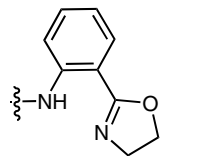

Oxa
Scheme 99

Shi and co-workers described a palladium-catalyzed direct sulfonylation of non-activated $\mathrm{C}\left(\mathrm{sp}^{3}\right)-\mathrm{H}$ bonds with sodium sulfinates enabled by the 8-aminoquinoline moiety (Scheme 100). ${ }^{169}$ Late-stage sulfonylation of complex molecules can be achieved with this method. 

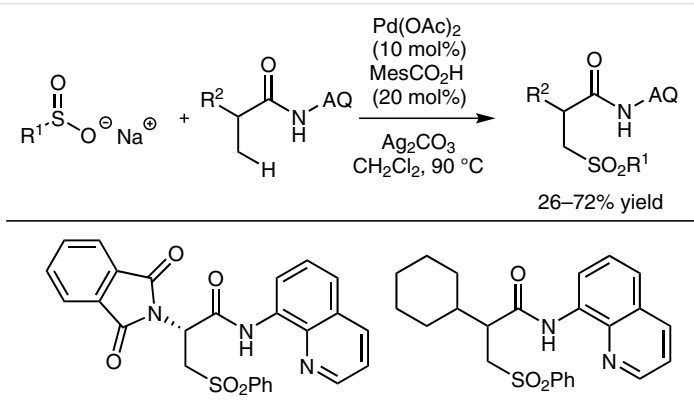<smiles>CO[C@H]1C2=C(C)C(=O)C=C[C@]2(C)CC[C@H]1C(COc1ccccc1)C(=O)Nc1cccc2cccnc12</smiles>

$44 \%$

Scheme 100

The copper-catalyzed oxidative coupling of oxime acetates with sodium sulfinates provides access to sulfonylvinylamines and keto sulfones via a formal $\mathrm{C}\left(\mathrm{sp}^{3}\right)-\mathrm{H}$ bond activation (Scheme 101). ${ }^{170}$

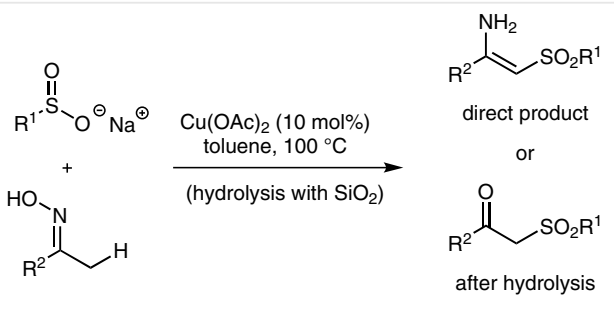

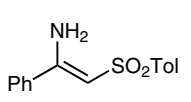<smiles>O=C(C[Se]O[Na])c1cccs1</smiles>

$78 \%$

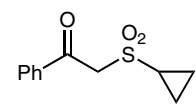

$97 \%$

Scheme 101

Kamijo and co-workers reported a photoinduced sulfonylation of ethereal $\mathrm{C}-\mathrm{H}$ bonds with sulfonyl chlorides. ${ }^{171}$ The $\mathrm{C}-\mathrm{H}$ bond activation is achieved by hydrogen abstraction with photoexcited benzophenone (Scheme 102).

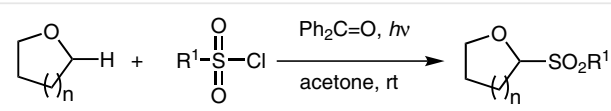

44-100\% yield

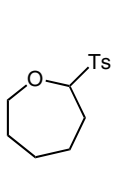

$44 \%$

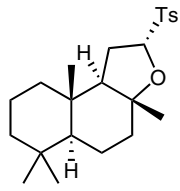

$100 \%$

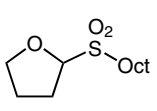

$74 \%$

Scheme 102

$\mathrm{Qu}$, Zhao and co-workers developed a metal-free, Hphosphonate-mediated direct sulfonylation of heteroaromatic $N$-oxides with sulfonyl chlorides, ${ }^{172}$ wherein 2 -sulfonyl- $N$-heterocycles are obtained as products (Scheme 103).
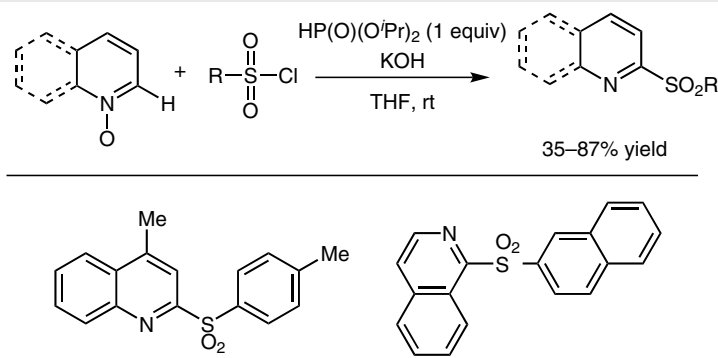

$86 \%$<smiles>O=S(c1ccccc1)c1ccccn1</smiles>

$60 \%$<smiles>Cc1ccc(S(=O)(=O)c2cnc3ccccc3n2)cc1</smiles>

$35 \%$

\section{Scheme 103}

The groups of Deng and Kuhakarn described methods for the regioselective C2-sulfonylation of indoles with sodium sulfinates catalyzed or mediated by iodine (Scheme 104). ${ }^{173}$ Both authors propose an addition-elimination mechanism for this transformation. Later, an extension to the coupling of azetidine and oxetane sulfinate salts was reported. ${ }^{174}$

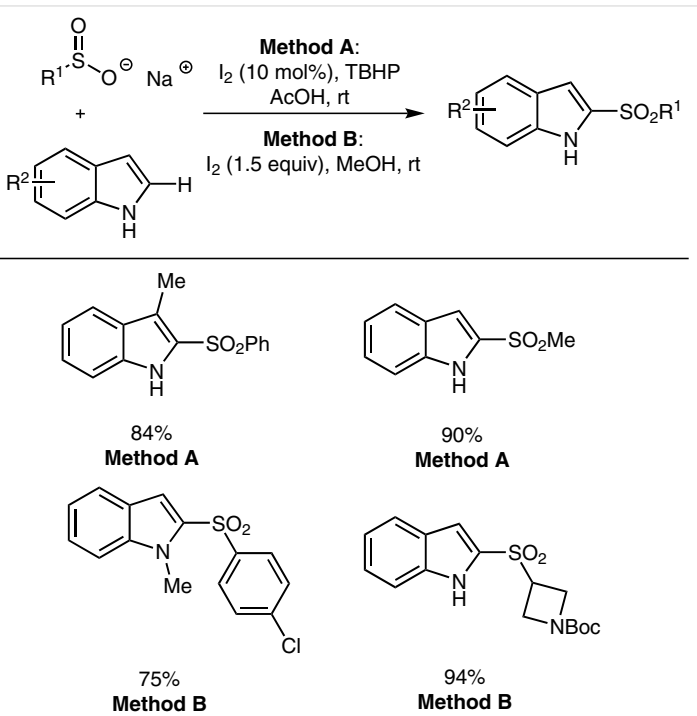

\section{Scheme 104}

TBHP/TBAI-mediated oxidative coupling of C2/C3-unsubstituted indoles with sulfonyl hydrazides leads to the formation of 3-sulfonyl-2-sulfonyldiazenyl-1 $\mathrm{H}$-indoles (Scheme 105). ${ }^{175}$ 


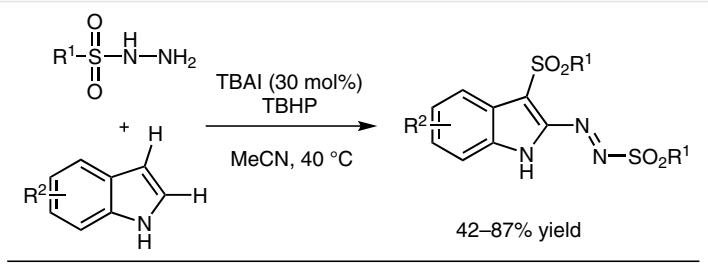

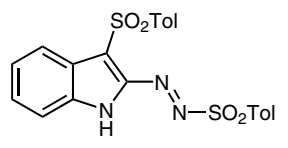

$87 \%$
$72 \%$

Scheme 105

Xiao, Deng and co-workers reported a metal-free direct sulfonylation of 2-methylquinolines with sodium sulfinates mediated by potassium iodide and TBHP (Scheme 106). ${ }^{176}$

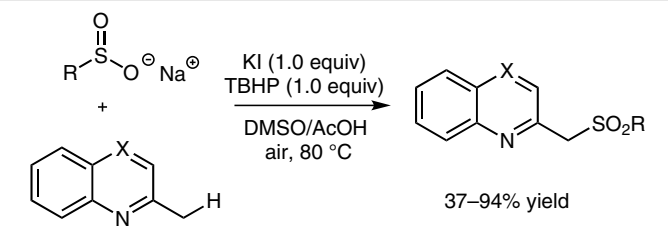<smiles>O=S(=O)(Cc1ccc2ccc(F)cc2n1)c1ccccc1</smiles><smiles>O=S(=O)(O)c1ccc2ccccc2c1</smiles>

$51 \%$<smiles>O=S(=O)(Oc1ccccc1)c1nc2ccccc2nc1-c1ccccc1</smiles>

$69 \%$<smiles>O=C(Cc1ccc2ccccc2n1)C1CC1</smiles>

$56 \%$
Scheme 106

\section{Sulfur Dioxide Based Three-Component Approaches}

Almost all hitherto-described methods for the synthesis of sulfones utilize starting materials that already contain a sulfur functionality. Only a few of these sulfur-containing starting materials are commercially available, and their synthesis can be quite cumbersome. Therefore, efficient methods for the incorporation of the sulfonyl moiety from simple, readily available sources offer a very attractive approach for the preparation of sulfones. In the last 10 to 15 years, the development of new one-pot and multicomponent processes for the synthesis of sulfones from two sulfur-free starting materials and a simple sulfonyl source has become a very active area of research. ${ }^{177}$
Of course, sulfur dioxide $\left(\mathrm{SO}_{2}\right)$ would be an obvious choice as reagent for the installation of a sulfonyl $\left(-\mathrm{SO}_{2}{ }^{-}\right)$ moiety. Sulfur dioxide is produced on an enormous scale and has been utilized by mankind since ancient times. However, it is a toxic and corrosive gas. The associated safety considerations and the difficult handling can limit the use of sulfur dioxide in the laboratory-scale synthesis of fine chemicals. Despite this, sulfur dioxide has found various applications in organic synthesis. ${ }^{178}$ Important examples include the sulfur dioxide ene reaction and the associated sulfur dioxide induced alkene isomerization, ${ }^{179}$ as well as copolymerizations with alkenes to produce polysulfones. ${ }^{180}$

Vogel and co-workers were among the first to investigate the potential of sulfur dioxide as a reagent in the synthesis of complex molecules. ${ }^{177 d}$ They reported a Lewis acid promoted ene reaction of enoxysilanes and allylsilanes or allylstannanes. ${ }^{181}$ The formed sulfinates can be trapped in situ with a variety of electrophiles, enabling a one-pot, three-componenet synthesis of polyfunctional sulfones (Scheme 107).
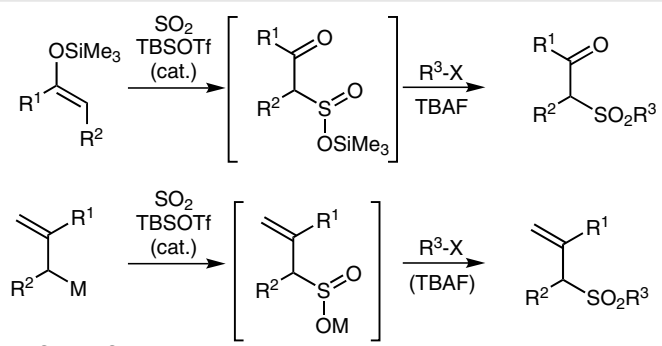

$\mathrm{M}=\mathrm{SiMe}_{3}, \mathrm{SnBu}_{3}$

$50-88 \%$ yield

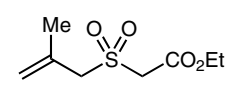

$60 \%$<smiles>CCOC(=O)CS(=O)(=O)C(C)C(=O)OC</smiles>

$50 \%$

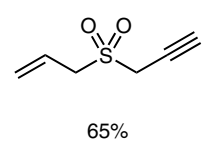

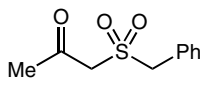

$70 \%$
Scheme 107

Unfunctionalized alkenes can react with sulfur dioxide in the presence of stoichiometric amounts of boron trichloride to form sulfinic acid-boron trichloride adducts, which can be hydrolyzed with base to generate sulfinates. ${ }^{182}$ Reaction of the latter with alkyl halides yields $\alpha, \beta$-unsaturated sulfones in a one-pot transformation (Scheme 108). 


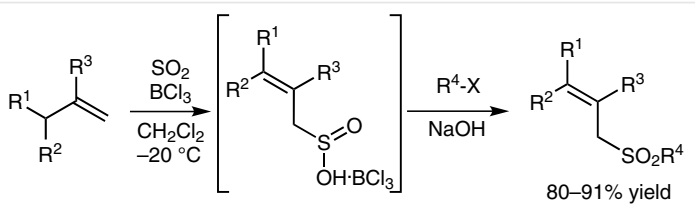<smiles>C=CCS(=O)(=O)Cc1ccccc1</smiles>

$80 \%$<smiles>CC(C)=CCS(=O)(=O)CC(=O)c1ccccc1</smiles>

$87 \%$<smiles>C=CC([N+](=O)[O-])S(=O)(=O)Cc1ccccc1</smiles>

$85 \%$
Scheme 108

Vogel and co-workers pioneered the use of sulfur dioxide in Lewis acid mediated hetero-Diels-Alder processes as a novel method to construct $\mathrm{C}-\mathrm{C}$ bonds via an umpolung of electron-rich 1,3-dienes. ${ }^{183}$ A typical example is depicted in Scheme 109. Reaction of a mixture of an electron-rich diene with sulfur dioxide and a silyl enol ether in the presence of a Lewis acid affords a silyl sulfinate. The Lewis acid catalyzes the initial formation and heterolysis of the hetero-DielsAlder adduct to from a zwitterionic sulfinate, which is trapped by the enoxy silane as terminal nucleophile. Treatment of the sulfinate with tetrabutylammonium fluoride (TBAF) and methyl iodide affords the corresponding sulfone in $63 \%$ yield and high stereoselectivity. This method allows the one-pot, four-component synthesis of polyfunctional sulfones and sulfonamides and has found application in the total synthesis of complex molecules and natural products. ${ }^{183,184}$
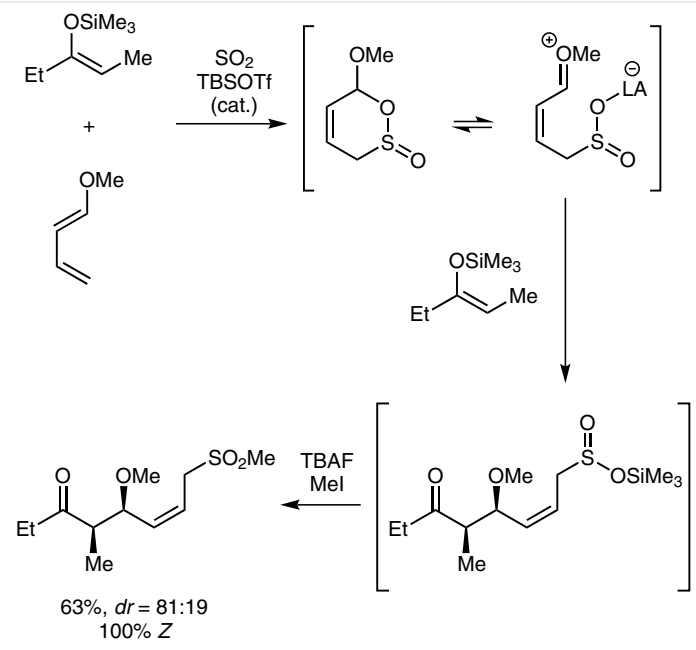

Scheme 109
The reaction of organometallic compounds with sulfur dioxide gas for the preparation of sulfinates is well documented.1178a Direct trapping of these salts without prior isolation provides a convenient one-pot approach for the synthesis of sulfones. Since various efficient procedures for the preparation of a plethora of highly functionalized organometallic reactions are known, ${ }^{185}$ this process offers an attractive approach for the synthesis of complex sulfones.

A group from Boehringer Ingelheim developed a practical three-step protocol for the transformation of (hetero)aromatic halides into sulfones (Scheme 110). ${ }^{186}$ Their procedure consists of (1) generation of a Grignard reagent via magnesium-halide exchange; (2) reaction of the Grignard reagent with sulfur dioxide to afford the corresponding magnesium sulfinate; and (3) trapping of the sulfinate with an alkylating agent.

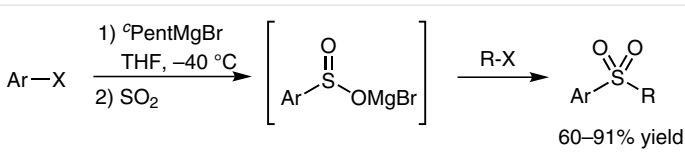<smiles>CCOC(=O)OCCS(=O)(=O)c1ccc(C(=O)OCC)cc1</smiles><smiles>CCOC(=O)c1ccc(S(=O)(=O)C2C=CCCC2)cc1</smiles><smiles>CC(=O)OCS(=O)(=O)c1cccnc1</smiles><smiles></smiles>

$60 \%$

$94 \%$

Scheme 110

A similar one-pot sequence has been reported with a diaryliodonium salt as terminal electrophile (Scheme 111). ${ }^{187}$ This procedure allows the efficient synthesis of aryl sulfones starting from (hetero)aromatic or aliphatic halides as well as non-prefunctionalized (hetero)arenes. The lithium, magnesium and zinc reagents were prepared via metal insertion, exchange or deprotonation.

It has been shown that lithium sulfinates, prepared in situ from the reaction of organolithium compounds with sulfur dioxide, can undergo oxidative coupling with benzoic acids bearing the amide-oxazoline (Oxa) directing group via copper-mediated $\mathrm{C}-\mathrm{H}$ bond activation (Scheme 112). ${ }^{168}$ 


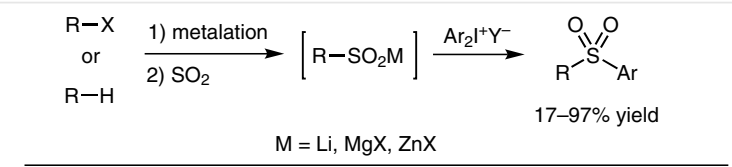<smiles>CCOC(=O)c1ccc(S(=O)(=O)c2ccccc2)cc1</smiles><smiles>N#CCCS(=O)(=O)c1ccccc1</smiles><smiles>O=S(=O)(c1ccccc1)c1cccnc1</smiles>
$51 \%$

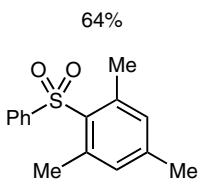

$80 \%$

Scheme 111

$$
\stackrel{\text { (R) }}{\longrightarrow}
$$

Scheme 112

Despite its potential utility, there are some drawbacks associated with the toxic, corrosive and gaseous nature of sulfur dioxide. A popular strategy to overcome this limitation is the use of solid, easy-to-handle surrogates. ${ }^{10 c, 177} \mathrm{Sim}-$ ple, commercially available metal sulfites $\left(\mathrm{MSO}_{3}\right)$ or metabisulfites $\left(\mathrm{M}_{2} \mathrm{~S}_{2} \mathrm{O}_{5}\right)$ can release sulfur dioxide upon the addition of Brønsted acids or upon heating to high temperatures. Researchers from Pfizer described a palladium-catalyzed sulfonylation of (hetero)aryl halides with potassium metabisulfite $\left(\mathrm{K}_{2} \mathrm{~S}_{2} \mathrm{O}_{5}\right)$ and sodium formate (Scheme 113). ${ }^{188}$ Direct reaction of the generated sulfinates with alkyl halides enables the one-pot synthesis of sulfones.

They later reported a palladium-catalyzed three-component synthesis of sulfones from (hetero)arylboronic acids, alkyl halides and potassium metabisulfite (Scheme 114). ${ }^{189}$ The authors propose an in situ formation of a palladium sulfinate, which then reacts with the alkyl halide.

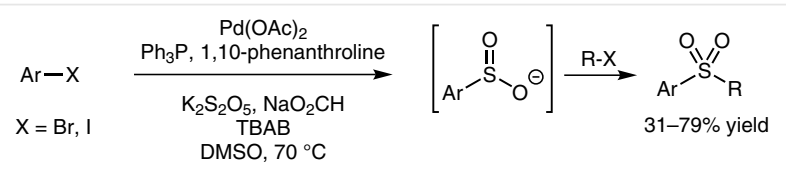<smiles>COc1ccc(S(C)(=O)=O)cn1</smiles>

$58 \%$<smiles>COc1ccc(S(=O)(=O)CC(=O)OCc2ccccc2)cc1</smiles><smiles>CS(=O)(=O)c1ccc2ncccc2c1</smiles>

$68 \%$

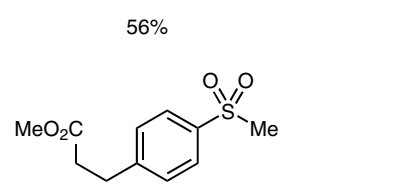

$57 \%$
Scheme 113

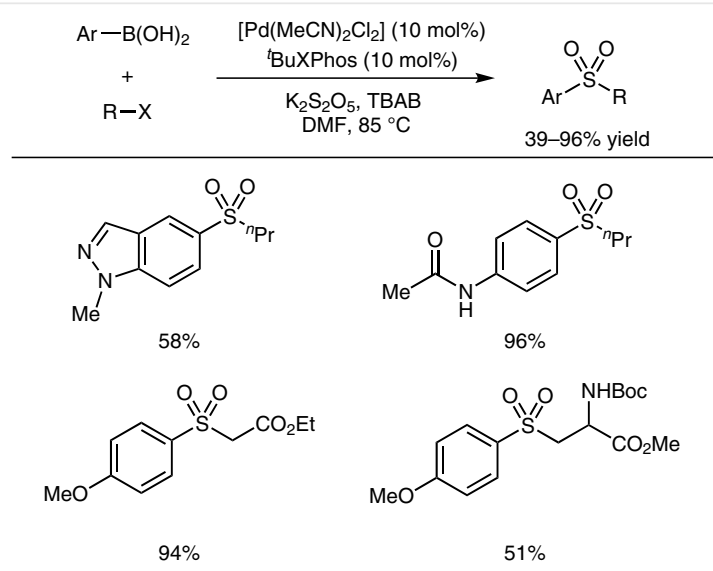

Scheme 114

The gold-catalyzed reaction of (hetero)arylboronic acids with $\mathrm{K}_{2} \mathrm{~S}_{2} \mathrm{O}_{5}$ and alkyl halides yields the corresponding sulfones in a similar fashion (Scheme 115). ${ }^{190}$

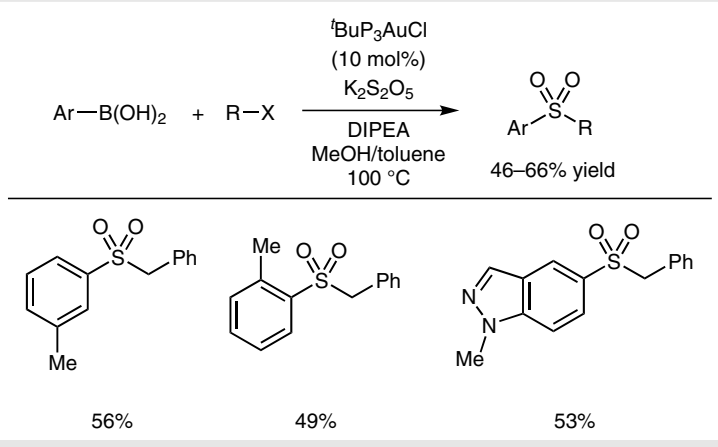

Scheme 115 
Willis and co-workers pioneered the use of the 1,4-diazabicyclo[2.2.2] octane-bis(sulfur dioxide) adduct DABSO as very useful, solid and bench-stable sulfur dioxide surrogate. ${ }^{191}$ The addition of organolithium or organomagnesium reagents to DABSO generates the corresponding sulfinates, which can be directly trapped with a variety of different electrophiles, such as alkyl halides, epoxides or diaryliodonium salts (Scheme 116). ${ }^{192}$ This method enables the onepot synthesis of a diverse set of sulfones. Organozinc reagents react with DABSO in a similar manner, and the generated zinc sulfinates can be alkylated to form sulfones (Scheme 117). ${ }^{193}$

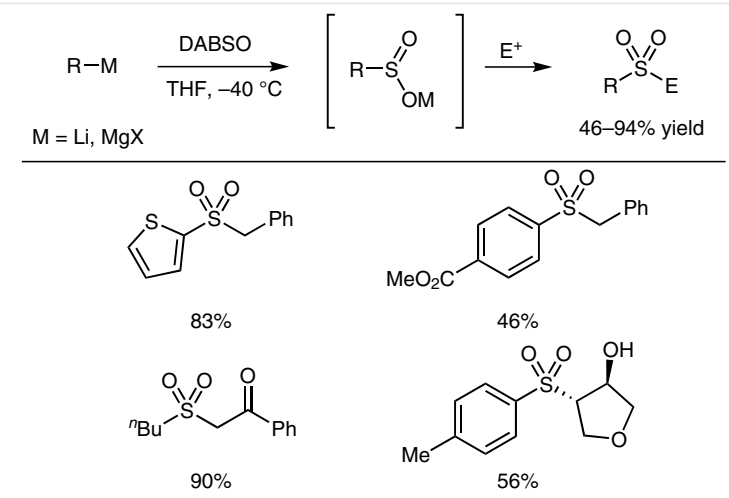

Scheme 116

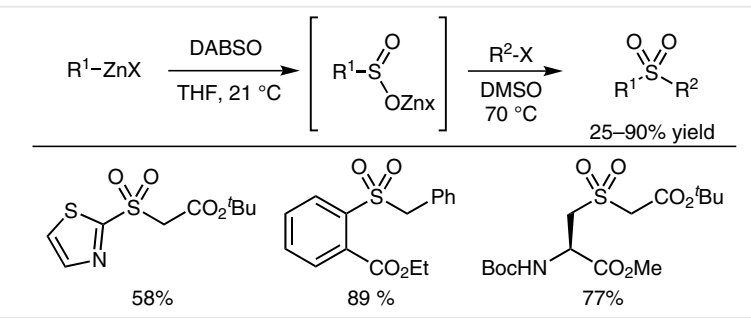

Scheme 117

Reaction of organolithium reagents with DABSO, followed by palladium-catalyzed cross-coupling of the formed lithium sulfinate with (hetero)aryl halides allows the threecomponent synthesis of aryl sulfones (Scheme 118). ${ }^{194}$ The lithium reagents can be prepared in situ through halogenlithium exchange.

Palladium-catalyzed coupling of aryl halides with DABSO in the presence of triethylamine yields ammonium sulfinates. These salts can be directly converted into a variety of sulfones by trapping with different electrophiles (Scheme 119). ${ }^{195}$

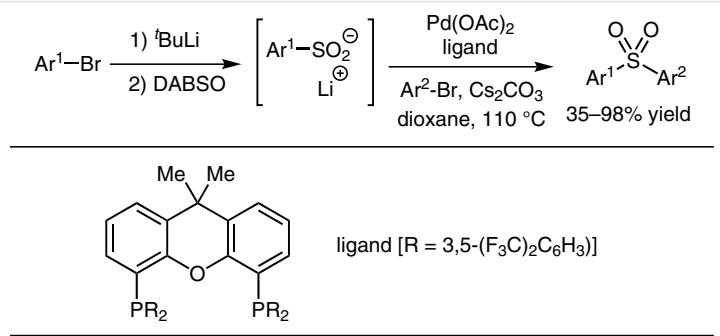

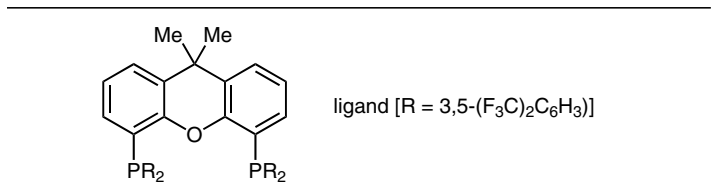

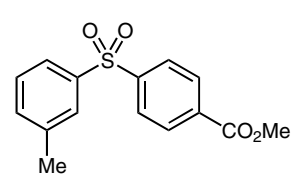
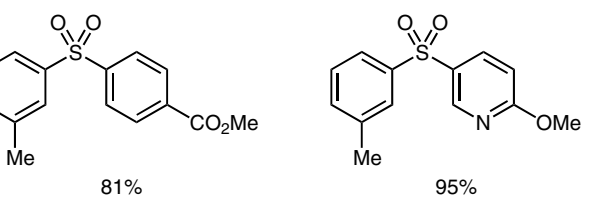

$95 \%$<smiles>COc1cccc(S(=O)(=O)c2cccc(C(F)(F)F)c2)c1</smiles>

$92 \%$<smiles>COc1cccc(S(=O)(=O)c2cc(C)c(Cl)c([O-])c2)c1</smiles>

$93 \%$
Scheme 118

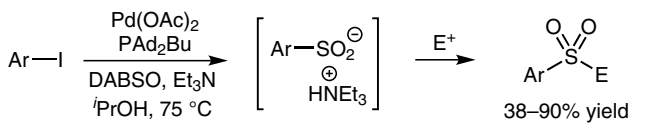<smiles>CC(=O)c1ccc(S(=O)(=O)CC(=O)OC(C)(C)C)cc1</smiles>

$74 \%$<smiles>Cc1cc(C)cc(S(=O)(=O)Cc2ccccc2)c1</smiles>

$85 \%$
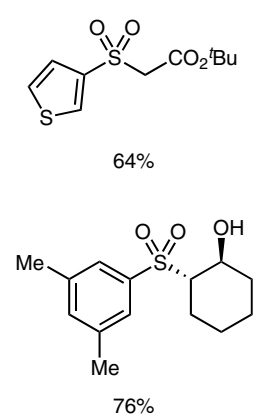

Scheme 119

Waser and Chen reported a one-pot, three-component synthesis of aryl alkynyl sulfones through the reaction of in situ generated sulfinates with ethynyl-benziodoxolone (EBX). ${ }^{196}$ The sulfinates were prepared from DABSO and an organomagnesium reagent or aryl iodide and a palladium catalyst (Scheme 120). 

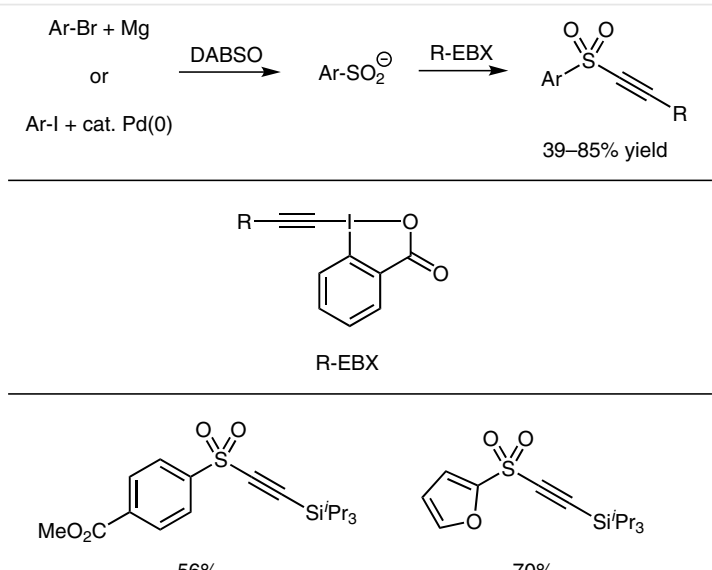<smiles>Cc1ccc(S(=O)(=O)C#CBr)cc1</smiles><smiles>C=CCS(=O)(=O)C#C[Se][Ba]</smiles>

$79 \%$

$46 \%$

Scheme 120

Building on their previous results with the palladiumcatalyzed aminosulfonylation of aryl halides, ${ }^{197}$ the Willis group developed a different approach for the one-pot synthesis of aryl sulfones based on in situ generated sulfonyl hydrazines. ${ }^{198}$ Key steps in this transformation are the palladium-catalyzed aminosulfonylation of the aryl halide with DABSO and the hydrazine, degradation of the generated sulfonyl hydrazine to the corresponding sulfinate, and sulfinate alkylation to yield the desired sulfone (Scheme 121).

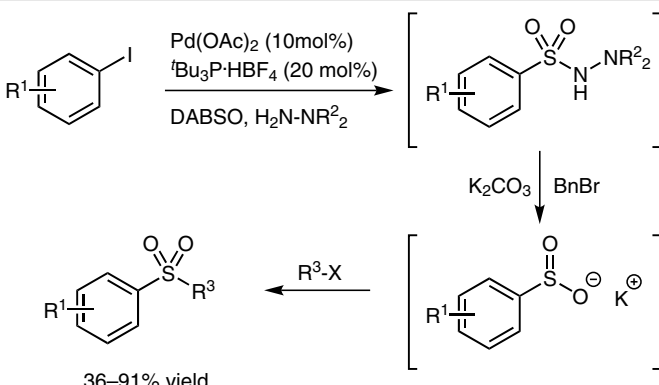<smiles>O=S(=O)(Cc1ccccc1)c1ccc2[nH]ccc2c1</smiles><smiles>Cc1ccc(S(=O)(=O)CSc2ccccc2)cc1</smiles><smiles>CCCS(=O)(=O)c1ccc(OCC)cc1</smiles><smiles>CCOC(=O)C(C)(C)S(=O)(=O)c1ccc(OCC)cc1</smiles>

$55 \%$ $57 \%$
$\mathrm{Wu}$ and co-workers extended this approach to the synthesis of diaryl sulfones utilizing diaryliodonium salts as electrophiles. ${ }^{199}$ In this study, the intermediate sulfonyl hydrazines were prepared by reaction of diazonium salts with DABSO and hydrazines (Scheme 122). ${ }^{200}$

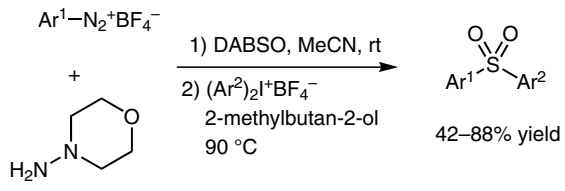

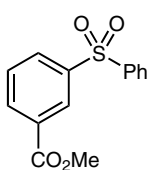

$74 \%$<smiles>O=S(=O)(O)c1ccccc1O</smiles>

$88 \%$

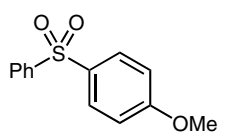

$42 \%$
Scheme 122

Feng and co-workers reported an iodide-catalyzed three-component synthesis of vinyl sulfones from aryldiazonium salts, DABSO and alkenes (Scheme 123). ${ }^{201}$

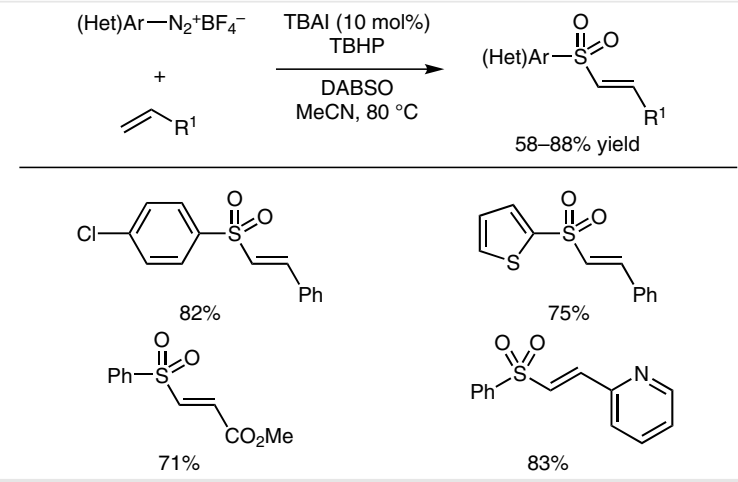

Scheme 123

\section{Biological Synthesis of Sulfones}

Considering the biological activity profile of sulfones, and especially their antibacterial activities, it is very surprising that there are only three known examples of naturally occurring sulfones (Figure 2). The diaryl sulfone echinosulfone $\mathrm{A}$, a bromoindole derivative, was isolated from the marine sponge Echinodictyum $s p .{ }^{202}$ So far nothing is known about the biosynthesis of echinosulfone A. Only as recently as 2015 did Hertweck and co-workers report the isolation of two more diaryl sulfones, sulfadixiamycins B and $\mathrm{C}$, from recombinant Streptomyces species harboring the entire xiamycin biosynthesis gene cluster. ${ }^{203}$ The authors propose a flavoprotein-mediated incorporation of sulfur dioxide, via a radical copolymerization of two carba- 
zoles with sulfur dioxide. This report might provide useful insights for biomimetic synthesis of sulfones in organic laboratories.
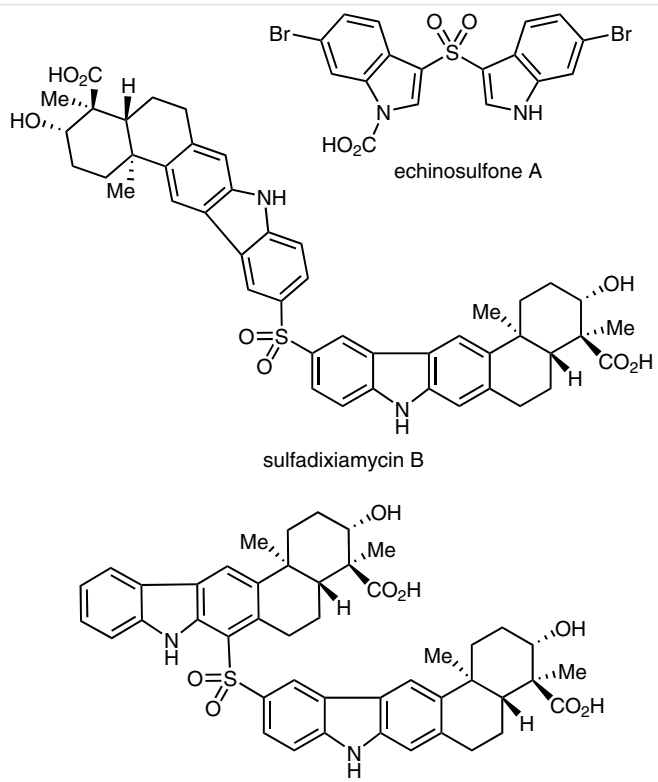

sulfadixiamycin C

Figure 2

\section{Conclusion}

Sulfones $\left(\mathrm{R}-\mathrm{SO}_{2}-\mathrm{R}\right)$ have been known for over 100 years, and they have found widespread application in organic synthesis and as pharmaceuticals, agrochemicals and polymers. Indeed, the first sulfone-based drug, sulfonal, dates back to $1888 .{ }^{204}$ The chemistry of sulfones has been subject to a formidable evolution since their initial discovery and experienced a considerable growth in the last 15 years. The transition-metal-catalyzed reactions, selective $\mathrm{C}-\mathrm{H}$ functionalizations, and methods based on sulfur dioxide and sulfur dioxide surrogates, in particular, have led to major improvements for the synthetic preparation of sulfones and related applications. Nevertheless, there is a constant high demand for novel general and sustainable methods for the synthesis of sulfones. Regioselective $\mathrm{C}-\mathrm{H}$ functionalizations, sulfur dioxide based introductions of the sulfonyl moiety and biomimetic syntheses remain largely unexplored and new innovative possibilities still lie ahead.

\section{Acknowledgment}

We thank Prof. Michael Göbel for his support. Funding by the Fonds der Chemischen Industrie (Liebig Fellowship to G.M.), the Deutsche Forschungsgemeinschaft (DFG), and the Chinese Scholarship Council (PhD fellowship to S.L.) is gratefully acknowledged.

\section{References}

(1) (a) Whitham, G. H. Organosulfur Chemistry; Oxford University Press: Oxford/New York, 1995. (b) Oae, S. Organic Chemistry of Sulfur; Plenium Press: New York, 1977. (c) Stirling, C. J. M. Organic sulphur chemistry: Structure, mechanism, and synthesis; Butterworths: London/Boston, 1975. (d) Patai, S.; Rappoport, Z.; Stirling, C. J. M. The Chemistry of Sulphones and Sulphoxides; Wiley: New York, 1988.

(2) Trost, B. M.; Chadiri, M. R. J. Am. Chem. Soc. 1984, 106, 7260.

(3) (a) Simpkins, N. S. Tetrahedron 1990, 46, 6951. (b) Forristal, I. J. Sulfur Chem. 2005, 26, 163.

(4) (a) Alonso, D. A.; Ájera, C. N. Org. React. 2009, 72, 367. (b) Gui, J.; Zhou, Q.; Pan, C.-M.; Yabe, Y.; Burns, A. C.; Collins, M. R.; Ornelas, M. A.; Ishihara, Y.; Baran, P. S. J. Am. Chem. Soc. 2014, 136, 4853. (c) Ku, Y.-Y.; Patel, R. R.; Roden, B. A.; Sawick, D. P. Tetrahedron Lett. 1994, 35, 6017. (d) Brown, A. C.; Carpino, L. A. J. Org. Chem. 1985, 50, 1749. (e) Kumar, V.; Ramesh, N. G. Chem. Commun. 2006, 4952. (f) Abrunhosa, I.; Gulea, M.; Masson, S. Synthesis 2004, 928.

(5) (a) Seeliger, F.; Mayr, H. Org. Biomol. Chem. 2008, 6, 3052. (b) Magnus, P. D. Tetrahedron 1977, 33, 2019.

(6) (a) Ramberg, L.; Bäcklund, B. Ark. Chim., Mineral Geol. 1940, 27, 1. (b) Taylor, R. J. K.; Casy, G. Org. React. 2004, 62, 359.

(7) (a) Julia, M.; Paris, J.-M. Tetrahedron Lett. 1973, 14, 4833. (b) Kocienski, P. J.; Lythgoe, B.; Ruston, S. J. Chem. Soc., Perkin Trans. 1 1978, 829. (c) Aïssa, C. J. Org. Chem. 2006, 71, 360. (d) Blakemore, P. R. J. Chem. Soc., Perkin Trans. 1 2002, 2563.

(8) (a) Li, J. J. Name Reactions in Heterocyclic Chemistry; John Wiley \& Sons: Hoboken, 2005. (b) van Leusen, A. M.; Hoogenboom, B. E.; Siderius, H. Tetrahedron Lett. 1972, 13, 2369. (c) van Leusen, A. M.; Wildeman, J.; Oldenziel, O. H.J. Org. Chem. 1977, 42, 1153.

(9) Swenson, R. E.; Sowin, T. J.; Zhang, H. Q. J. Org. Chem. 2002, 67, 9182.

(10) (a) Acton, Q. A. Sulfones-Advances in Research and Application; Scholarly Editions: Atlanta, 2013. (b) Meadows, D. C.; GervayHague, J. Med. Res. Rev. 2006, 26, 793. (c) Bisseret, P.; Blanchard, N. Org. Biomol. Chem. 2013, 11, 5393.

(11) (a) Goadsby, P. J.; Ferrari, M. D.; Olesen, J.; Stovner, L. J.; Senard, J. M.; Jackson, N. C.; Poole, P. H. Neurology 2000, 54, 156. (b) Sandrini, G.; Farkkila, M.; Burgess, G.; Forster, E.; Haughie, S. Neurology 2002, 59, 1210.

(12) (a) Iversen, P.; Tyrrell, C. J.; Kaisary, A. V.; Anderson, J. B.; van Poppel, H.; Tammela, T. L.; Chamberlain, M.; Carroll, K.; Melezinek, I. J. Urol. 2000, 164, 1579. (b) Le, Y.; Ji, H.; Chen, J.-F.; Shen, Z.; Yun, J.; Pu, M. Int. J. Pharm. 2009, 370, 175. (c) Kanfer, I. J. Pharm. Pharm. Sci. 2000, 5, 1.

(13) (a) Yazdanyar, S.; Boer, J.; Ingvarsson, G.; Szepietowski, J. C.; Jemec, G. B. E. Dermatology 2011, 222, 342. (b) Lopez de Compadre Rosa, L.; Pearlstein, R. A.; Hopfinger, A. J.; Seydel, J. K. J. Med. Chem. 1987, 30, 900. (c) Zhang, F.-R.; Liu, H.; Irwanto, A.; Fu, X.A.; Li, Y.; Yu, G.-Q.; Yu, Y.-X.; Chen, M.-F.; Low, H.-Q.; Li, J.-H.; Bao, F.-F.; Foo, J.-N.; Bei, J.-X.; Jia, X.-M.; Liu, J.; Liany, H.; Wang, N.; Niu, G.-Y.; Wang, Z.-Z.; Shi, B.-Q.; Tian, H.-Q.; Liu, H.-X.; Ma, S.-S.; Zhou, Y.; You, J.-B.; Yang, Q.; Wang, C.; Chu, T.-S.; Liu, D.C.; Yu, X.-L.; Sun, Y.-H.; Ning, Y.; Wei, Z.-H.; Chen, S.-L.; Chen, X.-C.; Zhang, Z.-X.; Liu, Y.-X.; Pulit, S. L.; Wu, W.-B.; Zheng, Z.-Y.; Yang, R.-D.; Long, H.; Liu, Z.-S.; Wang, J.-Q.; Li, M.; Zhang, L.-H.; Wang, H.; Wang, L.-M.; Xiao, P.; Li, J.-L.; Huang, Z.-M.; Huang, J.X.; Li, Z.; Xiong, L.; Yang, J.; Wang, X.-D.; Yu, D.-B.; Lu, X.-M.; Zhou, G.-Z.; Yan, L.-B.; Shen, J.-P.; Zhang, G.-C.; Zeng, Y.-X.; de Bakker, P.; Chen, S.-M.; Liu, J.-J. N. Engl. J. Med. 2013, 369, 1620. 
(14) (a) Mitchell, G.; Bartlett, D. W.; Fraser, T. E. M.; Hawkes, T. R.; Holt, D. C.; Townson, J. K.; Wichert, R. A. Pest. Manag. Sci. 2001, 57, 120. (b) Beaudegnies, R.; Edmunds, A. J. F.; Fraser, T. E. M.; Hall, R. G.; Hawkes, T. R.; Mitchell, G.; Schaetzer, J.; Wendeborn, S.; Wibley, J. Bioorg. Med. Chem. 2009, 17, 4134.

(15) Tanetani, Y.; Kaku, K.; Kawai, K.; Fujioka, T.; Shimizu, T. Pest. Biochem. Physiol. 2009, 95, 47.

(16) Takahashi, H.; Ohki, A.; Kanzaki, M.; Tanaka, A.; Sato, Y.; Matthes, B.; Böger, P.; Wakabayashi, K. Z. Naturforsch. C 2001, 56, 781.

(17) El-Hibri, M. J.; Weinberg, S. A. In Encyclopedia of Polymer Science and Technology; Mark, H. F., Ed.; Wiley: New York, 2014, 179.

(18) (a) Pritzius, A. B.; Breit, B. Angew. Chem. Int. Ed. 2015, 54, 3121. (b) Griffin, R. J.; Henderson, A.; Curtin, N. J.; Echalier, A.; Endicott, J. A.; Hardcastle, I. R.; Newell, D. R.; Noble, M. E. M.; Wang, L.-Z.; Golding, B. T. J. Am. Chem. Soc. 2006, 128, 6012. (c) Catarinella, M.; Grüner, T.; Strittmatter, T.; Marx, A.; Mayer, T. U. Angew. Chem. Int. Ed. 2009, 48, 9072. (d) Posner, G. H.; Maxwell, J. P.; O’Dowd, H.; Krasavin, M.; Xie, S.; Shapiro, T. A. Bioorg. Med. Chem. 2000, 8, 1361. (e) Tozkoparan, B.; Küpeli, E.; Yeşilada, E.; Ertan, M. Bioorg. Med. Chem. 2007, 15, 1808.

(19) Varma, R. S.; Naicker, K. P. Org. Lett. 1999, 1, 189.

(20) (a) Kirihara, M.; Itou, A.; Noguchi, T.; Yamamoto, J. Synlett 2010, 1557. (b) Bahrami, K.; Khodaei, M. M.; Sheikh Arabi, M. J. Org. Chem. 2010, 75, 6208. (c) Karimi, B.; Ghoreishi-Nezhad, M.; Clark, J. H. Org. Lett. 2005, 7, 625. (d) Jana, N. K.; Verkade, J. G. Org. Lett. 2003, 5, 3787. (e) Fukuda, N.; Ikemoto, T. J. Org. Chem. 2010, 75, 4629 .

(21) Shaabani, A.; Mirzaei, P.; Naderi, S.; Lee, D. G. Tetrahedron 2004, $60,11415$.

(22) Jereb, M. Green Chem. 2012, 14, 3047.

(23) Olah, G. A. Friedel-Crafts and Related Reactions; Wiley-Interscience: New York, 1964.

(24) (a) Jensen, F. R.; Goldman, G. In Friedel-Crafts and Related Reactions; Olah, G. A., Ed.; Wiley-Interscience: New York, 1964, 1319. (b) Olah, G. A.; Kobayashi, S.; Nishimura, J. J. Am. Chem. Soc. 1973, 95, 564. (c) Olah, G. A.; Lin, H. C. Synthesis 1974, 342. (d) Hyatt, J. A.; White, A. W. Synthesis 1984, 214. (e) Effenberger, F.; Huthmacher, K. Angew. Chem. Int. Ed. 1974, 13, 409. (f) Répichet, S.; Le Roux, C.; Hernandez, P.; Dubac, J.; Desmurs, J.-R. J. Org. Chem. 1999, 64, 6479. (g) Graybill, B. M. J. Org. Chem. 1967, 32, 2931. (h) Sipe, H. J. Jr; Clary, D. W.; White, S. B. Synthesis 1984, 283. (i) Ueda, M.; Uchiyama, K.; Kano, T. Synthesis 1984, 323. (j) Effenberger, F.; Huthmacher, K. Chem. Ber. 1976, 109, 2315. (k) Ono, M.; Nakamura, Y.; Sato, S.; Itoh, I. Chem. Lett. 1988, 395.

(25) (a) Choudary, B. M.; Chowdari, N.; Kantam, M.; Kannan, R. Tetrahedron Lett. 1999, 40, 2859. (b) Singh, R. P.; Kamble, R. M.; Chandra, K. L.; Saravanan, P.; Singh, V. K. Tetrahedron 2001, 57, 241. (c) Jang, D. O.; Moon, K. S.; Cho, D. H.; Kim, J.-G. Tetrahedron Lett. 2006, 47, 6063. (d) Bahrami, K.; Khodei, M. M.; Shahbazi, F. Tetrahedron Lett. 2008, 49, 3931. (e) Choudary, B. M.; Chowdari, N. S.; Kantam, M. L. J. Chem. Soc., Perkin Trans. 1 2000, 2689. (f) Nara, S. J.; Harjani, J. R.; Salunkhe, M. M. J. Org. Chem. 2001, 66, 8616. (g) Noronha, R. G.; Fernandes, A. C.; Romão, C. C. Tetrahedron Lett. 2009, 50, 1407. (h) Borujeni, K. P.; Tamami, B. Catal. Commun. 2007, 8, 1191. (i) Marquié, J.; Laporterie, A.; Dubac, J.; Roques, N.; Desmurs, J.-R. J. Org. Chem. 2001, 66, 421.

(26) (a) Olah, G. A.; Mathew, T.; Surya Prakash, G. K. Chem. Commun. 2001, 1696. (b) Li, H.-Z.; Xiao, L.-W.; Li, H.-Y.; Wang, K.-F.; Li, X. J. Chem. Res., Synop. 2003, 493.
(27) (a) Mirjalali, M. B.; Zolfigol, M. A.; Bamoniri, A.; Khazdooz, L. Bull. Korean Chem. Soc. 2003, 24, 1009. (b) Alizadeh, A.; Khodaei, M. M.; Nazari, E. Tetrahedron Lett. 2007, 48, 6805.

(28) Rueggerberg, W. H. C.; Sauls, T. W.; Norwood, S. L. J. Org. Chem. 1955, 20, 455.

(29) (a) Fouque, G.; Lacroix, J. Bull. Soc. Chim. Fr. 1923, 33, 180. (b) Kozlov, V. V.; Vol'fson, T. I.; Kozlova, N. A.; Tubyarskaya, G. S. J. Gen. Chem. USSR 1962, 32, 3373.

(30) Joly, R.; Bucourt, R.; Mathieu, J. Recl. Trav. Chim. Pays-Bas 1959, 78, 527.

(31) Yang, Y.; Chen, Z.; Rao, Y. Chem. Commun. 2014, 50, 15037.

(32) Yao, B.; Zhang, Y. Tetrahedron Lett. 2008, 49, 5385.

(33) Aziz, J.; Messaoudi, S.; Alami, M.; Hamze, A. Org. Biomol. Chem. 2014, 12, 9743.

(34) Meek, J. S.; Fowler, J. S. J. Org. Chem. 1968, 33, 3422.

(35) Oxley, P.; Partridge, M. W.; Robson, T. D.; Short, W. F. J. Chem. Soc. 1946, 763.

(36) Culvenor, C. C. J.; Davies, W.; Heath, N. S. J. Chem. Soc. 1949, 278.

(37) (a) Achmatowicz, O.; Michalski, J. Rocz. Chem. 1956, 30, 243. (b) Hansen, O. R.; Hammer, R.; Vister, T. Acta Chem. Scand. 1953, 7, 1331 .

(38) Roblin, R. O.; Williams, J. H.; Anderson, G. W. J. Am. Chem. Soc. 1941, 63, 1930.

(39) (a) Maloney, K. M.; Kuethe, J. T.; Linn, K. Org. Lett. 2011, 13, 102. (b) Liang, S.; Zhang, R.-Y.; Xi, L.-Y.; Chen, S.-Y.; Yu, X.-Q. J. Org. Chem. 2013, 78, 11874.

(40) (a) Merritt, E. A.; Olofsson, B. Angew. Chem. Int. Ed. 2009, 48, 9052. (b) Zhdankin, V. V.; Stang, P. J. Chem. Rev. 2008, 108, 5299. (c) Olofsson, B. Arylation with Diaryliodonium Salts, In Topics in Current Chemistry; Springer: Berlin/Heidelberg, 2015, 1. (d) Silva, L. F. Jr.; Olofsson, B. Nat. Prod. Rep. 2011, 28, 1722.

(41) Umierski, N.; Manolikakes, G. Org. Lett. 2013, 15, 188.

(42) Pandya, V. G.; Mhaske, S. B. Org. Lett. 2014, 16, 3836.

(43) Liang, S.; Zhang, R.-Y.; Wang, G.; Chen, S.-Y.; Yu, X.-Q. Eur. J. Org. Chem. 2013, 7050.

(44) Chawla, R.; Kapoor, R.; Singh, A. K.; Yadav, L. D. S. Green Chem. 2012, 14, 1308 .

(45) Guan, Z.-H.; Zuo, W.; Zhao, L.-B.; Ren, Z.-H.; Liang, Y.-M. Synthesis 2007, 1465.

(46) Reddy, M. A.; Reddy, P. S.; Sreedhar, B. Adv. Synth. Catal. 2010, 352,1861

(47) Chu, X.-Q.; Meng, H.; Xu, X.-P.; Ji, S.-J. Chem. Eur. J. 2015, 21, 11359.

(48) Liu, C.-R.; Li, M.-B.; Cheng, D.-J.; Yang, C.-F.; Tian, S.-K. Org. Lett. 2009, 11, 2543.

(49) (a) Dornow, A.; Bartsch, W. Liebigs Ann. Chem. 1957, 602, 23. (b) Powell, B. F.; Overberger, C. G.; Anselme, J.-P. J. Heterocycl. Chem. 1983, 20, 121. (c) Carter, P.; Stevens, T. S. J. Chem. Soc. 1961, 1743. (d) Lemal, D. M.; Rave, T. W.; McGregor, S. D. J. Am. Chem. Soc. 1963, 85, 1944. (e) Lemal, D. M.; Menger, F.; Coats, E. J. Am. Chem. Soc. 1964, 86, 2395. (f) Carpino, L. A. Chem. Ind. 1957, 172. (g) Carpino, L. A. J. Am. Chem. Soc. 1957, 79, 4427. (h) Baker, W.; McOmie, J. F. W.; Preston, D. R. J. Chem. Soc. 1961, 2971.

(50) Ballini, R.; Marcantoni, E.; Petrini, M. Tetrahedron 1989, 45, 6791.

(51) Yang, Y.; Tang, L.; Zhang, S.; Guo, X.; Zha, Z.; Wang, Z. Green Chem. 2014, 16, 4106.

(52) Li, X.; Xu, X.; Tang, Y. Org. Biomol. Chem. 2013, 11, 1739.

(53) Song, R.-J.; Liu, Y.; Liu, Y.-Y.; Li, J.-H.J. Org. Chem. 2011, 76, 1001.

(54) Reddy, L. R.; Hu, B.; Prashad, M.; Prasad, K. Angew. Chem. Int. Ed. 2009, 48, 172. 
(55) Li, H.-H.; Dong, D.-J.; Jin, Y.-H.; Tian, S.-K. J. Org. Chem. 2009, 74, 9501.

(56) Pan, X.-Q.; Zou, J.-P.; Yi, W.-B.; Zhang, W. Tetrahedron 2015, 71, 7481.

(57) (a) Asscher, M.; Vofsi, D. J. Chem. Soc. 1964, 4962. (b) Skell, P. S.; Woodworth, R. C.; McNamara, J. H. J. Am. Chem. Soc. 1957, 79, 1253. (c) Cristol, S. J.; Davies, D. I. J. Org. Chem. 1964, 29, 1282.

(58) (a) Dénès, F.; Pichowicz, M.; Povie, G.; Renaud, P. Chem. Rev. 2014, 114, 2587. (b) Dénès, F.; Schiesser, C. H.; Renaud, P. Chem. Soc. Rev. 2013, 42, 7900. (c) Majumdar, K. C.; Debnath, P. Tetrahedron 2008, 64, 9799. (d) Hart, D. J. In Radicals in Organic Synthesis; Renaud, P.; Sibi, M. P., Eds.; Wiley-VCH: Weinheim, 2001, 279. (e) Bertrand, M. P.; Ferreri, C. In Radicals in Organic Synthesis; Renaud, P.; Sibi, M. P., Eds.; Wiley-VCH: Weinheim, 2001, 485. (f) Alfassi, Z. B. S-Centered Radicals; Wiley: Chichester, 1999.

(59) (a) Quebatte, L.; Thommes, K.; Severin, K.J. Am. Chem. Soc. 2006, 128, 7440. (b) Nair, R. P.; Kim, T. H.; Frost, B. J. Organometallics 2009, 28, 4681.

(60) Kamigata, N.; Shimizu, T. Rev. Heteroat. Chem. 1997, 17, 1.

(61) Zeng, X.; Ilies, L.; Nakamura, E. Org. Lett. 2012, 14, 954.

(62) Gilmore, K.; Gold, B.; Clark, R. J.; Alabugin, I. V. Aust. J. Chem. 2013, 66, 336

(63) (a) Kang, S.-K.; Ko, B.-S.; Ha, Y.-H. J. Org. Chem. 2001, 66, 3630. (b) Kang, S.-K.; Ko, B.-S.; Lee, D.-M. Synth. Commun. 2006, 32, 3263. (c) Kang, S.-K.; Seo, H.-W.; Ha, Y.-H. Synthesis 2001, 1321.

(64) Kang, S.-K.; Ha, Y.-H.; Kim, D.-H.; Lim, Y.; Jung, J. Chem. Commun. 2001, 1306.

(65) Alabugin, I. V.; Timokhin, V. I.; Abrams, J. N.; Manoharan, M.; Abrams, R.; Ghiviriga, I. J. Am. Chem. Soc. 2008, 130, 10984.

(66) Mantrand, N.; Renaud, P. Tetrahedron 2008, 64, 11860.

(67) Taniguchi, N. Synlett 2011, 1308.

(68) Taniguchi, N. Tetrahedron 2014, 70, 1984.

(69) Xu, Y.; Zhao, J.; Tang, X.; Wu, W.; Jiang, H. Adv. Synth. Catal. 2014, 356, 2029.

(70) Katrun, P.; Chiampanichayakul, S.; Korworapan, K.; Pohmakotr, M.; Reutrakul, V.; Jaipetch, T.; Kuhakarn, C. Eur. J. Org. Chem. 2010, 5633.

(71) Wei, W.; Wen, J.; Yang, D.; Du, J.; You, J.; Wang, H. Green Chem. 2014, 16, 2988.

(72) Xi, Y.; Dong, B.; McClain, E. J.; Wang, Q.; Gregg, T. L.; Akhmedov, N. G.; Petersen, J. L.; Shi, X. Angew. Chem. Int. Ed. 2014, 53, 4657.

(73) Meyer, A. U.; Jäger, S.; Prasad Hari, D.; König, B. Adv. Synth. Catal. 2015, 357, 2050.

(74) Xia, D.; Miao, T.; Li, P.; Wang, L. Chem. Asian J. 2015, 10, 1919.

(75) Yang, W.; Yang, S.; Li, P.; Wang, L. Chem. Commun. 2015, 51, 7520.

(76) Taniguchi, N. J. Org. Chem. 2015, 80, 7797.

(77) Kariya, A.; Yamaguchi, T.; Nobuta, T.; Tada, N.; Miura, T.; Itoh, A. RSC Adv. 2014, 4, 13191.

(78) Lu, Q.; Zhang, J.; Wei, F.; Qi, Y.; Wang, H.; Liu, Z.; Lei, A. Angew. Chem. Int. Ed. 2013, 52, 7156.

(79) Singh, A. K.; Chawla, R.; Yadav, L. D. S. Tetrahedron Lett. 2014, 55, 4742.

(80) Lu, Q.; Zhang, J.; Zhao, G.; Qi, Y.; Wang, H.; Lei, A. J. Am. Chem. Soc. 2013, 135, 11481.

(81) Li, X.; Xu, Y.; Wu, W.; Jiang, C.; Qi, C.; Jiang, H. Chem. Eur. J. 2014, 20, 7911.

(82) Tang, S.; Wu, Y.; Liao, W.; Bai, R.; Liu, C.; Lei, A. Chem. Commun. 2014, 50, 4496.

(83) Sun, K.; Lv, Y.; Zhu, Z.; Jiang, Y.; Qi, J.; Wu, H.; Zhang, Z.; Zhang, G.; Wang, X. RSC Adv. 2015, 5, 50701.

(84) Li, X.; Xu, X.; Shi, X. Tetrahedron Lett. 2013, 54, 3071.
(85) Rong, G.; Mao, J.; Yan, H.; Zheng, Y.; Zhang, G.J. Org. Chem. 2015, $80,4697$.

(86) Taniguchi, T.; Idota, A.; Ishibashi, H. Org. Biomol. Chem. 2011, 9, 3151.

(87) Wei, W.; Liu, C.; Yang, D.; Wen, J.; You, J.; Suo, Y.; Wang, H. Chem. Commun. 2013, 49, 10239.

(88) Xu, K.; Khakyzadeh, V.; Bury, T.; Breit, B. J. Am. Chem. Soc. 2014, $136,16124$.

(89) Li, X.; Xu, X.; Zhou, C. Chem. Commun. 2012, 48, 12240.

(90) Liu, Z.; Chen, X.; Chen, J.; Qu, L.; Xia, Y.; Wu, H.; Ma, H.; Zhu, S.; Zhao, Y. RSC Adv. 2015, 5, 71215.

(91) Gao, X.; Pan, X.; Gao, J.; Huang, H.; Yuan, G.; Li, Y. Chem. Commun. 2015, 51, 210.

(92) (a) Chen, J.-Y.; Chen, X.-L.; Li, X.; Qu, L.-B.; Zhang, Q.; Duan, L.K.; Xia, Y.-Y.; Chen, X.; Sun, K.; Liu, Z.-D.; Zhao, Y.-F. Eur. J. Org. Chem. 2015, 314. (b) Jiang, Y.; Loh, T.-P. Chem. Sci. 2014, 5, 4939.

(93) Katrun, P.; Hlekhlai, S.; Meesin, J.; Pohmakotr, M.; Reutrakul, V.; Jaipetch, T.; Soorukram, D.; Kuhakarn, C. Org. Biomol. Chem. 2015, 13, 4785.

(94) Jiang, Q.; Xu, B.; Jia, J.; Zhao, A.; Zhao, Y.-R.; Li, Y.-Y.; He, N.-N.; Guo, C.-C. J. Org. Chem. 2014, 79, 7372.

(95) Chen, J.; Mao, J.; Zheng, Y.; Liu, D.; Rong, G.; Yan, H.; Zhang, C.; Shi, D. Tetrahedron 2015, 71, 5059.

(96) Gao, J.; Lai, J.; Yuan, G. RSC Adv. 2015, 5, 66723.

(97) Xu, Y.; Tang, X.; Hu, W.; Wu, W.; Jiang, H. Green Chem. 2014, 16, 3720.

(98) Li, H.-S.; Liu, G. J. Org. Chem. 2014, 79, 509.

(99) Rong, G.; Mao, J.; Yan, H.; Zheng, Y.; Zhang, G. J. Org. Chem. 2015, $80,7652$.

(100) Singh, R.; Allam, B. K.; Singh, N.; Kumari, K.; Singh, S. K.; Singh, K. N. Org. Lett. 2015, 17, 2656.

(101) Li, S.; Li, X.; Yang, F.; Wu, Y. Org. Chem. Front. 2015, 2, 1076.

(102) Lu, Q.; Zhang, J.; Peng, P.; Zhang, G.; Huang, Z.; Yi, H.; Miller, J. T.; Lei, A. Chem. Sci. 2015, 6, 4851.

(103) Yadav, V. K.; Srivastava, V. P.; Yadav, L. D. S. Synlett 2016, 27, 427.

(104)Tang, Y.; Fan, Y.; Gao, H.; Li, X.; Xu, X. Tetrahedron Lett. 2015, 56, 5616.

(105) Jiang, H.; Cheng, Y.; Zhang, Y.; Yu, S. Eur. J. Org. Chem. 2013, 5485.

(106) Tang, Y.; Zhang, Y.; Wang, K.; Li, X.; Xu, X.; Du, X. Org. Biomol. Chem. 2015, 13, 7084.

(107) (a) Gilman, H.; Beaber, N. J.; Myers, C. H. J. Am. Chem. Soc. 1925, 47, 2047. (b) Burton, H.; Davy, W. A. J. Chem. Soc. 1948, 528. (c) Whitmore, F. C.; Thurman, N. J. Am. Chem. Soc. 1923, 45, 1068.

(108) Gilman, H.; Fothergill, R. E. J. Am. Chem. Soc. 1929, 51, 3501.

(109)Shirota, Y.; Nagai, T.; Tokura, N. Tetrahedron 1969, 25, 3193.

(110) Katritzky, A. R.; Abdel-Fattah, A. A.; Vakulenko, A. V.; Tao, H. J. Org. Chem. 2005, 70, 9191.

(111)(a) Gerasimova, T. N.; Bushmelev, V. A.; Koptyug, V. A. Russ. J. Org. Chem. 1965, 1, 1667. (b) Bradley, W.; Hannon, J. D. Chem. Ind. 1959, 540.

(112) Mao, S.; Gao, Y. R.; Zhu, X. Q.; Guo, D. D.; Wang, Y. Q. Org. Lett. 2015, 17, 1692.

(113) Ojha, D. P.; Prabhu, K. R. Org. Lett. 2015, 17, 18.

(114) Feng, X. W.; Wang, J.; Zhang, J.; Yang, J.; Wang, N.; Yu, X. Q. Org. Lett. 2010, 12, 4408.

(115) Yang, Z.; Hao, W. J.; Wang, S. L.; Zhang, J. P.; Jiang, B.; Li, G.; Tu, S. J. J. Org. Chem. 2015, 80, 9224.

(116) Gigant, N.; Drège, E.; Retailleau, P.; Joseph, D. Chem. Eur. J. 2015, $21,15544$.

(117) Mock, W. L. J. Am. Chem. Soc. 1966, 88, 2857. 
(118) Smith, M. March's Advanced Organic Chemistry. Reactions, Mechanisms, and Structure; Wiley: Hoboken, 2013.

(119) (a) Deguin, B.; Vogel, P. J. Am. Chem. Soc. 1992, 114, 9210. (b) Vogel, P.; Sordo, J. A. Curr. Org. Chem. 2006, 10, 2007. (c) Suarez, D.; Sordo, T. L.; Sordo, J. A. J. Org. Chem. 1995, 60, 2848. (d) Suarez, D.; Gonzalez, J.; Sordo, T. L.; Sordo, J. A. J. Org. Chem. 1994, 59, 8058. (e) Suarez, D.; Sordo, T. L.; Sordo, J. A. J. Am. Chem. Soc. 1994, 116, 763.

(120) Suzuki, H.; Abe, H. Tetrahedron Lett. 1995, 36, 6239.

(121)Zhu, W.; Ma, D. J. Org. Chem. 2005, 70, 2696.

(122) Baskin, J. M.; Wang, Z. Org. Lett. 2002, 4, 4423.

(123) Yang, M.; Shen, H.; Li, Y.; Shen, C.; Zhang, P. RSC Adv. 2014, 4, 26295.

(124) Bian, M.; Xu, F.; Ma, C. Synthesis 2007, 2951.

(125) Srinivas, B. T. V.; Rawat, V. S.; Konda, K.; Sreedhar, B. Adv. Synth. Catal. 2014, 356, 805.

(126) Yuan, Y. Q.; Guo, S. R. Synlett 2011, 2750.

(127) Gund, S. H.; Shelkar, R. S.; Nagarkar, J. M. RSC Adv. 2015, 5, 62926.

(128)Zhang, K.; Xu, X. H.; Qing, F. L. J. Org. Chem. 2015, 80, 7658.

(129) (a) Cacchi, S.; Fabrizi, G.; Goggiamani, A.; Parisi, L. M. Org. Lett. 2002, 4, 4719. (b) Cacchi, S.; Fabrizi, G.; Goggiamani, A.; Parisi, L. M. Synlett 2003, 361. (c) Cacchi, S.; Fabrizi, G.; Goggiamani, A.; Parisi, L. M.; Bernini, R. J. Org. Chem. 2004, 69, 5608.

(130) Reeves, D. C.; Rodriguez, S.; Lee, H.; Haddad, N.; Krishnamurthy, D.; Senanayake, C. H. Tetrahedron Lett. 2009, 50, 2870.

(131)Tian, H.; Cao, A.; Qiao, L.; Yu, A.; Chang, J.; Wu, Y. Tetrahedron 2014, 70, 9107.

(132) Beaulieu, C.; Guay, D.; Wang, Z.; Evans, D. A. Tetrahedron Lett. 2004, 45, 3233.

(133) Kir, A.; Sayyed, I. A.; Lo, W. F.; Kaiser, H. M.; Beller, M.; Tse, M. K. Org. Lett. 2007, 9, 3405.

(134) Huang, F.; Batey, R. A. Tetrahedron 2007, 63, 7667.

(135)Kantam, M.; Neelima, B.; Sreedhar, B.; Chakravarti, R. Synlett 2008, 1455.

(136) Yang, H.; Li, Y.; Jiang, M.; Wang, J.; Fu, H. Chem. Eur. J. 2011, 17, 5652.

(137)Zhou, P. X.; Ye, Y. Y.; Zhao, L. B.; Hou, J. Y.; Kang, X.; Chen, D. Q.; Tang, Q.; Zhang, J. Y.; Huang, Q. X.; Zheng, L.; Ma, J. W.; Xu, P. F.; Liang, Y. M. Chem. Eur. J. 2014, 20, 16093.

(138) (a) Tsuji, J. Acc. Chem. Res. 1969, 2, 144. (b) Trost, B. M. Tetrahedron 1977, 33, 2615. (c) Trost, B. M.; Van Vranken, D. L. Chem. Rev. 1996, 96, 395. (d) Trost, B. M.; Crawley, M. L. Chem. Rev. 2003, 103, 2921.

(139)(a) Billamboz, M.; Mangin, F.; Drillaud, N.; Chevrin-Villette, C.; Banaszak-Léonard, E.; Len, C. J. Org. Chem. 2014, 79, 493. (b) Inomata, K.; Yamamoto, T.; Kotake, H. Chem. Lett. 1981, 1357. (c) Felpin, F.-X.; Landais, Y. J. Org. Chem. 2005, 70, 6441. (d) Liao, M.-C.; Duan, X.-H.; Liang, Y.-M. Tetrahedron Lett. 2005, 46, 3469. (e) Uozumi, Y.; Danjo, H.; Hayashi, T. Tetrahedron Lett. 1997, 38, 3557. (f) Seebach, D.; Devaquet, E.; Ernst, A.; Hayakawa, M.; Kühnle, F. N. M.; Schweizer, W. B.; Weber, B. Helv. Chim. Acta 1995, 78, 1636. (g) Vasen, D.; Salzer, A.; Gerhards, F.; Gais, H.-J.; Bieler, N. H.; Togni, A. Organometallics 2000, 19, 539. (h) Trost, B. M.; Crawley, M. L.; Lee, C. B. Chem. Eur. J. 2006, 12, 2171. (i) Boldrini, G. P.; Savoia, D.; Tagliavini, E.; Trombini, C.; Umani-Ronchi, A. J. Organomet. Chem. 1984, 268, 97.

(140) (a) Safi, M.; Sinou, D. Tetrahedron Lett. 1991, 32, 2025. (b) Kang, S.-K.; Park, D.-C.; Jeon, J.-H.; Rho, H.-S.; Yu, C.-M. Tetrahedron Lett. 1994, 35, 2357. (141)(a) Chandrasekhar, S.; Jagadeshwar, V.; Saritha, B.; Narsihmulu, C. J. Org. Chem. 2005, 70, 6506. (b) Ma, X.-T.; Dai, R.-H.; Zhnag, J.; Gu, Y.; Tian, S.-K. Adv. Synth. Catal. 2014, 356, 2984.

(142)(a) Ono, N.; Hamamoto, I.; Kawai, T.; Kaji, A.; Tamura, R.; Kakihana, M. Bull. Chem. Soc. Jpn. 1986, 59, 405. (b) Tamura, R.; Kai, Y.; Kakihana, M.; Hayashi, K.; Tsuji, M.; Nakamura, T.; Oda, D. J. Org. Chem. 1986, 51, 4375.

(143) Wu, X. S.; Chen, Y.; Li, M. B.; Zhou, M. G.; Tian, S. K. J. Am. Chem. Soc. 2012, 134, 14694.

(144) (a) Hiroi, K.; Kurihara, Y. J. Chem. Soc., Chem. Commun. 1989, 1778. (b) Hiroi, K.; Makino, K. Chem. Pharm. Bull. 1988, 36, 1744. (c) Hiroi, K.; Makino, K. Chem. Lett. 1986, 617. (d) Hiroi, K.; Kitayama, R.; Sato, S. J. Chem. Soc., Chem. Commun. 1984, 303. (e) Hiroi, K.; Kitayama, R.; Sato, S. Chem. Pharm. Bull. 1984, 32, 2628. (f) Hiroi, K.; Kitayama, R.; Sato, S. J. Chem. Soc., Chem. Commun. 1983, 1470. (g) Eichelmann, H.; Gais, H.-J. Tetrahedron: Asymmetry 1995, 6, 643. (h) Gavrilov, K. N.; Bondarev, O. G.; Tsarev, V. N.; Shiryaev, A. A.; Lyubimov, S. E.; Kucherenko, A. S.; Davankov, V. A. Russ. Chem. Bull. 2003, 52, 122. (i) Wolfe, J. A.; Hitchcock, S. R. Tetrahedron: Asymmetry 2010, 21, 2690. (j) Gais, H.-J.; Eichelmann, H.; Spalthoff, N.; Gerhards, F.; Frank, M.; Raabe, G. Tetrahedron: Asymmetry 1998, 9, 235. (k) Tsarev, V. N.; Konkin, S. I.; Shyryaev, A. A.; Davankov, V. A.; Gavrilov, K. N. Tetrahedron: Asymmetry 2005, 16, 1737.

(145) Trost, B. M.; Organ, M. G.; O'Doherty, G. A. J. Am. Chem. Soc. 1995, 117, 9662.

(146)Ueda, M.; Hartwig, J. F. Org. Lett. 2010, 12, 92.

(147)Jegelka, M.; Plietker, B. Org. Lett. 2009, 11, 3462.

(148) Jegelka, M.; Plietker, B. Chem. Eur. J. 2011, 17, 10417.

(149) (a) Dubbaka, S. R.; Vogel, P. Angew. Chem. Int. Ed. 2005, 44, 7674. (b) Dubbaka, S. R.; Vogel, P. Tetrahedron Lett. 2006, 47, 3345. (c) Dubbaka, S. R.; Vogel, P. Org. Lett. 2004, 6, 95. (d) Dubbaka, S. R.; Vogel, P. J. Am. Chem. Soc. 2003, 125, 15292. (e) Volla, C. M. R.; Dubbaka, S. R.; Vogel, P. Tetrahedron 2009, 65, 504.

(150) Labadie, S. S. J. Org. Chem. 1989, 54, 2496.

(151) Bandgar, B. P.; Bettigeri, S. V.; Phopase, J. Org. Lett. 2004, 6, 2105.

(152) Hu, F.; Lei, X. ChemCatChem 2015, 7, 1539.

(153) Fu, Y.; Zhu, W.; Zhao, X.; Hügel, H.; Wu, Z.; Su, Y.; Du, Z.; Huang, D.; Hu, Y. Org. Biomol. Chem. 2014, 12, 4295.

(154) Liu, X.; Chen, X.; Mohr, J. T. Org. Lett. 2015, 17, 3572.

(155) (a) Yamaguchi, J.; Itami, K.; Yamaguchi, A. D. Angew. Chem. Int. Ed. 2012, 51, 8960. (b) Gutekunst, W. R.; Baran, P. S. Chem. Soc. Rev. 2011, 40, 1976. (c) Ackermann, L. Chem. Rev. 2011, 111, 1315. (d) Wencel-Delord, J.; Dröge, T.; Liu, F.; Glorius, F. Chem. Soc. Rev. 2011, 40, 4740. (e) Jazzar, R.; Hitce, J.; Renaudat, A.; Sofack-Kreutzer, J.; Baudoin, O. Chem. Eur. J. 2010, 16, 2654. (f) Crabtree, R. H. Chem. Rev. 2010, 110, 575. (g) Bergman, R. G. Nature 2007, 446, 391. (h) Godula, K.; Sames, D. Science 2006, $312,67$.

(156)Zhao, X.; Dimitrijevic, E.; Dong, V. M. J. Am. Chem. Soc. 2009, $131,3466$.

(157)Zhao, X.; Dong, V. M. Angew. Chem. Int. Ed. 2011, 50, 932.

(158) Xu, Y.; Liu, P.; Li, S. L.; Sun, P. J. Org. Chem. 2015, 80, 1269.

(159) (a) Zhang, D.; Cui, X.; Zhang, Q.; Wu, Y. J. Org. Chem. 2015, 80, 1517. (b) Xia, C.; Wei, Z.; Shen, C.; Xu, J.; Yang, Y.; Su, W.; Zhang, P. RSC Adv. 2015, 5, 52588.

(160) Xu, Y. H.; Wang, M.; Lu, P.; Loh, T. P. Tetrahedron 2013, 69, 4403.

(161) Ge, B.; Wang, D.; Dong, W.; Ma, P.; Li, Y.; Ding, Y. Tetrahedron Lett. 2014, 55, 5443.

(162) Wu, Z.; Song, H.; Cui, X.; Pi, C.; Du, W.; Wu, Y. Org. Lett. 2013, 15 , 1270. 
(163) Reddy, V. P.; Qiu, R.; Iwasaki, T.; Kambe, N. Org. Biomol. Chem. 2015, 13, 6803.

(164) Liang, H. W.; Jiang, K.; Ding, W.; Yuan, Y.; Shuai, L.; Chen, Y. C.; Wei, Y. Chem. Commun. 2015, 51, 16928.

(165) Saidi, O.; Marafie, J.; Ledger, A. E.; Liu, P. M.; Mahon, M. F.; Kociok-Köhn, G.; Whittlesey, M. K.; Frost, C. G. J. Am. Chem. Soc. 2011, 133, 19298.

(166) Liu, J.; Yu, L.; Zhuang, S.; Gui, Q.; Chen, X.; Wang, W.; Tan, Z. Chem. Commun. 2015, 51, 6418.

(167) Rao, W. H.; Shi, B. F. Org. Lett. 2015, 17, 2784.

(168) Liang, S.; Liu, N. W.; Manolikakes, G. Adv. Synth. Catal. 2016, 358, 159.

(169) Rao, W. H.; Zhan, B. B.; Chen, K.; Ling, P. X.; Zhang, Z. Z.; Shi, B. F. Org. Lett. 2015, 17, 3552.

(170)Tang, X.; Huang, L.; Xu, Y.; Yang, J.; Wu, W.; Jiang, H. Angew. Chem. Int. Ed. 2014, 53, 4205.

(171) Kamijo, S.; Hirota, M.; Tao, K.; Watanabe, M.; Murafuji, T. Tetrahedron Lett. 2014, 55, 5551.

(172)Sun, K.; Chen, X. L.; Li, X.; Qu, L. B.; Bi, W. Z.; Chen, X.; Ma, H. L.; Zhang, S. T.; Han, B. W.; Zhao, Y. F.; Li, C. J. Chem. Commun. 2015, $51,12111$.

(173) (a) Xiao, F.; Chen, H.; Xie, H.; Chen, S.; Yang, L.; Deng, G. J. Org. Lett. 2014, 16, 50. (b) Katrun, P.; Mueangkaew, C.; Pohmakotr, M.; Reutrakul, V.; Jaipetch, T.; Soorukram, D.; Kuhakarn, C. J. Org. Chem. 2014, 79, 1778.

(174) Nassoy, A. C. M.; Raubo, P.; Harrity, J. P. Chem. Commun. 2015, $51,5914$.

(175) Qiu, J. K.; Hao, W. J.; Wang, D. C.; Wei, P.; Sun, J.; Jiang, B.; Tu, S. J. Chem. Commun. 2014, 50, 14782.

(176)Xiao, F.; Chen, S.; Chen, Y.; Huang, H.; Deng, G. J. Chem. Commun. 2015, 51, 652.

(177) (a) Deeming, A. S.; Emmett, E. J.; Richards-Taylor, C. S.; Willis, M. C. Synthesis 2014, 46, 2701. (b) Emmett, E. J.; Willis, M. C. Asian J. Org. Chem. 2015, 4, 602. (c) Liu, G.; Fan, C.; Wu, J. Org. Biomol. Chem. 2015, 13, 1592. (d) Vogel, P.; Turks, M.; Bouchez, L.; Markovic, D.; Varela-Álvarez, A.; Sordo, J. Á. Acc. Chem. Res. 2007, 40, 931. (e) Floriańczyk, Z.; Raducha, D. Pol.J. Chem. 1995, $69,481$.

(178) (a) Burke, S. D. In Encyclopedia of Reagents for Organic Synthesis; John Wiley \& Sons: Chichester, 2001. (b) Pelzer, G.; Herwig, J.; Keim, W.; Goddard, R. Russ. Chem. Bull. 1998, 47, 904. (c) Hoffman, R. V. Org. Synth. 1981, 60, 121. (d) Malet-Sanz, L.; Madrzak, J.; Ley, S. V.; Baxendale, I. R. Org. Biomol. Chem. 2010, 8,5324 .

(179)(a) Hoffmann, H. M. R. Angew. Chem. Int. Ed. 1969, 8, 556. (b) Rogic, M. M.; Masilamani, D. J. Am. Chem. Soc. 1977, 99, 5219. (c) Markovic, D.; Varela-Alvarez, A.; Sordo, J. A.; Vogel, P. J. Am. Chem. Soc. 2006, 128, 7782.

(180) Wojcinski, L. M.; Boyer, M. T.; Sen, A. Inorg. Chim. Acta 1998, 270,8 .

(181) Bouchez, L.; Vogel, P. Synthesis 2002, 225.

(182) Marković, D.; Volla, C. M.; Vogel, P.; Varela-Álvarez, A.; Sordo, J. A. Chem. Eur. J. 2010, 16, 5969.
(183) (a) Deguin, B.; Roulet, J. M.; Vogel, P. Tetrahedron Lett. 1997, 38, 6197. (b) Bouchez, L. C.; Turks, M.; Dubbaka, S. R.; Fonquerne, F.; Craita, C.; Laclef, S.; Vogel, P. Tetrahedron 2005, 61, 11473. (c) Bouchez, L. C.; Dubbaka, S. R.; Turks, M.; Vogel, P. J. Org. Chem. 2004, 69, 6413. (d) Exner, C. J.; Laclef, S.; Poli, F.; Turks, M.; Vogel, P. J. Org. Chem. 2011, 76, 840. (e) Huang, X. G.; Vogel, P. Synthesis 2002, 232.

(184) (a) Bouchez, L. C.; Vogel, P. Chem. Eur. J. 2005, 11, 4609. (b) Turks, M.; Huang, X.; Vogel, P. Chem. Eur. J. 2005, 11, 465. (c) Turks, M.; Fonquerne, F.; Vogel, P. Org. Lett. 2004, 6, 1053. (d) Narkevitch, V.; Vogel, P.; Schenk, K. Helv. Chim. Acta 2002, 85, 1674. (e) Huang, X. G.; Craita, C.; Vogel, P. J. Org. Chem. 2004, 69, 4272. (f) Craita, C.; Didier, C.; Vogel, P. Chem. Commun. 2007, 2411.

(185)(a) Schlosser, M. Organometallics in Synthesis. Third Manual; Wiley: Hoboken, 2013. (b) Knochel, P. Handbook of Functionalized Organometallics. Application and Synthesis; Wiley-VCH: Weinheim, 2005.

(186)Wu, J. P.; Emeigh, J.; Su, X.-P. Org. Lett. 2005, 7, 1223.

(187) (a) Margraf, N.; Manolikakes, G. J. Org. Chem. 2015, 80, 2582. (b) Umierski, N.; Manolikakes, G. Org. Lett. 2013, 15, 4972.

(188) Shavnya, A.; Coffey, S. B.; Smith, A. C.; Mascitti, V. Org. Lett. 2013, 15, 6226.

(189) Shavnya, A.; Hesp, K. D.; Mascitti, V.; Smith, A. C. Angew. Chem. Int. Ed. 2015, 54, 13571.

(190)Johnson, M. W.; Bagley, S. W.; Mankad, N. P.; Bergman, R. G.; Mascitti, V.; Toste, F. D. Angew. Chem. Int. Ed. 2014, 53, 4404.

(191)Woolven, H.; González-Rodríguez, C.; Marco, I.; Thompson, A. L.; Willis, M. C. Org. Lett. 2011, 13, 4876.

(192) Deeming, A. S.; Russell, C. J.; Hennessy, A. J.; Willis, M. C. Org. Lett. 2014, 16, 150.

(193) Rocke, B. N.; Bahnck, K. B.; Herr, M.; Lavergne, S.; Mascitti, V.; Perreault, C.; Polivkova, J.; Shavnya, A. Org. Lett. 2014, 16, 154.

(194) Emmett, E. J.; Hayter, B. R.; Willis, M. C. Angew. Chem. Int. Ed. 2013, 52, 12679.

(195) Emmett, E. J.; Hayter, B. R.; Willis, M. C. Angew. Chem. Int. Ed. 2014, 53, 10204.

(196) Chen, C. C.; Waser, J. Org. Lett. 2015, 17, 736.

(197) (a) Nguyen, B.; Emmett, E. J.; Willis, M. C. J. Am. Chem. Soc. 2010, 132, 16372. (b) Emmett, E. J.; Richards-Taylor, C. S.; Nguyen, B.; Garcia-Rubia, A.; Hayter, B. R.; Willis, M. C. Org. Biomol. Chem. 2012, 10, 4007.

(198) Richards-Taylor, C. S.; Blakemore, D. C.; Willis, M. C. Chem. Sci. 2014, 5, 222.

(199) Liu, X.; Li, W.; Zheng, D.; Fan, X.; Wu, J. Tetrahedron 2015, 71, 3359.

(200)Zheng, D.; An, Y.; Li, Z.; Wu, J. Angew. Chem. Int. Ed. 2014, 53, 2451.

(201) Fan, W.; Su, J.; Shi, D.; Feng, B. Tetrahedron 2015, 71, 6740.

(202) Ovenden, S. P. B.; Capon, R. J. J. Nat. Prod. 1999, 62, 1246.

(203) Baunach, M.; Ding, L.; Willing, K.; Hertweck, C. Angew. Chem. Int. Ed. 2015, 54, 13279.

(204)Wendt, E. C. In The Medical Record; Vol. 33; Shrady, G. F.; Stedman, T. L., Eds.; W. Wood: New York, 1888, 597. 